$$
\begin{aligned}
& \text { المؤتمر العلمى الخامس } \\
& \text { كلية التجارة - - جامعة طنطا } \\
& \text { أثر أزمة كورونا على الاقتصاد القومي } \\
& \text { (المقترحات والحلول) }
\end{aligned}
$$

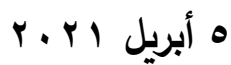

\title{
أثر جائحة كرونا على مؤشرات السلامة المالية للقطاع المصرفى (دراسة تطبيقية على البنوك العاملة فى مصر)
}

$$
\text { الدكتور }
$$

$$
\text { إكرامح جمال زهر }
$$

أستاذ المحاسبة المالية المساعد تهات

كلية التجارة - جامعة المنوفية
الأستاذ الدكتور محمد زيدان إبراهيم أستاذ الحماسبة المالية المثتغغ كلية التجارة - جامعة المنوفية

$$
\begin{aligned}
& \text { أ/ شريف سعد الصعيدى } \\
& \text { باحث دكثوراه } \\
& \text { كلية التجارة - جامعة المنوفية }
\end{aligned}
$$




\section{ملخص البحث}

اســتهدفت الدراســة تحليل لأهم الآثار المترتبة لجائحة كورونا (كوفيد-9 (1) على مؤشــرات

الســلامة المالية للقطاع المصـرفى المصـرى، باعتبار أن الجائحة هى متسـبب خارجى للصــدمة الاقتصـادية التى تعرض لها الاقتصـاد العالمى، وليس متسـبب داخلى كما كان فى الأزمة المالية A . . r والتى كان القطاع المالى هو مصدرها الأساسى.

ولتحقيق هذه الأهدافـ: اعتمدت الدراســــة على المنهج الوصــــى التحليلى، حيث تم تحليل

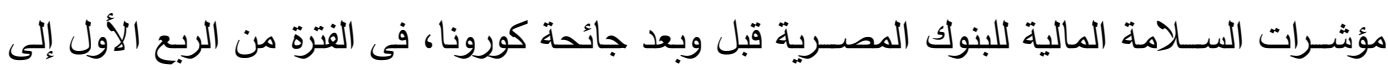

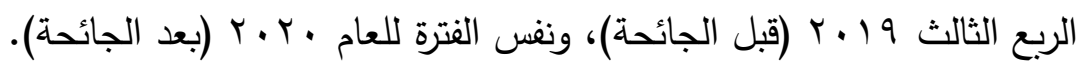
وتوصـلت الدراســة التحليلية إلى صــلابة وقوة القطاع المصـرفى المصـرى، وســلامة مؤشـراته المالية، وذلك بالرغم من الأزمـة العالمية التى تمر بها مختلف البلاد نتيجة جائحسة كورونـا. كما انتهت الدراسـة التطبيقية إلى وجود فروق جوهرية ذات دلالة إحصـائية لمؤشرات السـلامة المالية باستثناء مؤشرات جودة الائتمان - للبنوك المصرية قبل وبعد جائحة كورونا، وتتمثل هذه المؤشرات

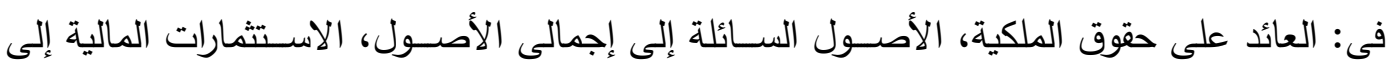

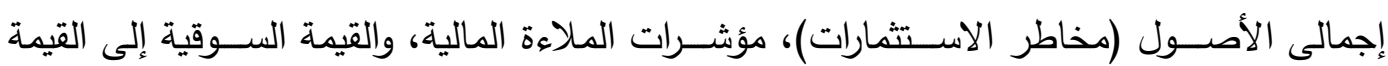

الدفترية لحقوق الملكية، وتعتبر هذه المؤشرات هى الأكثر تأثراً بتداعيات جائحة كورونا. وأوصت الدراسة بجملة من التوصيات أهمها: ضرورة قيام البنك المركزى والبنوك العاملة بوضع

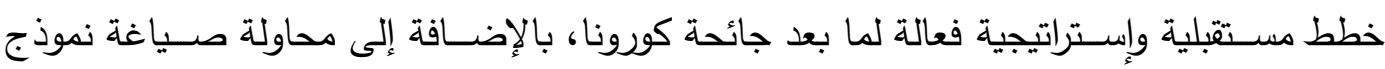
خاص بالتنبؤ بالأزمات المالية ويكون موضوع التطبيق لضمان الاستقرار المالى والمصرفى. 


\begin{abstract}
:
The study aimed to analyze the most important effects of the Corona pandemic (Covid-19) on the financial soundness indicators of the Egyptian banking sector, considering the pandemic as an external cause of the economic shock to the global economy, and not as internal cause as it was in the 2008 financial crisis, of which the financial sector was its source.

To achieve these goals: The study relied on the analytical descriptive approach, whereby the financial soundness indicators of Egyptian banks before and after the Corona pandemic were analyzed in the period from the first quarter to the third quarter of 2019 (before the pandemic), and the same period in 2020 (after the pandemic).

The analytical study found the robustness and strength of the Egyptian banking sector, and the soundness of its financial indicators, despite the global crisis that various countries are going through as a result of the Corona. The empirical study also concluded that there are statistically significant differences in the financial soundness indicators - with the exception of the credit quality indicators - for Egyptian banks before and after the Corona pandemic, and these indicators are: return on equity, liquid assets to total assets, financial investments to total assets (risks Investments), indicators of the financial solvency, and the market value to the book value, and these indicators are considered the most affected by the repercussions of the Corona pandemic.

The study recommended a set of recommendations, the most important of which are: The egyption central bank and the banks must to develop an effective future and strategic plans after the Corona starvation, in addition to seeking to preparing a model for forecasting the financial crises and be applied to ensure the financial and banking stability.
\end{abstract}




\section{القسم الأول: الاطار المنهجى للبحث}

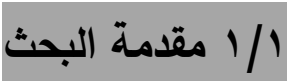

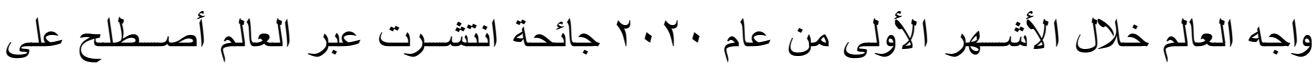

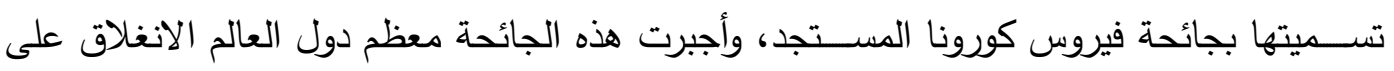
نفســها. وفي ظل تطوارت جائحة كورونا وانعكاســاتها على جميع القطاعات والمجالات كان لا بد للمحاسبة أن تستجيب لهذه التطوارت بما يناسـب ويلائم الحاجة الى القياس والافصـاح المحاسبى ولى ولى ولى وصولاً الى المعلومات التى توفرها المحاسبة للمستخدمين المختلفين. وتمثل جائحة كورونا أكبر اختبار للنظام المالى حتى الآن بعد الأزمة العالمية ^ ـ. . r، حيث يثـكل هذا الوباء صـدمة اقتصـادية كلية عالمية غير مسـبوقة تدفع بالاقتصـاد العالمى إلى الركود نتيجة الحجم والمدة الغير مؤكدين حتى تاريخه. ويواجه النظام المالى التحدى المزدوج المتمثل فى هي

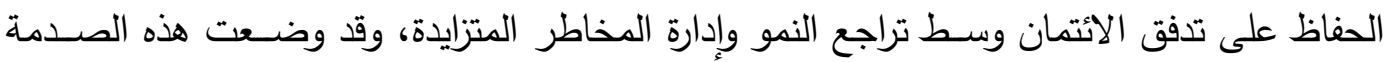
النظام المالى تحت الضـــغ، كما أدى هبوط النشــاط الاقتصـــادى والمخاطر المتزايدة إلى إعادة

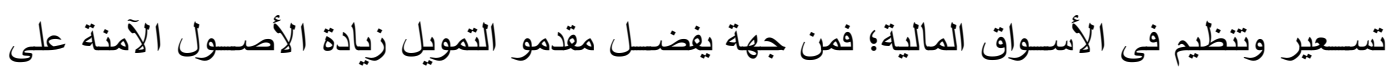

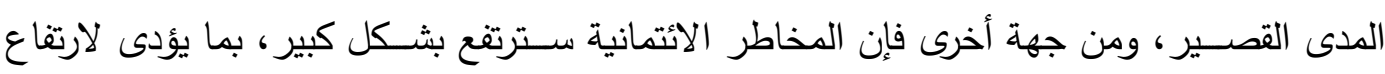
الطلب على رأس مال وسيولة النظام المالى (FSB, 2020, P.1). وقد تسببت جائحة كورونا فى زيادة مستوى عدم التأكد بالذسبة لمعظم المؤسسات، الأمر الذى مأى

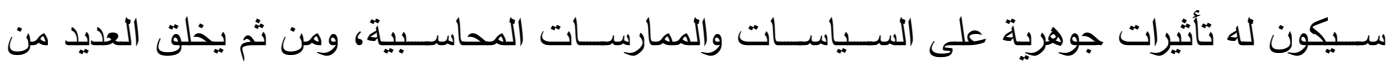
الصــوبات والمشــاكل والتحديات أمام الإدارة ومعدى التقارير المالية عند تطبيق متطلبات المعايير المحاسـبية؛ لذا سـيتعين على البنوك تقييم الآثار الجوهرية الحالية والمحتملة لتفثى جائحة كورونا

على التقارير المالية (Deloitte, 2020). وقد أثرت أزمة كورونا العالمية على الأداء المالى لللبنوك، نتيجة للآثار الاقتصــادية السـلبية

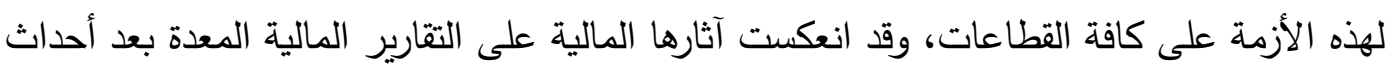
أزمـة كورونـا العالميـة، ويتوقع حدوث تأثير كبير لهذه الأزمـة على نتائج أعمال البنوك ومركزهـا

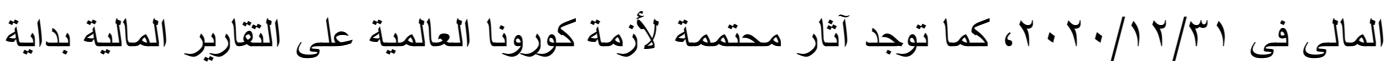

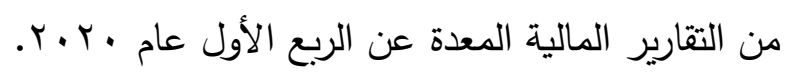
وبناءاً على ما سبق، تهدف هذه الدراسـة إلى تقييم الآثار الفعلية لجائحة كورونا على مؤشـرات السلامة المالية للقطاع المصرفى المصرى. r/l

تعتبر الأزمات بثكل عام مصدراً للقلق لاقتصـاد الدولة وللمنشآت أيضـاً؛ حيث أنها عبارة عن ظاهرة غير مستقرة تمثل تهديداً مباشـرة وصـريحاً لبقاء المنظمة واسـتمراريتها، وتتميز بدرجة معينة من المخاطرة، وتمثل نقطة تحول فى أوضـاع غير مسـتقرة تعود إلى نتائج غير مرغوبة توثر سـلباً

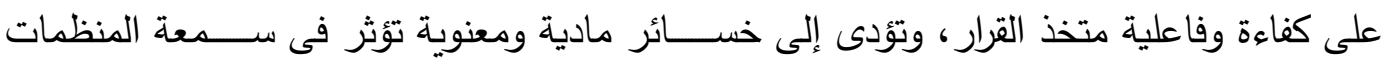

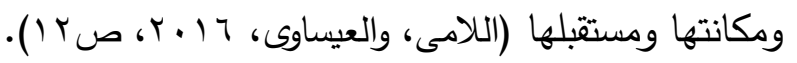


ويعانى العالم الآن من أزمات اقتصــــادية كبيرة جراء ما يتحملة من إجراءات لركافحة جائحة

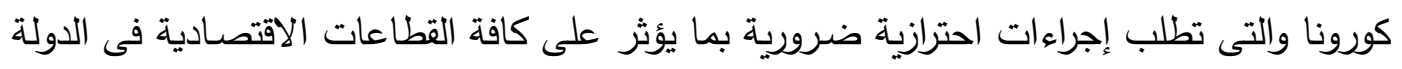
وعلى البنوك بصــفة خاصـــة. وقد تصـــادف هذا بعد إلزام البنوك العالمية بتطبيق المعيار الدولى IFRS9

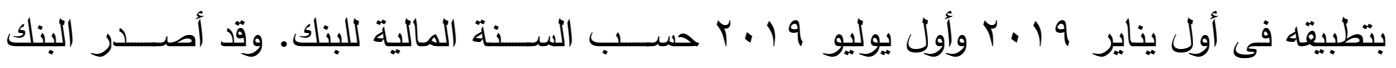
المركزى المصـرى فى مايو • · · r كتيب يتضــمن التعليمات التى يجب تطبيقها عند إعداد التقارير

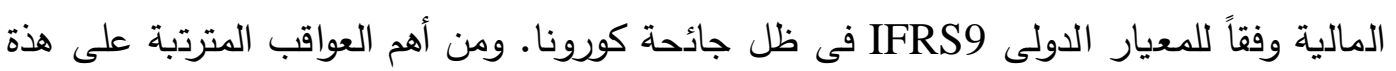

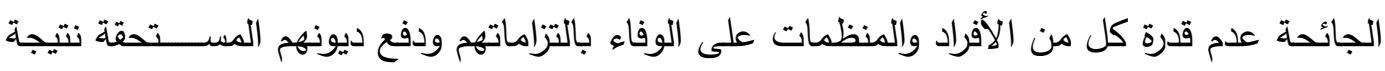

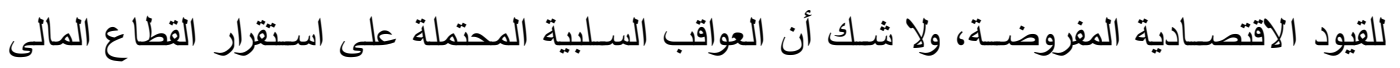
العالى غير مسبوقة بشكل ينافس الأزمات السابقة مثل الأزمة المالية العالمية م . . ؟.

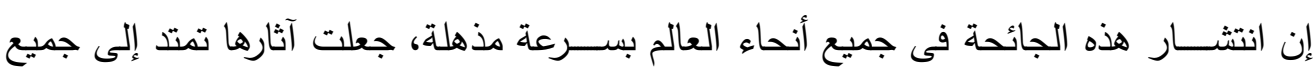
الثــركات والأســـواق المالية، وليس على حياة البثــر فقط، وتحتاج الثـــركات إلى مراعاة الآثار

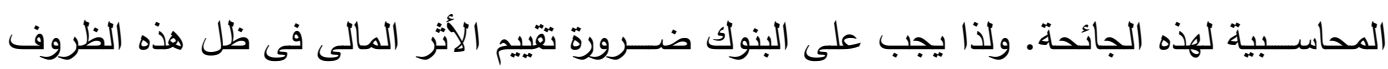

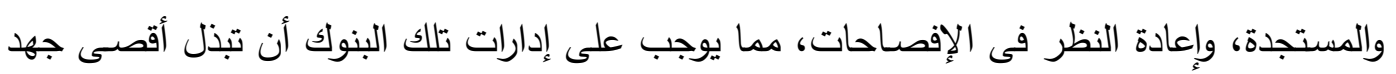
فى تقديرها لآثار هذه الجائحة.

\section{ويمكن صياغة مشكلة الاراسة في التساؤلات التالية:}

ا ـ ما هى أهم الآثار المحاسبية لجائحة كورونا؟

r ـ ما هى أهم التحديات التى تواجه القطاع المصرفى نتيجة جائحة كورونا؟

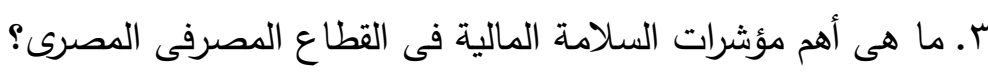

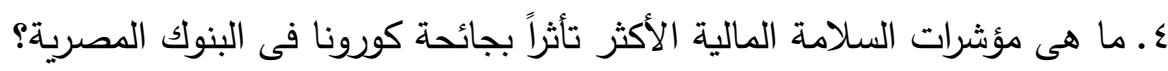

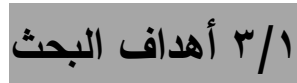

تهدف الدراسـة بشـكل أسـاسـى إلى اختبار مدى وجود فروق ذات دلالة إحصـائية لمؤشـرات

السلامة المالية قبل وبعد انتشار جائحة كورونا. ويسعى البحث لتحقيق الأهداف التالية: ا ـ دراسة وتحليل جائحة كورونا، وأهم الآثار المحاسبية التى أحدثتها. r ـ استعراض التحديات التى تواجه القطاع المصرفى فى ظل انتثار جائحة كورونا.

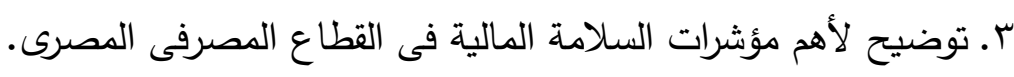
ع ـ اختبار أثر جائحة كورونا فى مؤشرات السلامة المالية للبنوك المصرية.

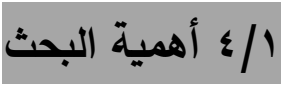

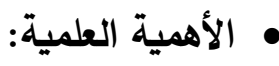

ا ـ التأصيل العلمى الدقيق لانعكاسات أزمة جائحة كوفيد-9 19 على البيئة المصرفية فى مصر ، فى

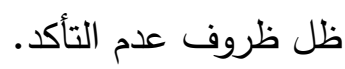
r. ندرة المراجع العربية والأجنبية، حيث لا توجد أية دراسـات أكاديمية اهتمت بالأثار الفعلية الناتجة عن تفشى جائحة كورونا على القطاع المصرفى. لعربه 
ז. أهمية البحث العلمى فى ظل الأزمة الاقتصــادية العالمية من جراء جائحة فيروس كورونا والتى أثرت على السلامة المالية لجميع الافطاعات الاقتصادية.

ـ ـ معرفة رد فعل جهات واضـــى المعايير والهيئات المنظمة لمهنتى المحاســـبة والمراجعة لآثار تقشى جائحة كورونا على نتائج أعمال البنوك ومدى استمريتها (قدرتها على البقاء فى السوق).

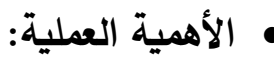
ا ـ تبرز الأهمية التطبيقية لهذه الدراسـة من أهمية القطاع المصــفى فى مصـر كأحد أهم مصـادر الإيرادات ودوره فى دفع العجلة الاقتصادية. r. توفير أدلة تجريبية من واقع بيانات البنوك العاملة فى مصـر ، بثـأن مؤشـرات الاسـتقرار المالى قبل وبعد جائحة كورونا. r. تقديم الفائدة للمســتثرين والأطراف ذات العلاقة حول الأثر الفعلى لجائحة كورونا على التقارير المالية للبنوك المصرية.

| 1/ / منهجية البحث أولاً: تتخذ الدراسة الأسلوب الاستتباطى فى البحث، حيث يتم الاعتماد بشكل أساسي على معلومات

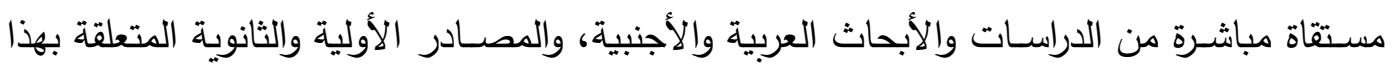
الموضوع. ثانياً: لتحقيق هدف الدراسـة، تم استخدام المنهج الوصـفى التحليلى من خلال تحليل التقارير المالية

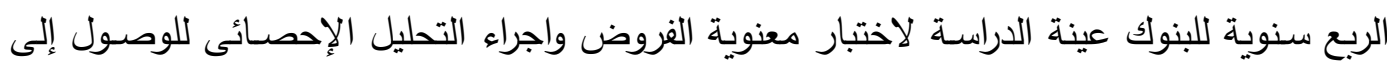
النتائج والاستتناجات. ف ا فى ضوء مشكلة الاراسة وأهدافها، تم تنظيمها على النحو التالى: القسم الأول: الإطار المنهجى للبحث، وأهم الدراسات السابقة ذات الصلة.

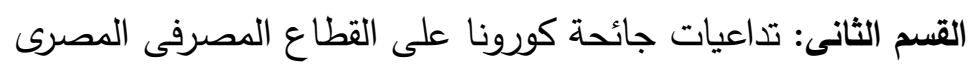
القسم الثالث: التحليل الإحصائى لمؤشرات السلامة المالية فى ضوء جائحة كورونا. القسم الرابع: النتائج والتوصيات والأبحاث المستقبلية المقترحة.

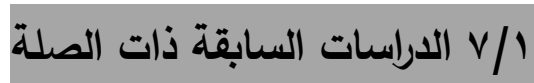

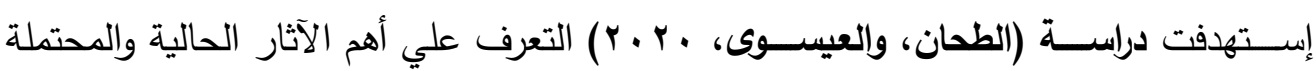
لتفثـي فيروس كورونا على ييئة التقرير المالى في ضـوه معايير المحاسبة الدولية والمصـرية. وقد توصـلت الدراســة إلي أن تفشـي فيروس كورونا سـيكون له العديد من الآثار الجوهرية المحاسـبية

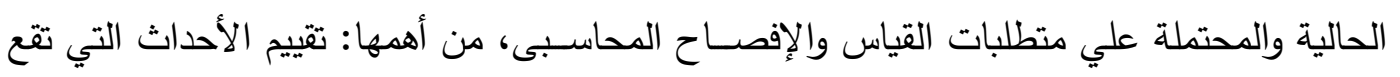

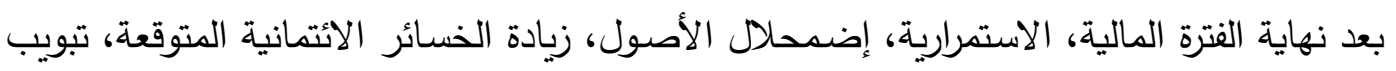

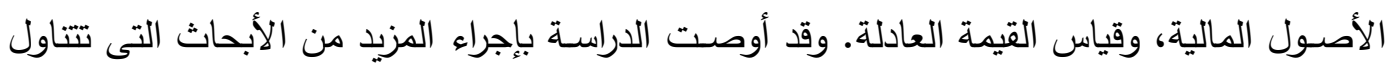
انعكاسات جائحة كورونا على القطاع المصرفى. 


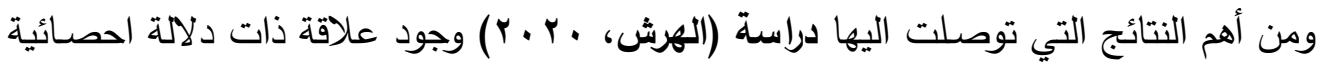

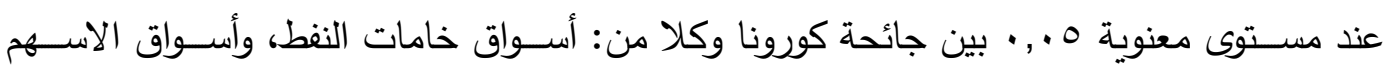
العالمية، وأسواق السلع الدولية، وكانت مؤشرات أسواق النفط الأعلى تأثراً بالجائحة تبعتها مؤشرات

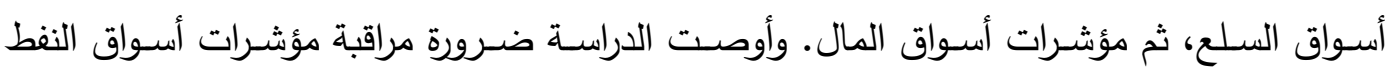
وأسـواق الســـع الدولية وأســواق الأسـهم الدولية تباعاً، وإلى اعتماد الذهب كخيار أو ملاذ آمن لانه

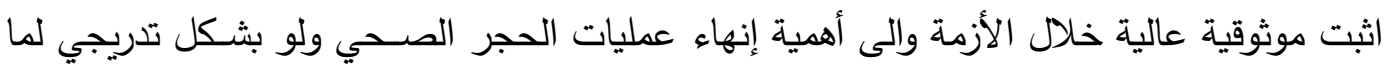
لها من تأثير بالغ على أسواق النفط والسلع الدولية.

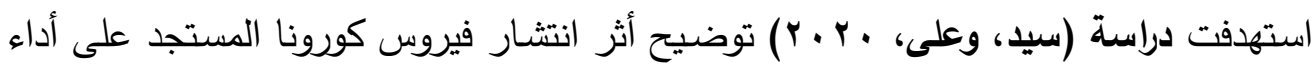

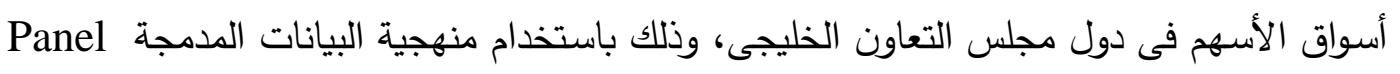

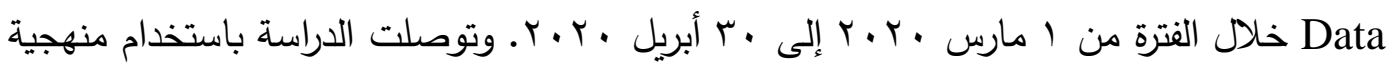
المربعات الصـــغرى المعدلة للبيانات المدمحة (FMOLS) والمربعات الصـــــرى الدينـاميكية للبيانات المدمجة، إلى وجود أثر سـلبى ومعنوى لانتثـــار الفيروس على أداء أســـاق

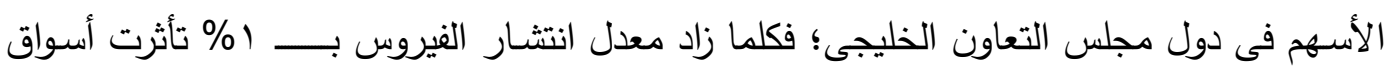

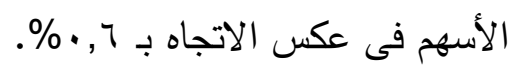

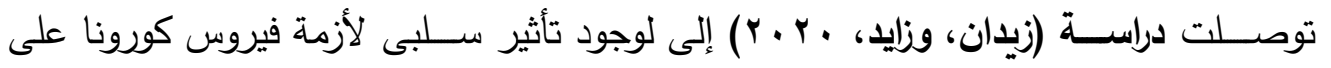

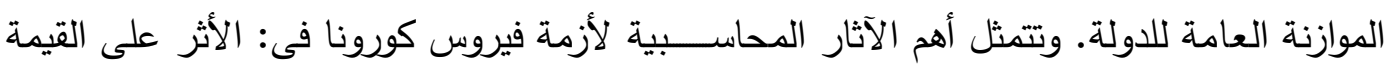

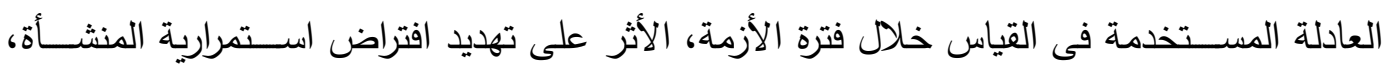

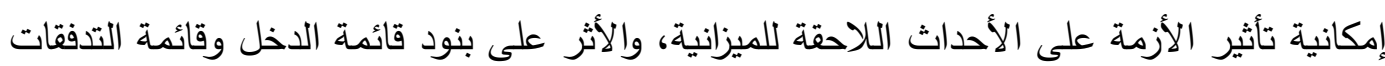

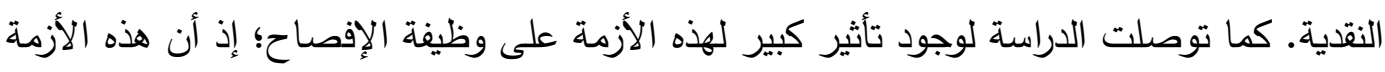
تتطلب مزيد من الإقصاح لدى الثركات. توصلت دراسة (عبد الرازق، • r • r) إلى ان الانعكاسات الإقتصـادية، والآثار المالية لفيروس

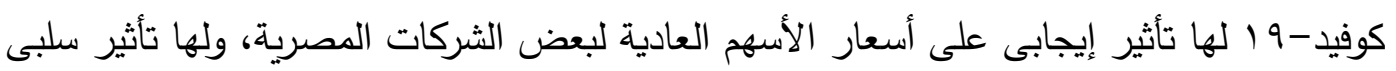

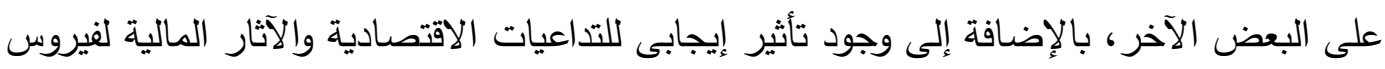

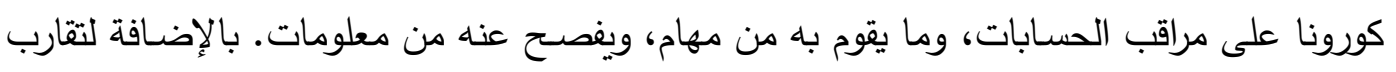

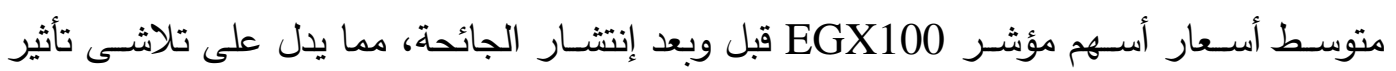
فيروس كورونا على أسعار الأسهح التى يشملها المؤشر •

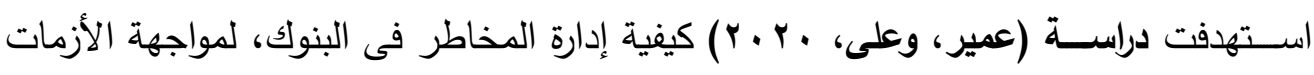

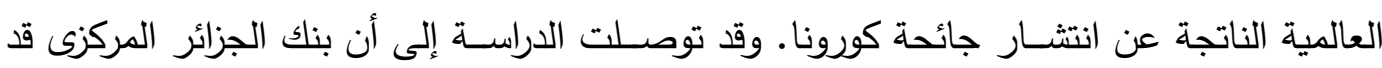
أصدر العديد من التعليمات لزيادة السيولة المالية ومنح القروض وتأجيلها وإعادة جدولتها واستعال ولتهال

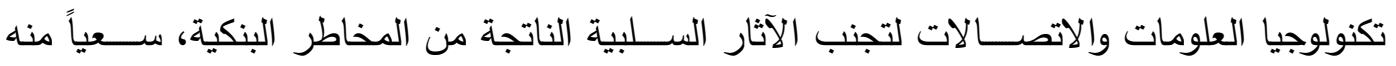
للحفاظ على سـلامة الاستقرار المالى للبلاد. كما توصـلت إلى أن انهيار سـعر النفط جراء جائحة كورونا قد أثر بشـكل كبير على اقتصـاديات الدول القوية منها والضـعيفة، فتاخلت البنوك لإحداث نوعاً من الاستقرار المالى للحياة الاقتصادية، وذلك من خلال أدوات السياسة النقدية. 


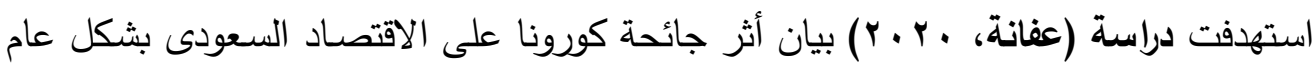
وعلى البنوك السـعودية بشكل خاص. واعتمدت الدراسـة على المنهج التحليلى للقوائم المالية للبنوك لك

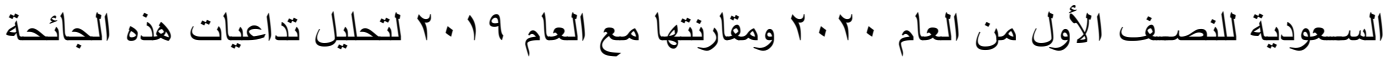

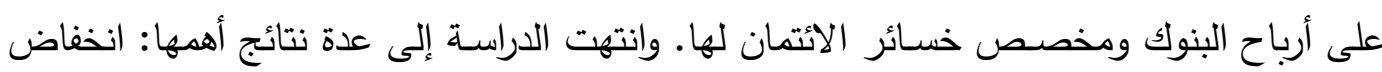

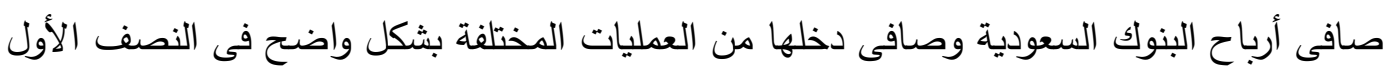

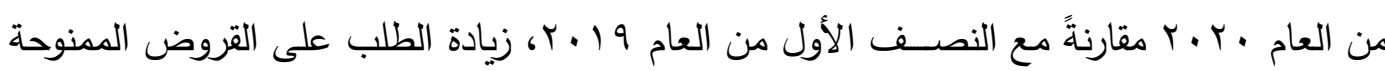

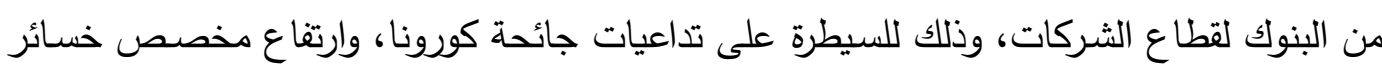

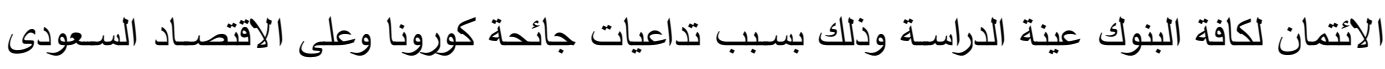
ككل وعلى القطاع المصـرفى السـعودى بثـكل خاص. وقد أوصــ الدراســة بقيام المملكة العربية السعودية بسياسات وإجراءات إضافية من شأنها تدعيم مقدرة البنوك السعودية لمواجهة هذه الجائحة

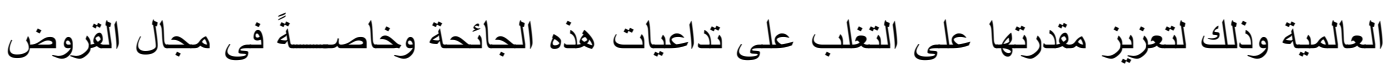

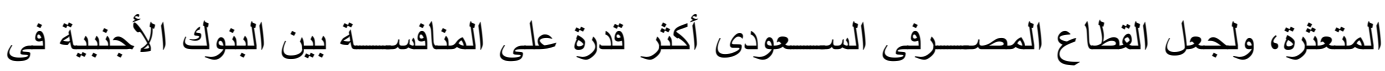

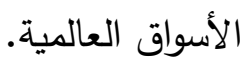

فحصــت دراســة (Abubaker, 2020) الأثر الضـار لجائحة فيروس كورونا على الأعمال

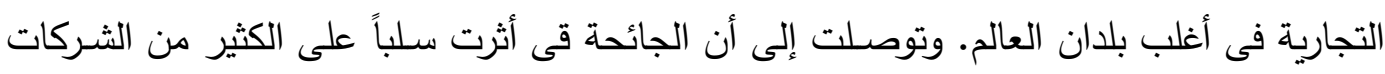

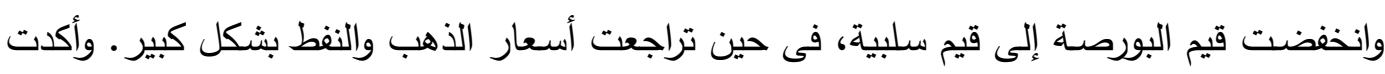

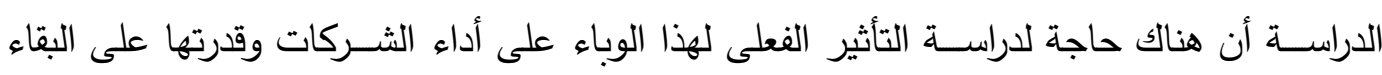

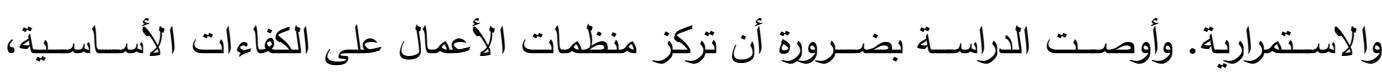
واستراتيجية تتمية القدرات من أجل البقاء فى وجود مثل هذا الوباء. استهدفت دراسـة (Aifuwa, et al. 2020) التحقق تجريبياً من تأثير وباء كورونا على الأداء المالى وغير المالى للثـركات فى نيجريا. وتم الحصــول على البيانات من الاسـتبيانات التى تدار عبر الإنترنت لأصـحاب الثركات الخاصـة، والمحللين الماليين فى ولاية لاغوس. وقد كثفت نتائج

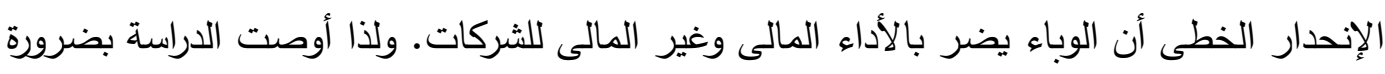
أن تدرج الحكومة النيجيرية الثركات الخاصة ضمن حزمها التحفيزية أو برامج التسكين للحفاظ على لـى عمل الثركات خاصةً بعد الوباء.

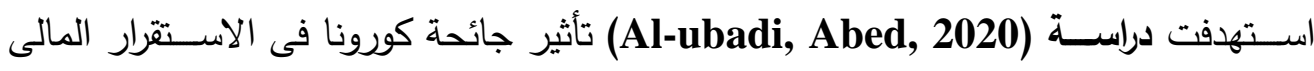

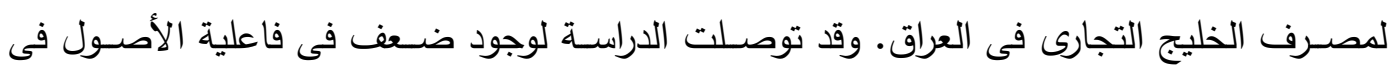

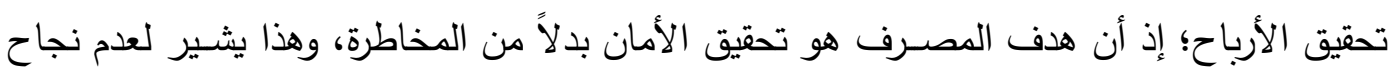

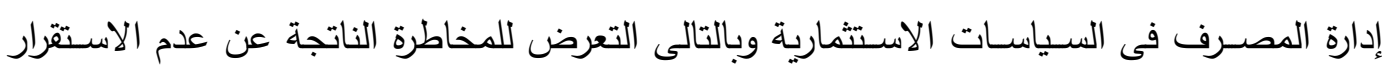

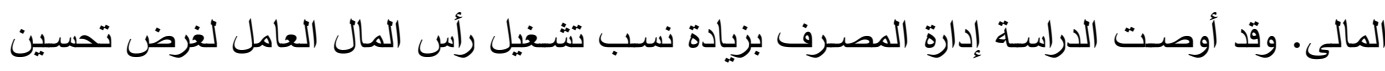

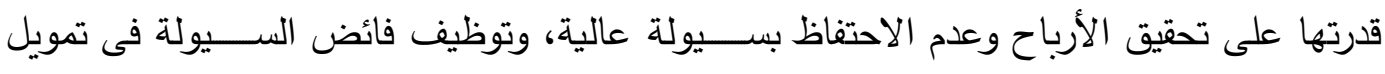
المشروعات والقروض، إضافة إلى الموازنة بين هدفى الأمان والمخاطرة. 
كما توقعت دراســـة (Deloitte, 2020) أن الكثير من الأصـــول المالية ســـوف تتعرض للإضمحلال نتيجة للآثار السلبية لجائحة فيروس كورونا، والتى ستؤدى إلى إنخفاض القيمة العادلة

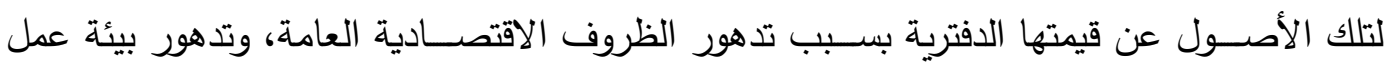
المنشـأة، وإنخفاض الطلب السـوقى على منتجات أو خدمات المنثـآة، وتدهور الأداء المالى نتيجة إنخفاض التدفقات النقدية أو تحقيق صـافى تدفقات نقدية سـالبة، أو إنخفاض الإيرادات أو الأرباح المتوقعة مقارنةً بالنتائج الفعلية للفترات السابقة ذات الصلة، وإنخفاض سيولة أسواق الأسهم والهيوط المستمر لسعر السعر.

تتاولت دراســة (Ehrentraud, Zamil, 2020) تدابير الإغاثة التتظيمية غير العادية التي

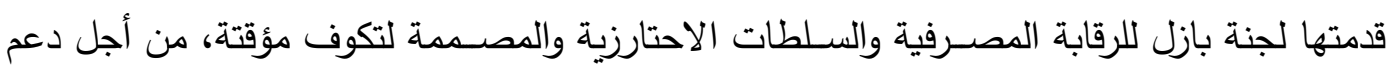

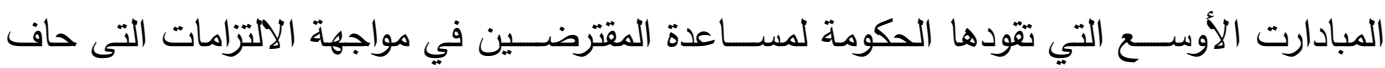
سدادها. وتوصـت الدراسـة إلى أنه طالما استمرت تداعيات الوباء، فإن تدابير الإغاثة المؤقتة هذه هوهاه

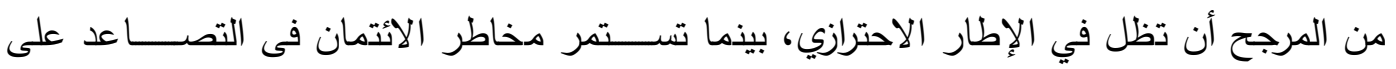

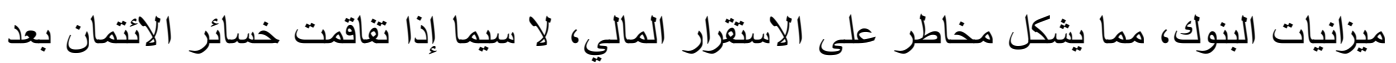

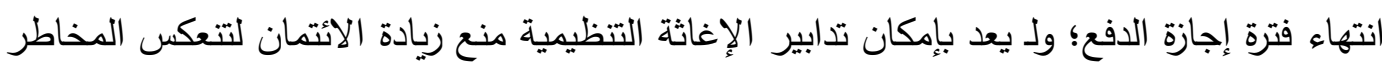
بشكل كامل فى مستوى NPAs للبنك ونسبة CET1، وكلاهما تستخدم على نطاق واسع كمعايير لتقييم صــحة البنوك والأنظمة المالية الوطنية. ولذا نادت الدراســة بوضــع ســيناريونات يمكن من وهن خلالها تصور كيفية تطبيق نموذج الخسائر الائتمانية المتوقعة. تتاولت دراسة (Liu et al., 2020) أثر انتثار فيروس كورونا على سلوك الأسهم في الأسواق المالية. وباستخدام أسعار الإغلاق اليومي للأسهم في الأسواق المالية لمجموعة مكونة من اب دولئة

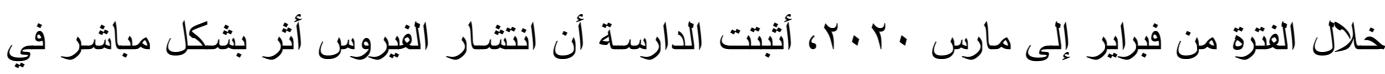

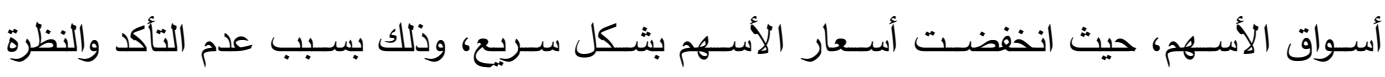
التثاؤمية لدى المستثمرين بثأن العوائد المستقبلية. التعليق على الاراسات السابقة أن هذه الدراسـات السـابقة تعمل فى ظل ظروف معينة واقتصـادية ذات طبيعة خاصـة، تختلف عن تلك الدارســـة الحالية فى البيئة المصــرية، وما يحيط بها من مســتجدات وتغيرات اجتماعية واقتصـادية حاليا نتيجة تفشى فيروس كورونا. وهو ما يميز الدراسـة الحالية عن الدراسـات السـابقة،

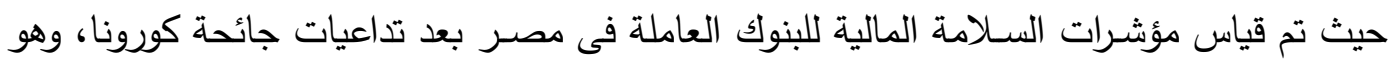

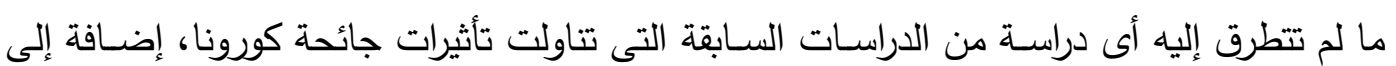
أنه تم أخذ تأثير تطبيق المعيار الدولى للتقارير المالية IFRS9 فى الاعتبار. 


\section{القسم الثانى: تداعيات جائحة كورونا فى القطاع المصرفى المصرى}

/ / ماهية ومراحل جائحة كورونا

جائحة فيروس كورونا أو جائحة كوفيد-9 1، هى جائحة عالمية مستمرة حالياً لمرضسى فيروس كورونا، سببها فيروس كورونا المرتبط بالمتلازمة التتفسية الحادة الثـديدة (سـارس-كوف-ب). وقد

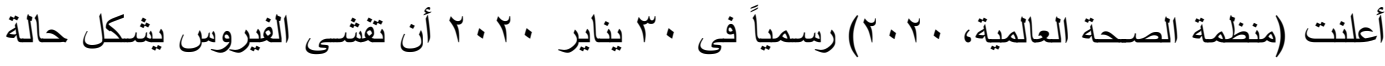

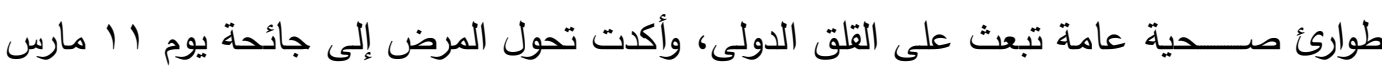

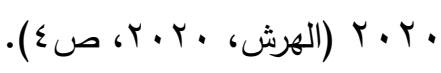

وتشكل فيروسـات كورونا هى مجموعة كبيرة من الفيروسـات التى تسبب المرض، ويتراوح بين

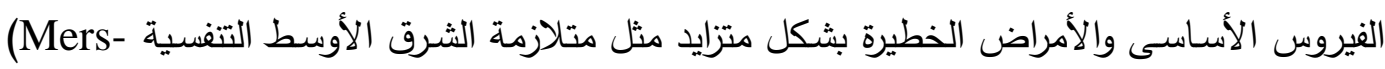
(Sars-Cov) ومتلازمة الجهاز التتفسى الحادة الوخيمة. الفيروس التاجى هو سـلالة أخرى

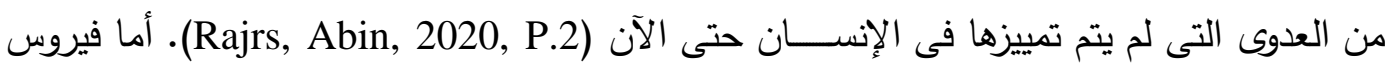

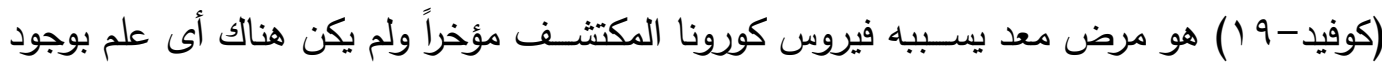

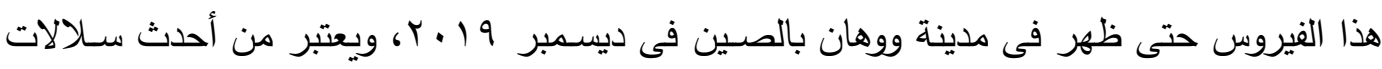

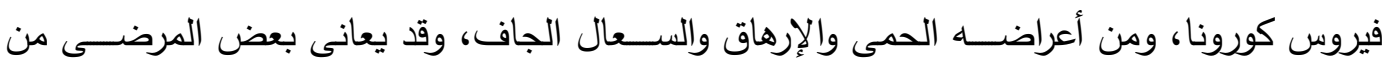

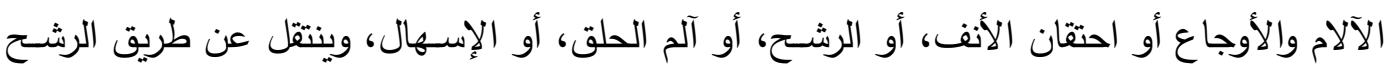

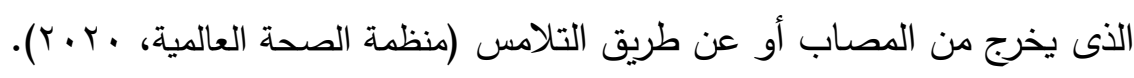

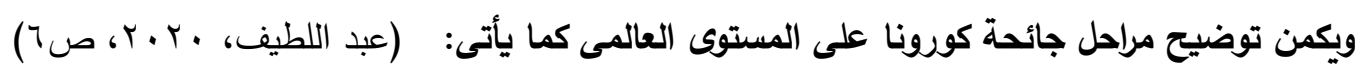
ا ـ ظهور الفيروس: شهدت بداية الأزمة وتفاقمها فى الصـين فقط، ولم تتأثر باقى دول العالم ومنها

$$
\text { الدول العربية والأوروبية بالأزمة بعد. }
$$

r. بداية الانتثـار : انتثــار واسـع للفيروس عالمياً، وتأثر الدول الأوروبية بثـــة به، وبدأت الدول

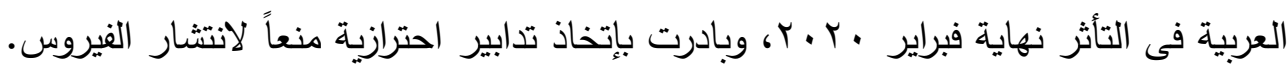

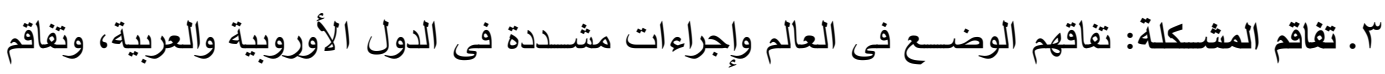

كبير فى إيطاليا، وبداية انحسار الفيروس فى الصين وانتثاره فى الولايات المتحدة الأمريكية.

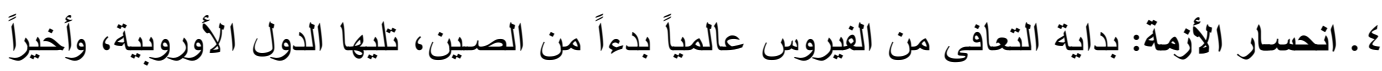
الدول العربية، والولايات المتحدة. ه. التعافى: التعافى الكامل بثـــكل تدريجى لجميع الدول ومنها الدول العربية، وان كان من المتوقع

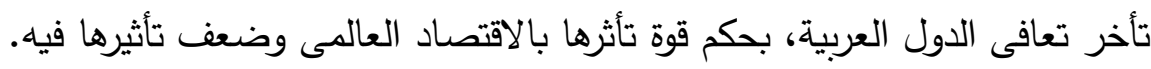

\section{r/r مدى تأثر مهنة المحاسبة جائحة كورونا}

تأثرت مهنة المحاســبة بجائحة كورونا، إذ أنها لا تعمل بمعزل عن البيئة المحيطة، وكلما زاد عدم التأكد المصـــاحب لبيئة الأعمال كلما زادت التحديات التي تواجهها مهنة المحاســــة للقيام بوظائفها المختلفة. وقد تسـببت جائحة كوفيد-19 في زيادة مسـتوى عدم التأكد بالنسـبة لمنشـأت الأعمال، مما يخلق العديد من الصعوبات والتحديات أمام إدارة هذه المنشآت ومعدى التقارير المالية

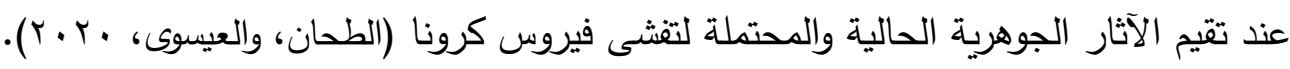




\section{وفيما يأتى تأثير جائحة كورونا على الفروض المحاسبية:}

\section{• الأثر على فرض الاستمرارية:}

أثرت جائحة كورونا بشكل كبير على فرض الإنر الاستمرائهرار المحاسبى، فالبرغم من طبيعة الفروض

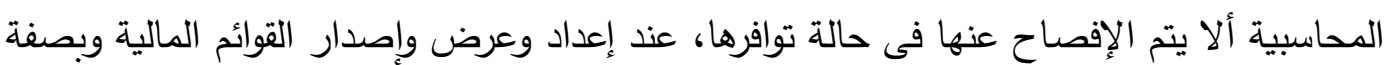

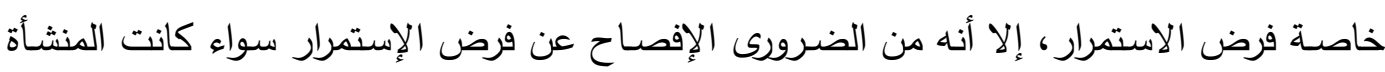
مستمرة أو لديها شك مؤثر فى توافر فرض الإستمرار حتى يطمئن أصحاب المصـالح، لذلك يتعين

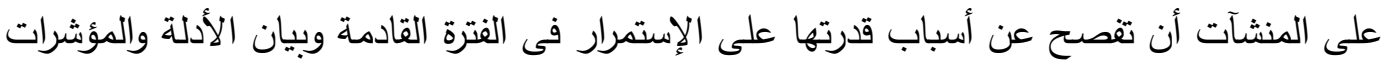

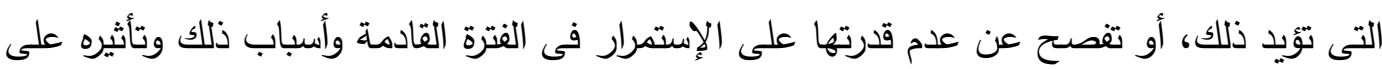

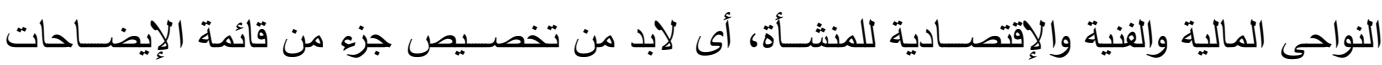

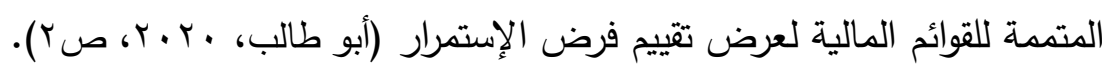

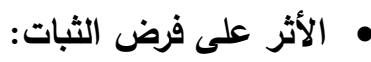

أثرت جائحة كورونا على هذا الفرض بشكل مباشر ، حيث اضطرت معظم المنشآت إلى تغيير سياساتها المحاسبية من جهة وإلى تغيير طريقة العرض المحاسبى من جهة أخرى، نتيجة المشاكل المالية والإقتصادية والفنية التى أثرت على نشاطها مما قلل من تحقيق هذا الفرض لأهدافه والمتمثلة

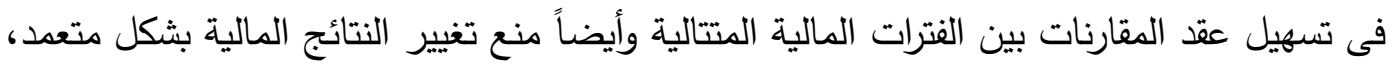
أى التلاعب بالحسابات بشكل مؤثر خصوصـاً بالمبالغة فى تكوين مخصصـات جديدة أو إستخدام

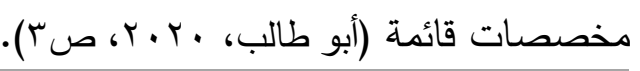

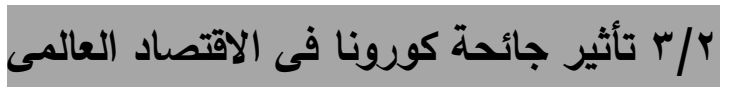

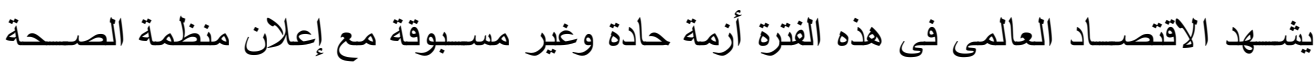

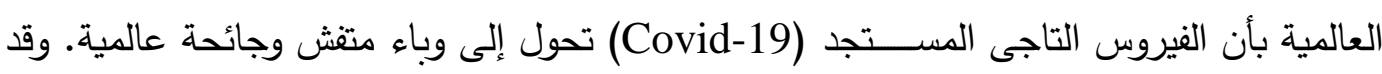
أصـابت هذه الجائحة الاقتصـاد العالمى بصـة متعددة الاتجاهات والأبعاد أدت إلى معاناة وخسائر

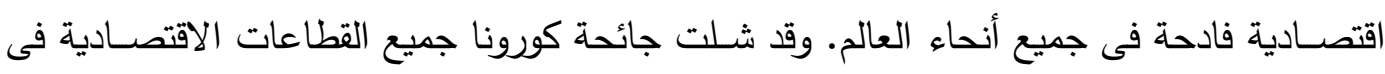
أغلب دول العالم لا سيما المتقدمة اقتصادياً منها. ويتمثل الخطر المالى والاقتصادى الخطر الأكبر

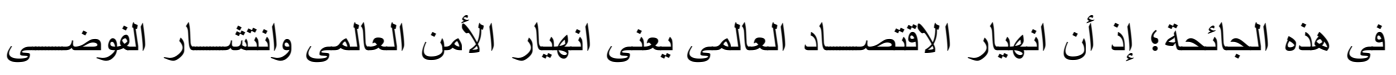

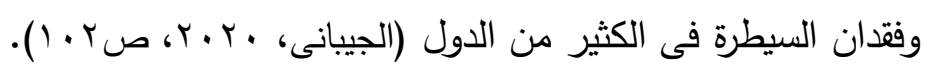

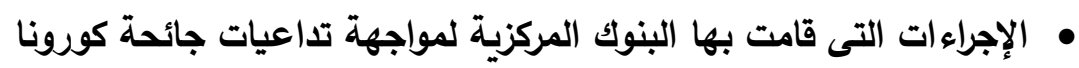

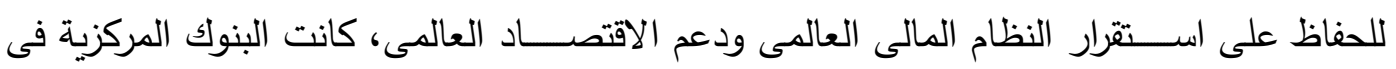
مختلف بلدان العالم هي أول خط للدفاع، حيث: (Adrian, Natalucci, 2020) ا ـ قامت البنوك المركزية بتيسير السـياسـة النقدية إلى حد كبير عن طريق تخفيض أسـعار الفائدة

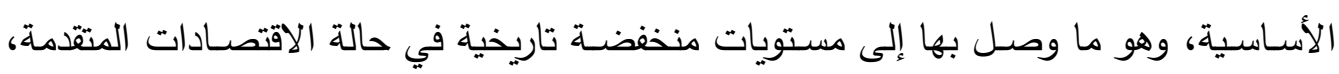
كذلك قام نصـف البنوك المركزية في الأســواق الصـاعدة والبلدان الأقل دخلا بتخفيض أسـعار الفائدة الأسـاسـية. وستتعزز آثار تخفيضـات أسـعار الفائدة من خلال إرشـادات البنوك المركزية حول المسار المستقبلي للسياسة النقدية والبرامج الموسعة لشراء الأصول. 
r. أعادت البنوك المركزية تفعيل البرامج التي اســـُخدِمت أثناء الأزمة المالية العالمية، كما أطلقت

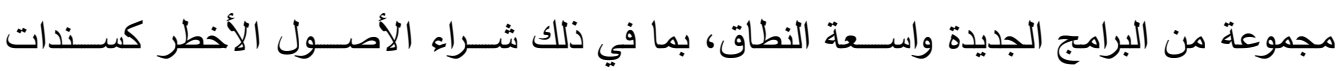

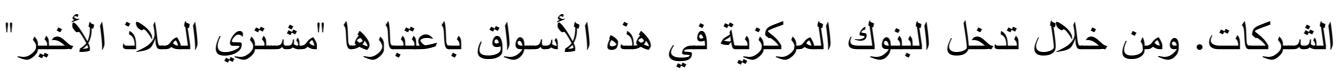
ومســاعدتها على احتواء الضــغوط الرافعة لتكلفة الائتمان، تضــــن هذه البنوك اسـتمرار إتاحة الأتتمان بسعر معقول لقطاعَي الأسر والثركات.

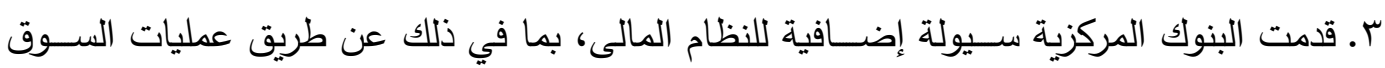
المفتوحة. ـ ـ اتفق عدد من البنوك المركزية على زيادة تقديم السيولة الدولارية عن طريق ترتيبات خطوط تبادل العملات.

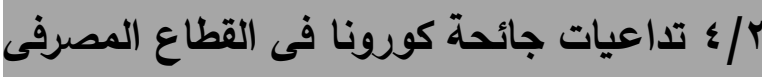

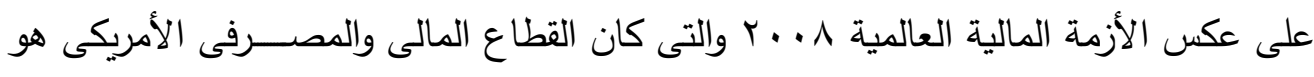

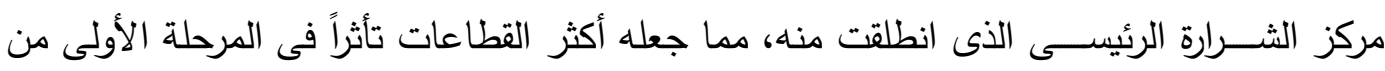

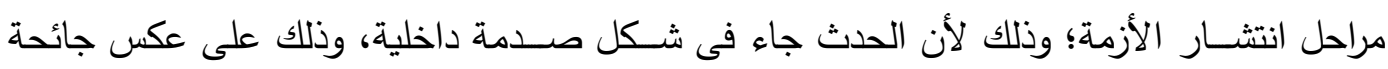
كورونا والتى تمثل صـدمة خارجية أصـابت القطاع الصـحى بشكل رئيسى ثم اندثرت بعد ذلك فى الكى

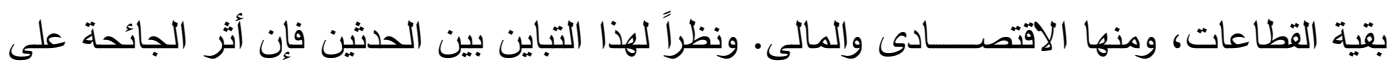

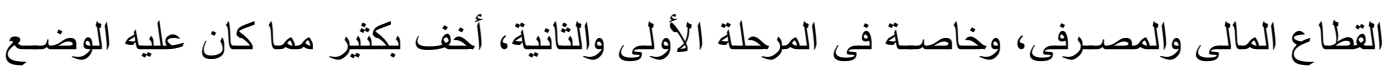
أثناء الأزمة المالية، بل أن البنوك أصبحت إحدى أهم قنوات الحل وذلك لقيامها بدور داعم للأنشطة

الاقتصادية والصحية فى العديد من دول العالم نتيجة متانة مراكزها المالية (WEF, 2020,P.8). ويواجه القطاع المصــرفى المصــرى شــأنه شـأن باقى القطاعات المصــرفية فى دول العالم

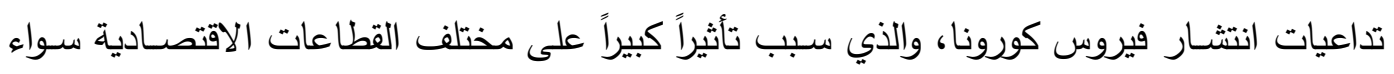

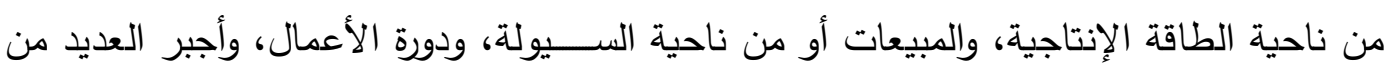

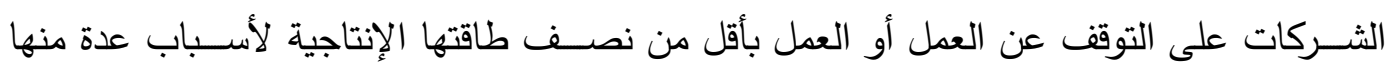
توقف سلاسل الإمداد واتخاذ ما يلزم من إجراءات لحماية العمالة والعملاء.

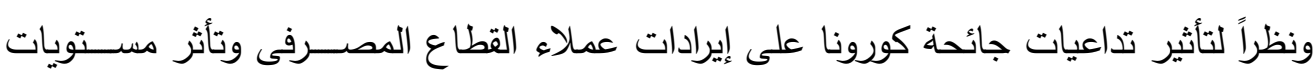
الســيولة لديهم، فمن المتوقع أن ينعكس ذلك على قدرتهم على خدمـة ديونهم للبنوك بالطريقـة المعتادة، ولإدراك البنك المركزي لكل تبعات هذا الحدث والأثار السلبية التي يخلقها، فقد بادر باتخاذ

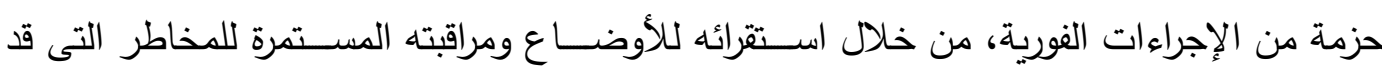
يتعرض لها القطاع المصـرفي والصـدمات التى قد تؤثر على الاقتصـاد والأسـواق المحلية والدولية،

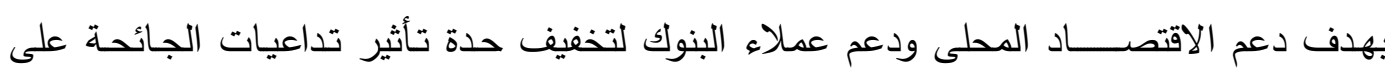
القطاعات الاقتصــــادية وقطاع الثـــركات والقطاع العائلى، وذلك بالاعتماد على الملاءة المالية

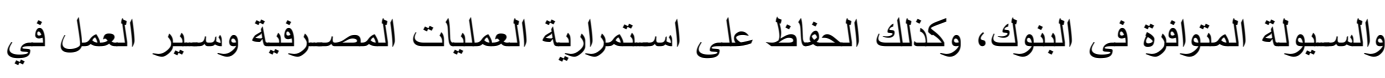
البنوك وضمان استمرارية عمل نظم الدفع بالكفاءة والفاعلية والأمان لتدفق الأموال وإجراء التسويات

$$
\text { بين البنوك داخلياً وخارجياً (تقرير الاستقرار المالى، } 9 \text { ( • ب، ص (r). }
$$


وقد اتخــ البنـك المركـزي المصرى إجـراءات احترازية كبيـرة وفعالـة لاحتـواء الآثـار السـلبية لجائحة كورونـا على الاقتصاد الوطنى، والتي سيتم تحقيقها بالتعاون مع البنوك العاملة فى مصر ،

\section{ومن أهم هذه الإجراءات '}

ا ـ تخفيض أسعار العائد لتحفيز الاقتصاد على النمو.

Y. تأجيل كافة الاستحقاقات الائتمانية للعملاء من المؤسسـات والأفراد لمدة ج أشـهر ، مع استبعاد العاد تأثير تلك الفترة عند حساب فترة التوقف عن السداد.

r. إجراءات للحد من التعاملات النقدية وتيسير استخدام وسائل وأدوات الدفع الإكترونى. ع. إتاحة التمويل اللازم لاستيراد السلع الاستراتيجة ودعم القطاعات والشركات الأكثر تأثراً. ه. إعفاء البنوك لمدة عام من احتسـاب متطلب زيادة فى رأس المال الرقابى لمقابلة مخاطر التركز

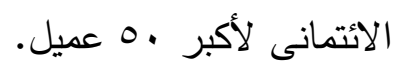

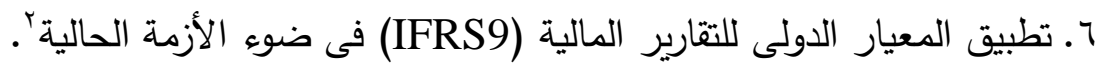
V. إطلاق مبادرة البنك المركزى للسداد الإلكترونى. ^. تقعيل دور شركة ضمان مخاطر الائتمان فى مبادرات دعم قطاعات السياحة والصناعة والزراعة والمقاولات.

\section{• المعيار الدولى (IFRS9) وجائحة كورونا}

دخل المعيار الدولى IFRS9 (الأدوات المالية) حيز التنفيذ فى أغلب الدول الأوروبية فى العام

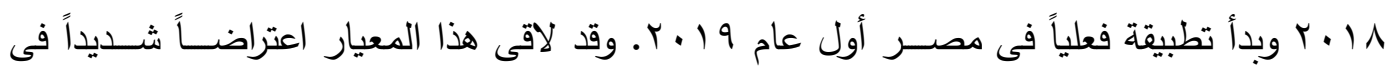

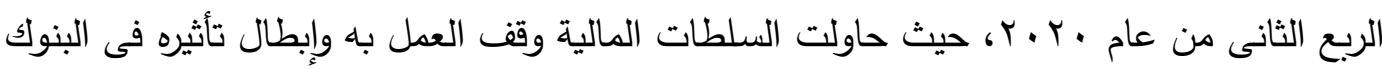
خلال جائحة كورونا، على اعتبار أن لهذا المعيار آثاراً خطيرة على العمل المصـــرفى خلال فترة

الانكماش الاقتصادى، نتيجة إلزام البنوك بزيادة المخصصات اللازمة لمقابلة الخسائر الائتمانية.

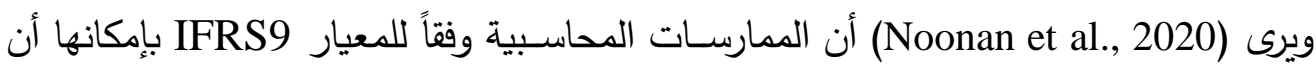
تشـل أجزاء من القطاع المصـرفى نتيجة لفرض الاعتراف المبكر بخسائر القروض؛ فجائحة كورونا سـتدفع اقتصـاديات العالم نحو الركود، ومع تطبيق هذا المعيار سـيزداد هذا الركود من خلال جعل لتصن

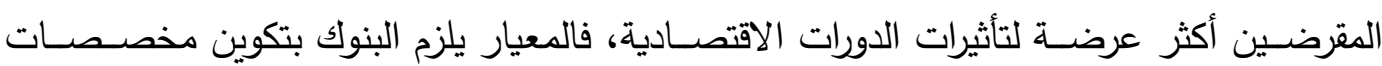
سـابقة للقروض التى يحتمل عدم إمكانية تحصـيلها وبصــة خاصـة فى ظروف عدم التأكد كما هو الحال فى جائحة كورونا، أو حدوث تغيرات جوهرية فى ظروف الســــوق، وهذا يؤدى إلى تكوين مخصـصــات طيلة مدة العمر الإنتاجى للقرض. وعلى النقيض من ذلك يتفق (Esma, 2020) مع وجهات نظر مجلس معايير الماســبة الدولية (IASB) بأن الطبيعة القائمة على المبادئ للمعيار

مرنة بما فيه الكفاية لتعكس بدقة تداعيات تفشى جائحة كورونا والإجراءات المرتبة بها.

1- البنك المركزى المصـرى: (.r.r.r)، "تعليمات وإجراءات البنك المركزى للحد من فيروس كورونا المستجد"، أوراق عمل، ديسمبر ·

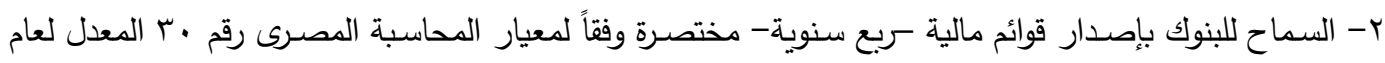

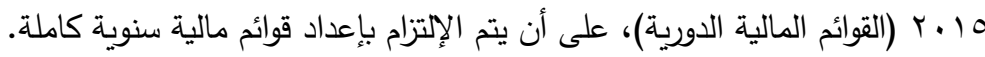


ويمكن أن تؤثر الجائحة على المقترضـين سـواء كانوا شـركات أو أفراد فى مجال قدرتهم على

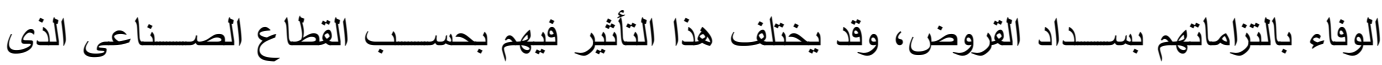

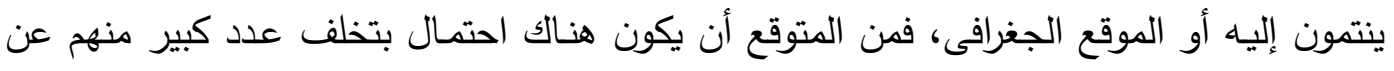

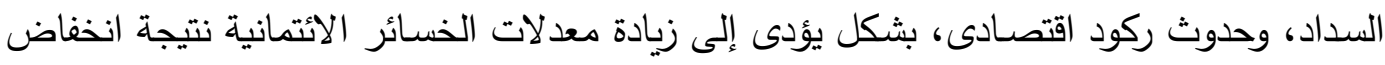

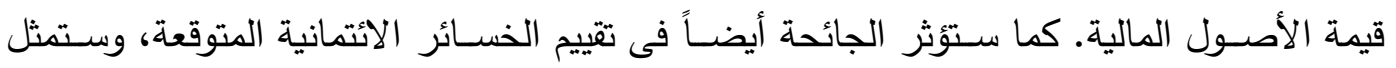
تحدياً كبيراً للبنوك وغيرها من شـركات الإقراض وحتى الثـركات المالية، وذلك بسـبب أن خسـائر الائتمان المتوقعة لا تنطبق على القروض فحسـب، ولكن أيضــاً على العديد من الاســتمارات فى

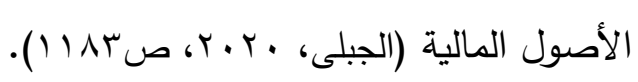

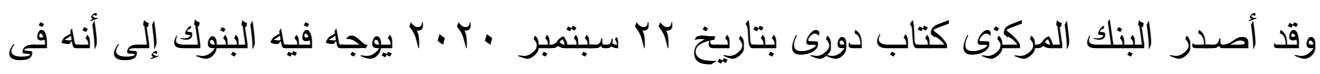

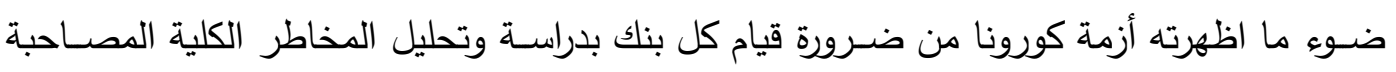
للأزمة الحالية ووضــــع الخطط لمواجهة الأزمات غير المتوقعة وتأثيرها على البنك. وفى إطـار

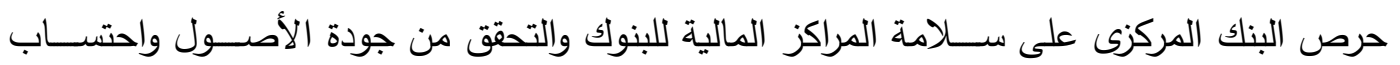
الخسائر الائمانية المتوقعة بصورة صحيحة خلال الأزمات، فقد تقرر قيام البنوك بما يأتى:

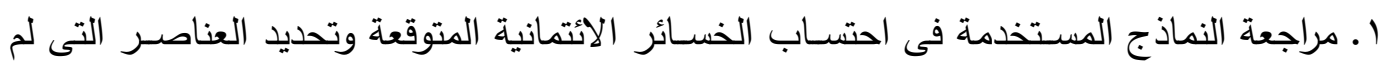

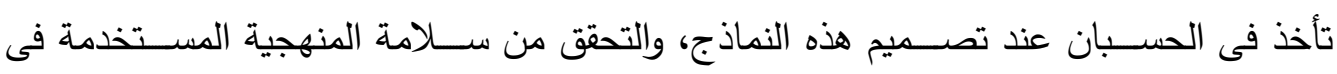

احتساب الخسائر الائتمانية المتوقعة.

r. التحقق من قياس جودة وكفاية نظم المعلومات، والمعلومات الحالية والمسـتقبلية المسـتخدمة فى المى تصميم النماذج.

\section{ب / بأثير جائحة كورونا فى الاستقرار المالى}

تثــكل جائحة كورونا تحدياً جديداً للاســتقرار المالى؛ إذ أن الاســتقرار المالى يتحقق عندما يتمكن القطاع المالى والمصرفى من تلبية احتياجات التتمية الاقتصادية والاجتماعية، وذلك فى ظل القوانين التى تحكم العمل المصــرفى. لذا يجب الوقوف على مدى الاسـتقرار المالى الذى يتمتع به القطاع المصــرفى من خلال قياس أثر جائحة كورونا فى الاســتقرار المالى. وفيما يأتى أهم الآثار الناتجة عن تفشى جائحة كورونا فى مؤشرات الاستقرار المالى العالمى:

(Fernandes, 2020, P.2)

ا ـ إعادة تسعير كبيرة، وإعادة تحديد الموقع فى الأسواق المالية العالمية. r. المراجعات الهابطة المستمرة لتوقعات النمو الاقتصادى، وتزايد النفور من المخاطرة. r. نوبات من التقلب الثديد فى الأسهم والأسواق الأخرى للأصول الخطرة. ع. تزايد عد من مقاييس الضغط إلى معدلات مرتفعة لدرجة كبيرة.

هـ تعرضت أسواق التمويل لضغوط نتيجة الطلب الثديد على النقدية والأصول شبه النقدية.

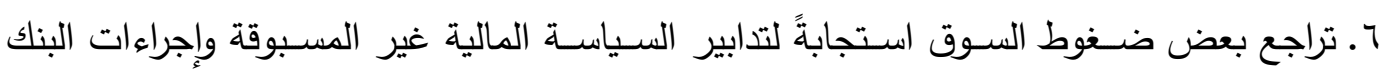

المركزى المتخذة لدعم الأسواق المالية. وعلى عكس ازمة ^ . . r، ظل النظام المصرفى الأساسى صامداً وسط كل هذه الضغوطات. 
وتعتبر جودة الأصول هى الجزء الأسـسى لضمان كفاءة وفعالية نشاط البنك والتى تؤدى إلى تحقيق المزيد من الإيرادات والربحية؛ فحيازة البنك لأصول جيدة تضمن له تحقيق دخل أكبر، سيولة الكئ

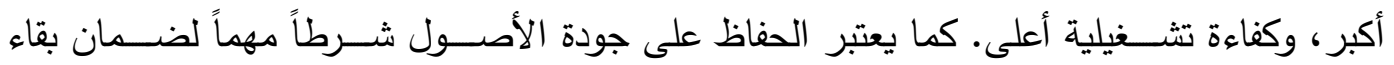
واســتمرار البنك فى الســـوق (Yeltulme et al, 2017, P.2). وفيما يأتى أهم الأثار المترتبة على

جائحة كورونا من منظور جودة الأصول:

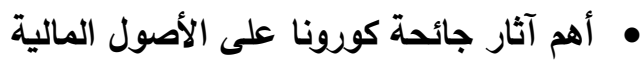

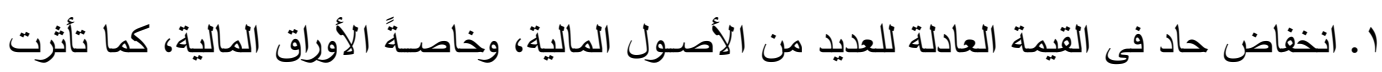
قدرة المدينين على الامتثال لشروط القروض والأدوات المماثلة بشكل سلبى. وستحتاج الشركات إلى النظر بعناية فى متطلبات القياس وتقدير خسائر انخفاض القيمة المناسبة وتطبيقها.

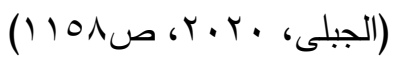

r. تدهور الجودة الائتمانية للمقترض، الأمر الذى قد يدفع إدارات المنثــآت المتضــررة إلى إتخاذ قرار بالتصرف فى أو بيع الاستثمارات المصنفة على أنها "محتفظ بها لتحصيل التدفقات النقدية التعاقدية"، وذلك نتيجة لزيادة المخاطر الائتمانية من جراء جائحة كورونا.

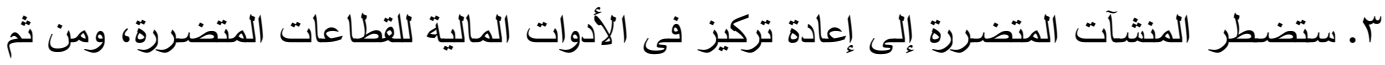

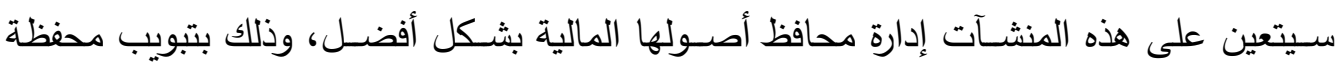
الأصــــول المـالية التى تديرها إلى محافظ فرعية مع المحافظة على تتويع هذه المحافظ وفقاً للخصائص المشتركة التى تجمعها بهدف تخفيض مخاطر التركز إلى أقل حد مدكن.

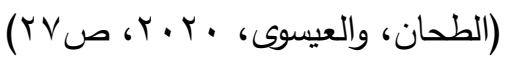

\section{• أهم آثار جائحة كورونا على جودة الأصول}

ا ـ الأثر على القروض المصــرفية: من خلال التعثر وعدم الســاد، مما يؤثر على المتانة المالية التى التى

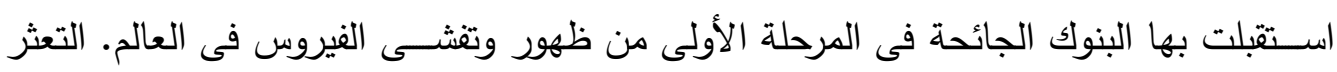

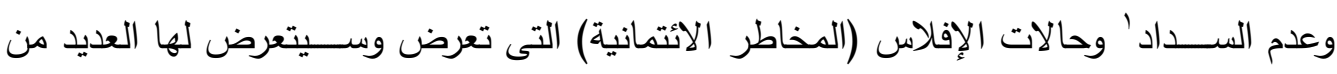

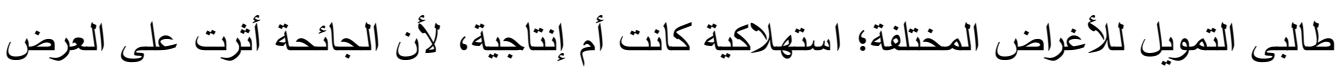

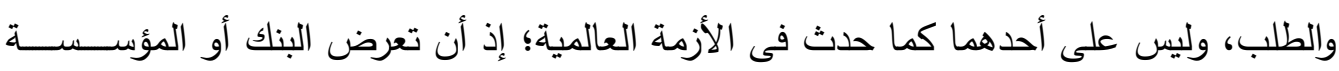

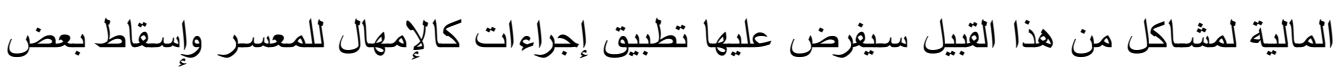

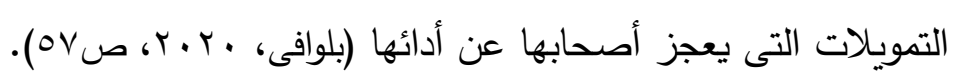

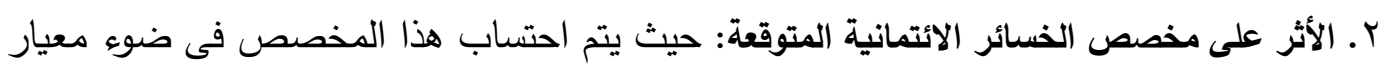
IFRS9، ومع التعرض لجائحة كورونا وتأثيرها على انخفاض أداء الثـــركات، وتحملها المزيد من التكاليف الغير متوقعة، ســوف ينعكس ذلك على احتمالات التعثر لدى عملاء البنوك، مما يسـهم فى زيادة مخصـص الخسـائر الائتمانية لمجابهة تلك الأخطار ، وسـيكون لذلك أثر كبير

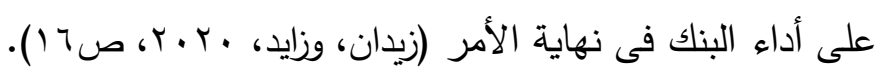

ا- يتم التفريق فى مثل هذه الأوضـاع، من الناحية المحاسبية والقانونية، بين الديون المتعثرة (NPLs) أى المشكوك

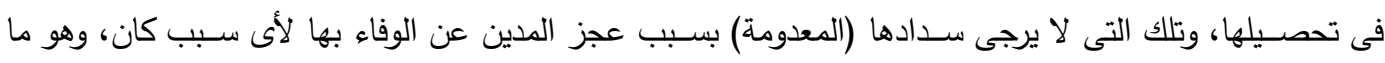
يتطلب إبراز ذلك فى التقارير المالية للبنوك المعنية بذلك). 
وقد انتقل النظام المصرفى العالمى إلى محاسبة الخسائر المتوقعة فى السنوات الأخيرة، بسبب ردة الفعل السياسية ضـد المعايير القائمة على الخسائر المتكبدة. وقد أخفقت العديد من البنوك فى في

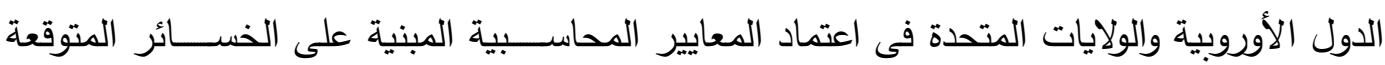
خلال جائحة كورونا (Davies, 2020). צ/ צ تأثير جائحة كورونا فى مؤشرات السلامة المالية للقطاع المصرفى المصرى شهد القطاع المصرفى المصرى مستوى مرتفع من الاستقرار المالى خلال السنوات الماضية، والذى تمثل فى قدرته على التعامل مع العديد من الأزمات واحتواء تداعياتها، وذلك بفضــل وضــــع الاستراتيجيات اللازمة لإدارة مختلف أنواع المخاطر، واتخاذ الإجراءات الاحترازية المناسبة، وتطبيق

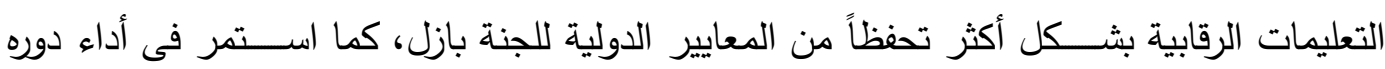
بنجاح فى الوسـاطة المالية مع تعزيز الثـمول المالى، ودعم النمو الاقتصـادي. وقد استقبل القطاع

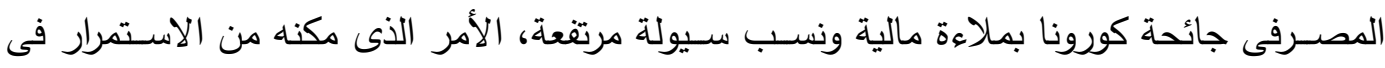
أداء دوره بنجاح فى الوسـاطة المالية دون لجوء البنك المركزى إلى تحرير أى من الدعامات المالية أو تخفيض الحدود الرقابية المقرة على القطاع المصرفى.

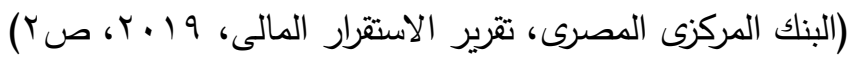
ويظهر اسـتقرار القطاع المصـرفي في تحسـن مؤشـرات السـلامة المالية - حتى مع تداعيات

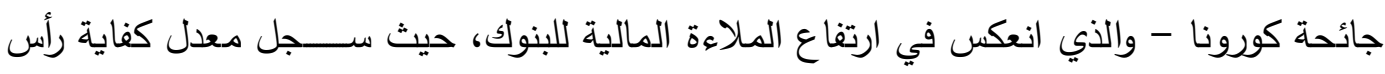

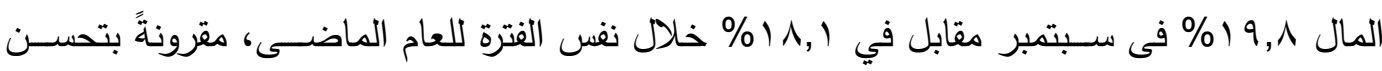

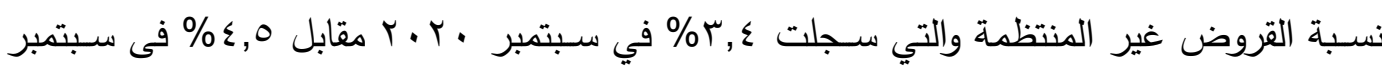

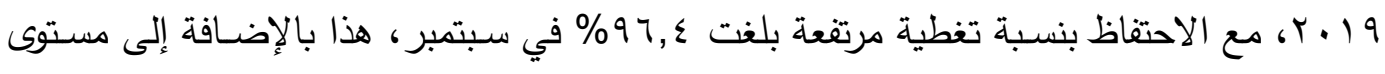

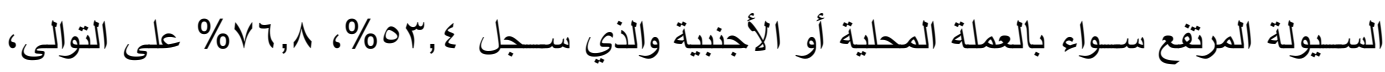

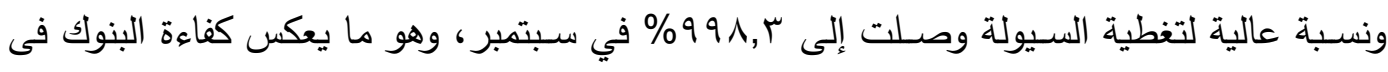
إدارة كافة المخاطر الرئيسـية المتمثلة فى مخاطر الائتمان والســوق والســيولة. هذا ويعتمد القطاع

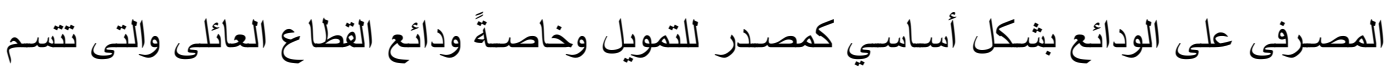

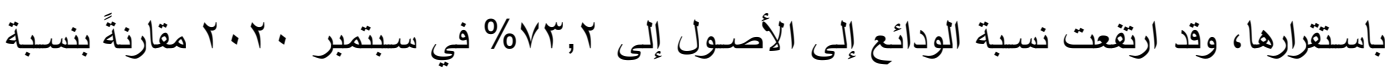

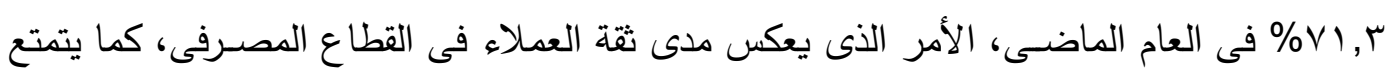

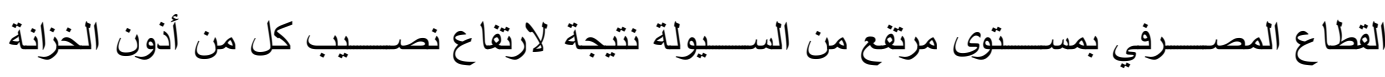
والاستثمارات المالية، والنقدية والأرصدة لدى البنوك من إجمالى أصول القطاع المصرفى. ونظراً لأن هذه الظروف الصعبة يمكن أن تستمر لأكثر من فترة طويلة ولها آثار سلبية طويلة

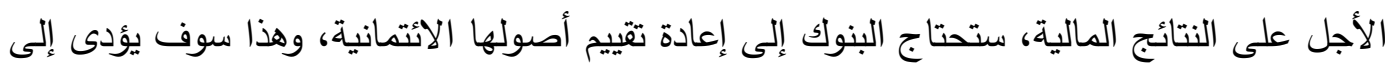

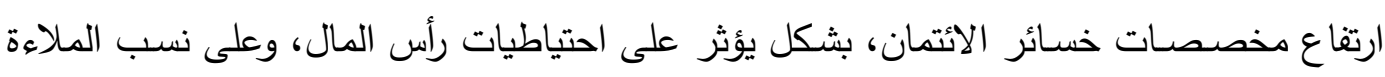
المالية والسيولة المحتملة للقطاع المصرفى.

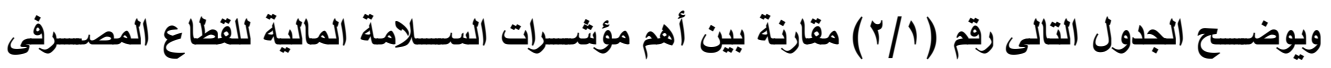


جدول رقم (Y/ Y): مؤشرات السلامة المالية للقطاع المصرفى قبل وبعد جائحة كورونا

\begin{tabular}{|c|c|c|c|c|c|c|c|c|}
\hline \multicolumn{4}{|c|}{ 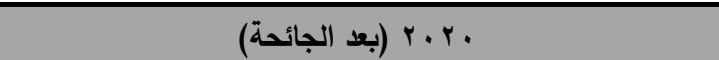 } & \multicolumn{4}{|c|}{ 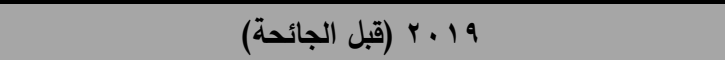 } & \\
\hline ديسمبر & سبتمبر & يونيو & مارس & ديسمبر & سبتمبر & يونيو & مارس & \\
\hline \multirow{21}{*}{ 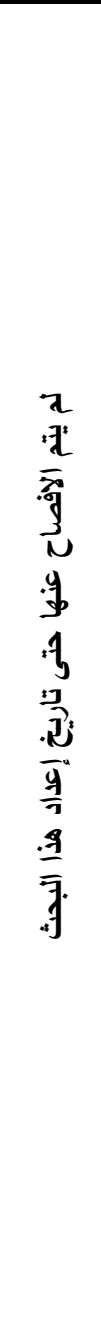 } & & & & & & & & أولاً: كفاية رأس المال \\
\hline & 19,1 & $r \cdot, 1$ & $1 \wedge, 7$ & $1 \wedge, \varepsilon$ & 11,1 & 17,9 & 17,0 & •القاعدة الرأسمالية إلى الأصول المرجحة بأوزان مخاطر \\
\hline & IV,r & $\mathrm{IV}, \mathrm{V}$ & 17,1 & 10,9 & 10,0 & $1 \varepsilon$, & $1 \%, 0$ & •الشريحة الأولى من رأس المال إلى الأصول المرجحة \\
\hline & $\mathrm{V}, \varepsilon$ & $v, 7$ & $v, r$ & $\mathrm{v}, \varepsilon$ & $V, r$ & $8, v$ & 7,7 & • الرافعة المالية \\
\hline & & & & & & & & ثانياً: جودة الأصول \\
\hline & $r, \varepsilon$ & $r, q$ & $\varepsilon, 1$ & $\varepsilon, r$ & $\varepsilon, 0$ & $\varepsilon, r$ & $\varepsilon, 1$ & • • القروض غير المنتظمة إلى إجمالى القروض \\
\hline & $94, \xi$ & $9 \vee, r$ & $9 V, r$ & $9 \vee, 9$ & $9 \vee, \xi$ & $9 \vee, \wedge$ & $9 \wedge$, & • مخصات القروض إلى القروض غير المنتظمة \\
\hline & 71, & 71,9 & $r$ r,V & $r r, r$ & $7 \varepsilon$, & 71,0 & $\Delta 9,9$ & •القروض المقدمة للقطاع الخاص إلى إجمالى قروض العملاء \\
\hline & & & & & & & & ثالثاً: الربحية \\
\hline & 1,1 & 1,1 & 1,1 & $1, \varepsilon$ & $1, \varepsilon$ & $1, \varepsilon$ & $1, \varepsilon$ & • العائد على متوسط الأصول \\
\hline & $r r, \varepsilon$ & $r r, \varepsilon$ & $r r, \varepsilon$ & $19, r$ & $19, r$ & $19, r$ & $19, r$ & •العائد على متوسط حقوق الملكية \\
\hline & $\varepsilon, 1$ & $\varepsilon, 1$ & $\varepsilon, 1$ & $r, \cdot$ & $r, \cdot$ & $r, \cdot$ & $r, \cdot$ & • صافى هامش العائد \\
\hline & & & & & & & & رابعاً: السيولة \\
\hline & & & & & & & & 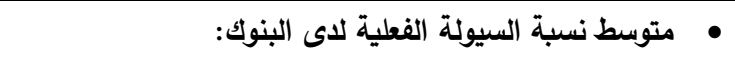 \\
\hline & or, \& & $0 \leq, r$ & $\varepsilon 9, \mathrm{~V}$ & $\leqslant 0, \wedge$ & $\leqslant 0,1$ & $\leqslant 1,9$ & $\varepsilon r, \xi$ & بالعملة المحلية \\
\hline & $\vee \vee, \wedge$ & $v \cdot, r$ & $v i, r$ & $V \leq$, & $V r, q$ & $7 \wedge, 7$ & $90, v$ & بالعملات الأجنبية \\
\hline & $99 \wedge, r$ & $q r r, 0$ & $V \bullet r, v$ & Arч,V & $\wedge q \diamond, \vee$ & Arч, & $v \leq \cdot, 1$ & • نسبة تغطية السيولة LCR \\
\hline & rrq, & $r r r, 1$ & $r r \leq, Y$ & $r \leq r, \Lambda$ & $r \leq \cdot, \cdot$ & $r \leq V, q$ & $r r \cdot, \Lambda$ & • نسبة صافى التمويل المستقر NSFR \\
\hline & $r r, 4$ & $r r, 1$ & $r r, r$ & $r \cdot, 0$ & $19, r$ & 17,7 & 10,1 & • الأورلق المالية إلى الأصول \\
\hline & $V r, r$ & $V r, r$ & $v_{1, v}$ & $V r, r$ & $v i, r$ & $V Y, Y$ & $99, r$ & • الودائع إلى الأصول \\
\hline & $\varepsilon \vee, \varepsilon$ & $\varepsilon \vee, 1$ & $\varepsilon 0,9$ & $\varepsilon \varepsilon, \wedge$ & $\leq \varepsilon, 1$ & $\varepsilon 4,0$ & $\varepsilon V, 0$ & • القروض إلى الودائع \\
\hline
\end{tabular}

المصدر: إعداد الباحثون اعتماداً على النشرات الإحصائية الثهرية للبنك المركزى المصرى 


\section{وفيما يأتى توضيح لأهم نتائج مؤشرات السلامة المالية قبل وبعد تداعيات جائحة كورونا: \\ أولاً: مؤشرات كفاية رأس المال توضيح لأن مؤشرات}

تثير النتائج الى ان نسبة كفاية رأس المال لدى البنوك المصرية على اساس مجمع بلغت نحو

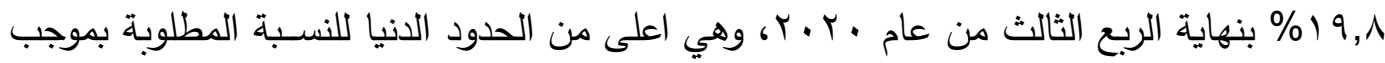
تعليمات البنك المركزي وقدرها ه, • ا\% . وقد نجدت توجيهات البنك المركزي المصــرى فى تدعيم البنوك لقواعدها الرأسمالية وتطورها في ادارة المخاطر خلال السنوات الماضية والمساهمة في تعزيز قدرة البنوك على الاحتفاظ بمعدلات عالية لمعايير كفاية رأس المال. كما بلغت نســبة الرفع المالي لاى البنوك المصرية بنهاية سبتمبر الماضسي نحو \&, ع وهو ما يفوق بشكل كبير النسبة العالية المقترحة من قبل لجنة بازل وقدرها ب\%؛ وقد جاءت هذه النسـبة مسـاندةً لمعايير كفاية رأس المال

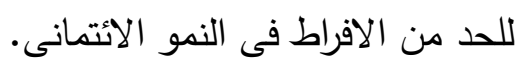
ثانياً: مؤشرات جودة الأصول

استمر التحسن الملحوظ فى جودة الاصـول لدى البنوك المصـرية، والذي يعكسـه تراجع نسبة

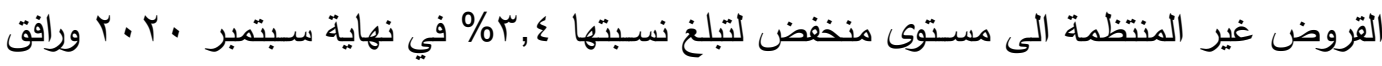
هذا التراجع فى نسـبة القروض غير المنتظمة ارتفاع ملموس ايضـاً فى نسبة تغطية القروض غير المنتظمة (المخصـصــات المتوافرة الى القروض غير المنتظمة) والتى وصــلت الى مســتى مرتفع

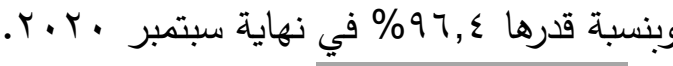

$$
\begin{aligned}
& \text { ثأثاً: مؤشرات الربحية }
\end{aligned}
$$

أعلنت البنوك المصـرية عن نتائج سـنوية تعكس تحديات البيئة التثـغيلية التى واجهتها على ملى

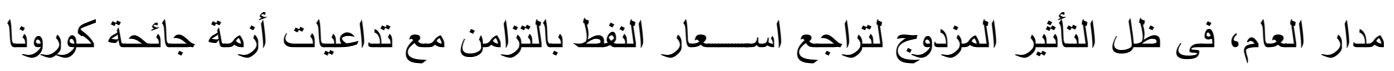
واغلاقات الاسـواق. ورغم ذلك نجحت البنوك فى الحفاظ على ربحيتها، وتحقيق معدلات تعبر جيدة

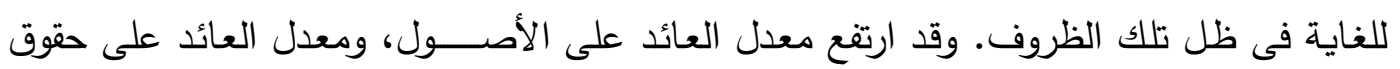

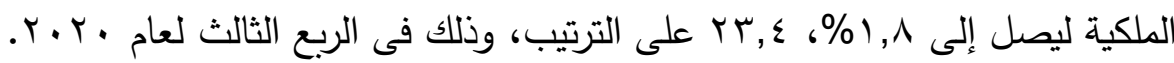

\section{•}

أصبحت البنوك أكثر قدرة على مواجهة مخاطر السيولة على المدى القصير من خلال توافر مخزون كاف من الاصول السائلة عالية الجودة لتلبية احتياجات السيولة التى قد تطرأ وفقاً لسيناريو ضغط لمدة • ب يوم حيث بلغت نسبة تغطية السيولة للبنوك وفقاً لمعيار تغطية السيولة أحد المعايير

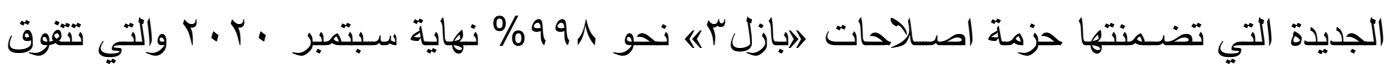

بثكل واضح على متطلبات المعيار الدولي وفقا لتوصيات لجنة بازل وهى نسبة قدرها . . 1\% . كما تتمتع البنوك بمصــادر تمويل مسـتقر عملت على تعزيزها طيلة الســنوات الماضـية بما يمكنها من الوفاء باسـتحقاقات الاصــول والالتزامات داخل وخارج ميزانياتها ما انعكس على نجاحها

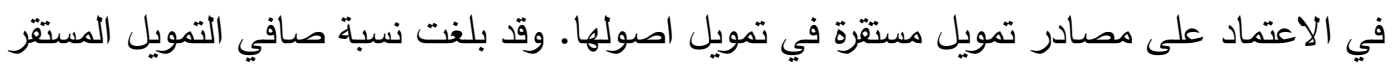

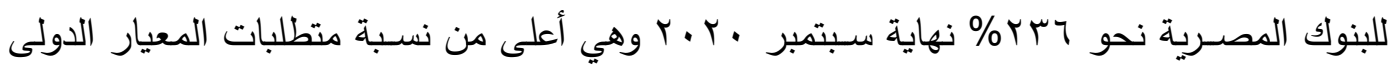
وفقاً لتوصيات لجنة بازل وقدرها . . 1\% 


\section{V/r تأثير جائحة كورونا فى مؤشرات البورصة المصرية}

تمثل تقلبات أسعار الأسهح مصدر قلق كبير للمستثمرين والمهتمين بأسواق المال؛ إذ أن زيادة

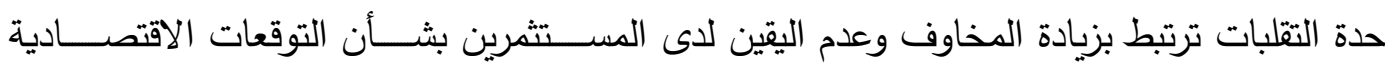

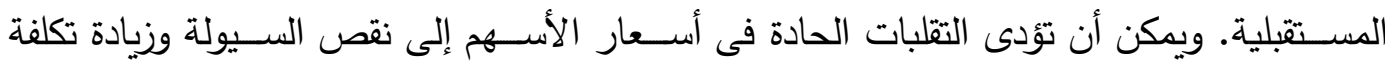

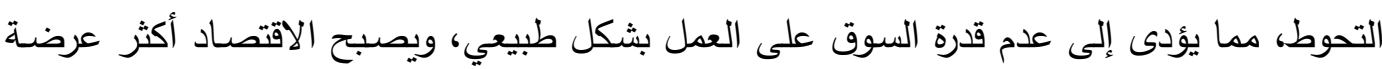

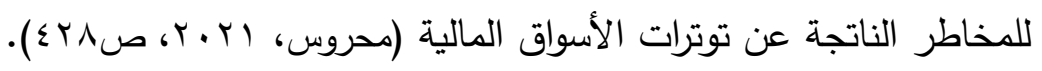
وقد ساهمت المخاوف من انتشار فيروس كورونا والإجراءات التي اتخذتها الدول للسيطرة على تقثي الفيروس في حالة من القلق والذعر لدى المستثمرين مما أثر بشكل كبير في استقرار أسعار

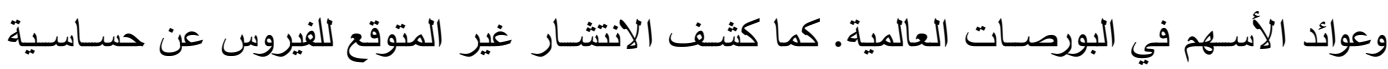
القرار الاستثمارى فى الأسواق المالية للأحداث غير المالية، حيث تعبر تعبر أسعار وعوائد الأسهر

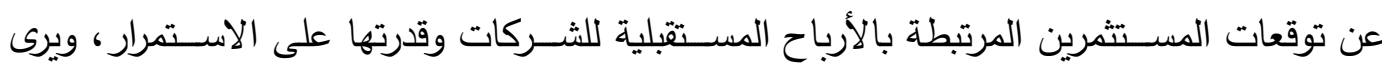

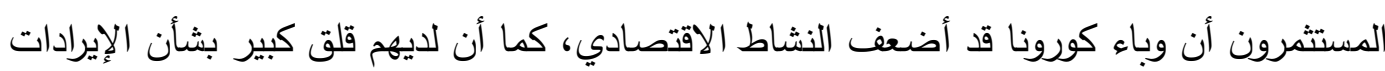
المستقبلية (Liu et al., 2020, P.9). وقد أدى انتشــار فيروس كورونا فى مصـر إلى أضـرار كبيرة بمختلف القطاعات الاقتصـادية،

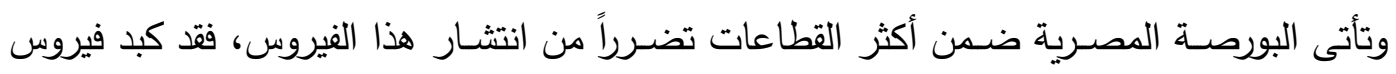
كورونا البورصة المصرية خسائر قياسية، وسط هبوط حاد فى المؤشرات، وخسائر ضخمة في رأس هن

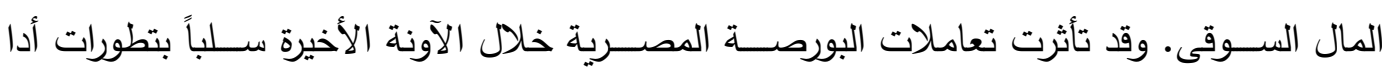
الاقتصــاد العالمى، وتقلبات الأســواق الناشـئة، ولا عجب فى ذلك فقد دعم ظهور الفيروس الأداء

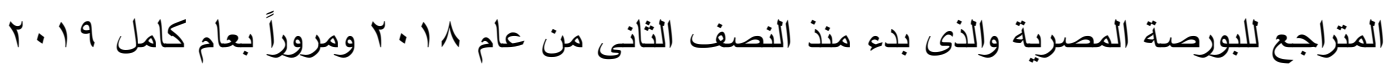

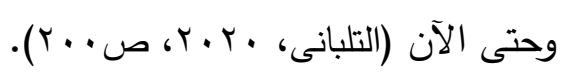

وقد سجلت مؤشرات الأسعار الخاصة بالبورصة المصرية تراجعاً فى نهاية الربع الرابع من عام

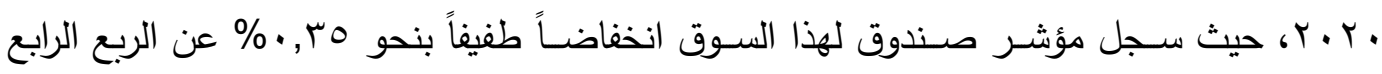

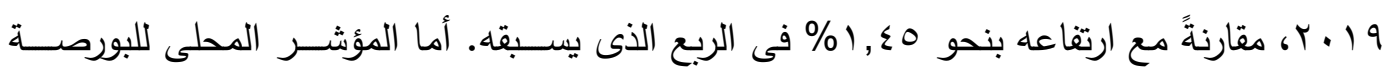

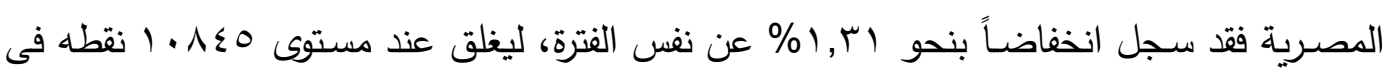

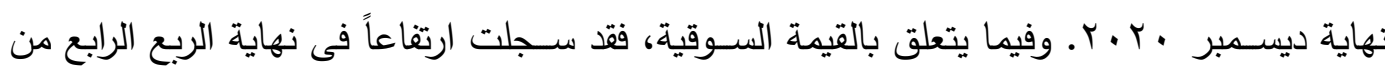

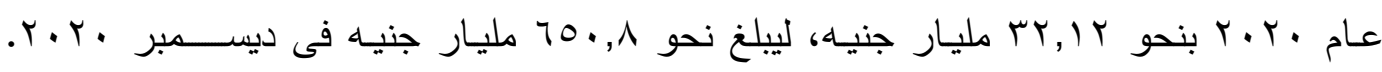

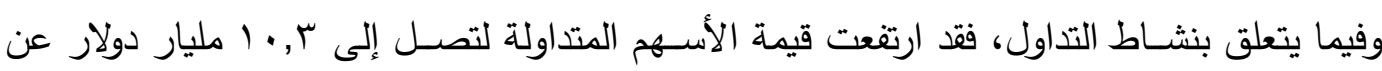

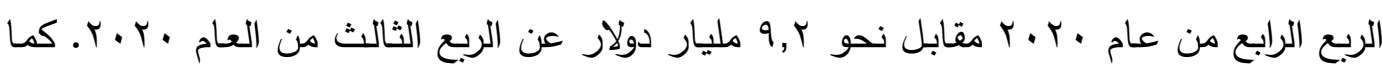

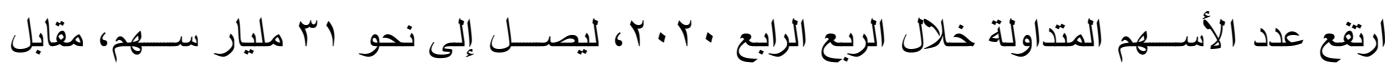
( مليار سهم تم تداولها فى الربع السابق عليه.

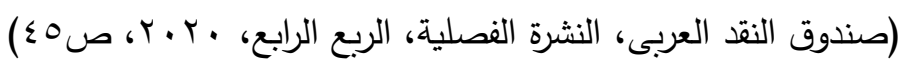

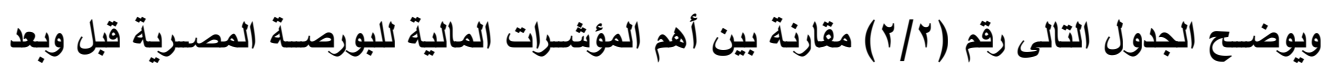


جدول رقم (r-r): المؤشرات المالية للبورصة المصرية قبل وبعد جائحة كورونا

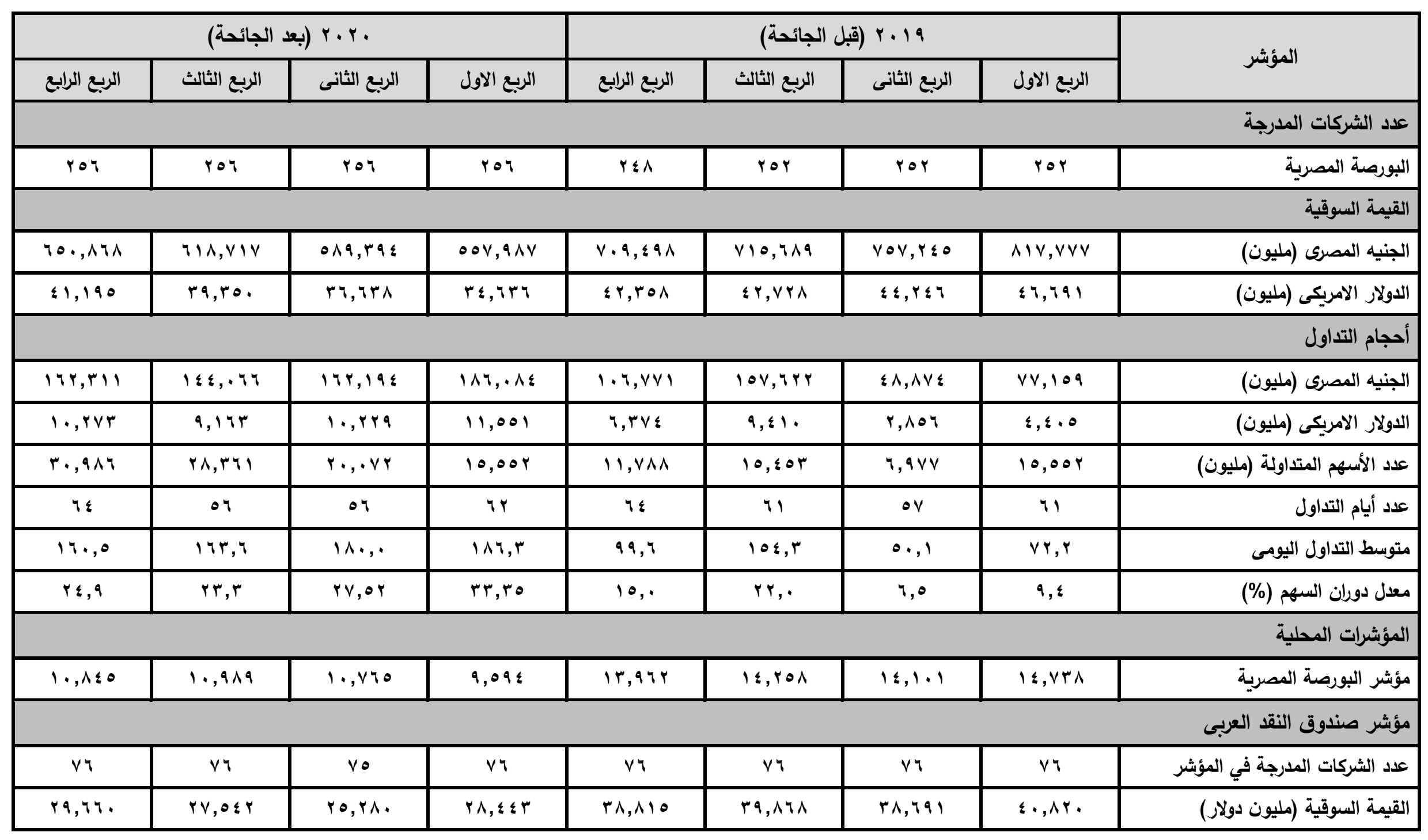

المصدر: إعداد الباحثون اعتماداً على التقارير الربع سنوية لصندوق النقد العربى خلال الفترة

$(r \cdot)$ 


\section{القسم الثالث}

\section{التحليل الإحصائى لمؤشرات السلامة المالية فى ضوء جائحة كورونا}

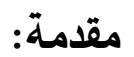

تهدف الدراســة التطبيقية إلى اختبار وتحليل الفروض المتعلقة بمدى وجود أثر لجائحة كورونا فى مؤشرات السلامة المالية للقطاع المصرفى. ولتحقيق أهداف تلك الدراسة التطبيقية يمكن تناولها

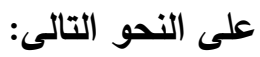

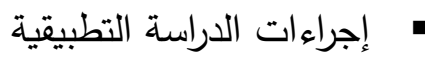
• اختبار الفروض الإحصائية واستخلاص نتائج الدراسة

ب/ إجراءات الدراسة التطبيقية

يتاول هذا الجزء الخطوات المنهجية المتبعة لإجراء تلك الدراســة التطبيقية، حيث توضــح لنا

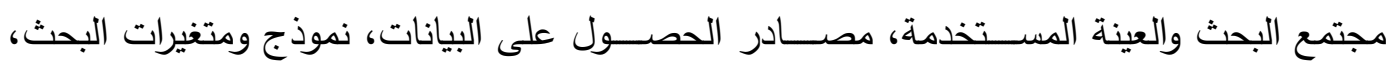
والأساليب الإحصائية المستخدمة. ويمكن توضيح ذلك على النحو التالى:

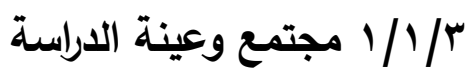

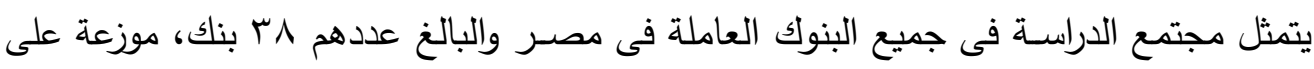

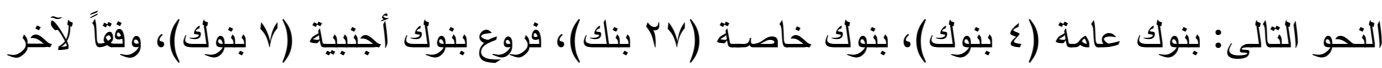

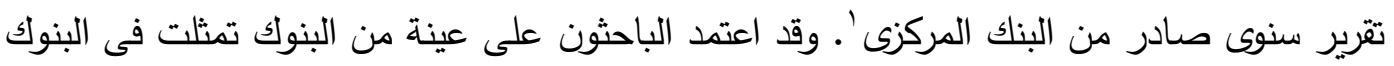

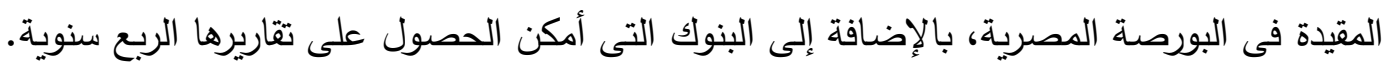

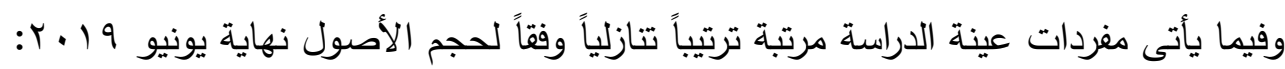
جدول رقم: ( آ/ ): البنوك المثثلة لعينة الدراسة التطبيقية

(القيمة بالمليار جنيه)

\begin{tabular}{|c|c|c|c|c|c|}
\hline حجم الأصول & إسم البنك & م & حجم الأصول & إسم البنك & 5 \\
\hline rr,ror & المصرى الخليجى * & 1. & MT, rVY & التجارى الدولى * & 1 \\
\hline T.,Vד & الإمارات دبى الوطنى & 11 & $r \leqslant \Lambda, Y, Y$ & قطر الأهلى الوطنى * & r \\
\hline $0 \varepsilon, .79$ & أبو ظبى الإسـلاهى " & ir & $r \mid r, r \leq r$ & العربى الأفريقى الدولى & $r$ \\
\hline $0 r, 109$ & كريدى أجريكول * & ir & $1 \vee q, \leqslant r_{0}$ & القاهرة & $\varepsilon$ \\
\hline 01,001 & قناة السويس * & $1 \varepsilon$ & $q \vee, \Lambda i r$ & الاسكندرية & 0 \\
\hline$\{\Lambda,\{r \mid$ & التعمير والاسكان * & 10 & $q \vee, Y \wedge q$ & فيصل الإسلامى * & 7 \\
\hline$\leqslant 1,79 \leqslant$ & بلوم مصر & 17 & $1 \cdot, 011$ & الشركة المصرفية العربية الدولية * & $\mathrm{v}$ \\
\hline$r \varepsilon, q, r$ & أبو ظبى التجارى " & iv & 71,001 & الكويت الوطنى * & $\bar{\wedge}$ \\
\hline$r, r \wedge r$ & الأهلى الكويتى & 11 & $74,1.7$ & البركة * & 9 \\
\hline
\end{tabular}

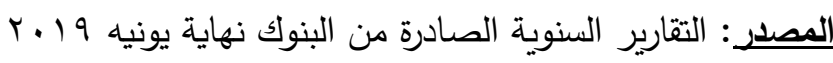

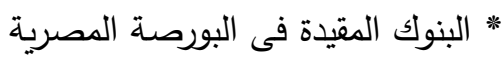

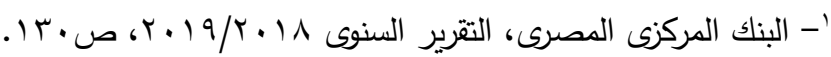


وقد تم انتقاء مفردات العينة وفقاً لأســلوب العينة الحكمية، على أن يحكم اختيار البنوك التى تضمنتها عينة البحث الثروط التالية خلال نطاق فترة الاراسة:

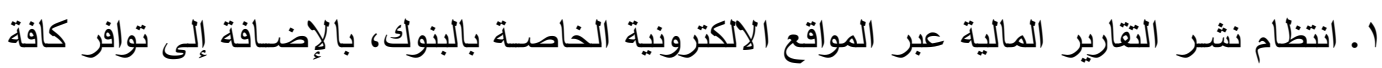
البيانات المالية الفعلية اللازمة لإجراء الاختبارات البحثية خلال فترة الدراسة.

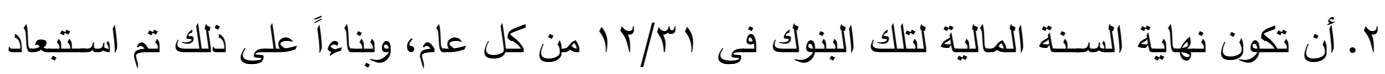
البنك المصرى لتتمية الصادرات من عينة الدرسة. r. أن يتم توحيد عملة إعداد القوائم المالية لجميع البنوك داخل عينة الدراســة لتكون بالعملة المحلية

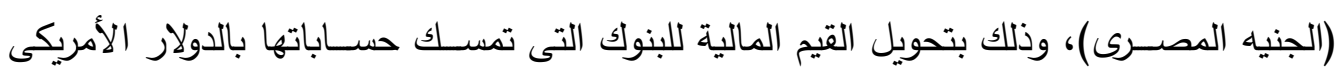
باستخدام سعر الصرف السائد فى تاريخ إعداد القوائم المالية' . ع. استبعاد بنك القاهرة نظراً لأنه قيد التسـيل بالبورصـة المصـرية، ولم يتم طرح أسـهمه للاكتتاب

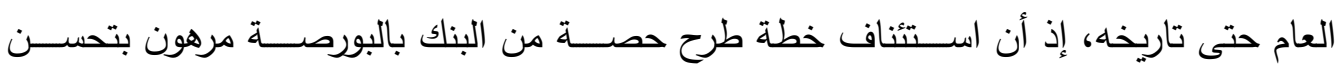
الأوضاع الراهنة التى نتجت عن تداعيات فيروس كورونا. ويوضح الجدول التالى نسبة عينة الدراسة إلى مجتمع الدراسة:

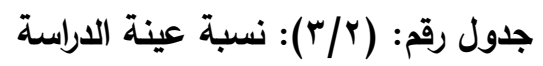

\begin{tabular}{|c|c|c|c|c|}
\hline النسبة & مجتمع الدراسة & عينة الدراسة & البيان & b \\
\hline$\% \leqslant V, r v$ & rᄉ & 11 & عدد البنوك & 1 \\
\hline & & $1, r Y V, \leqslant q r$ & 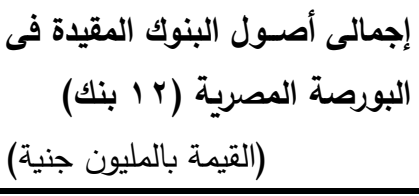 & \\
\hline - & & $r r r, \& r r$ & 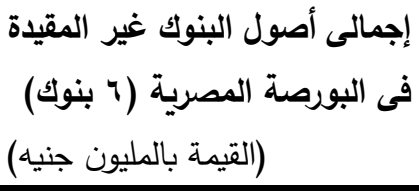 & $r$ \\
\hline$\% r r, 00$ & $0,017,1.7$ & $1, \wedge 0 ., 9 r \leqslant$ & إجمالى الأصول & \\
\hline
\end{tabular}

المصدر: إعداد الباحثون اعتماداً على التقارير السنوية للبنوك وللبنك المركزى المصرى r/T/ r/T مصادر الحصول على البيانات تم تجميع بيانات الاراسة التطبيقية من المصادر التالية: ا ـ التقارير المالية الربع سـويـة للبنوك والإيضـاحات المتممة لها الصـادرة عن تلك البنوك في الفترة

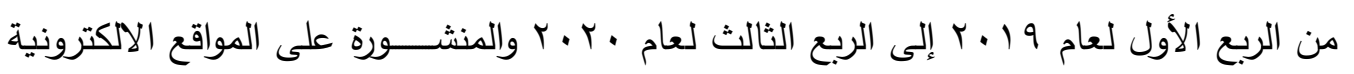

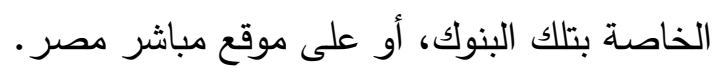

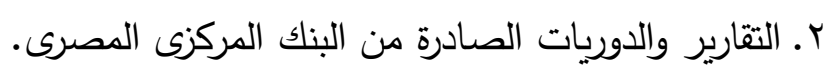
r. البيانات الخاصة بأسعار الأسهح تم الحصول عليها من موقع البورصة المصرية.

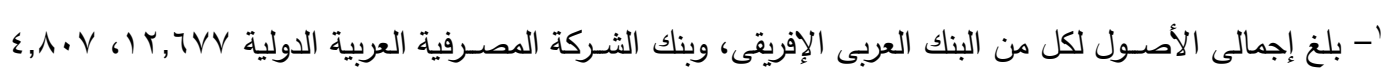

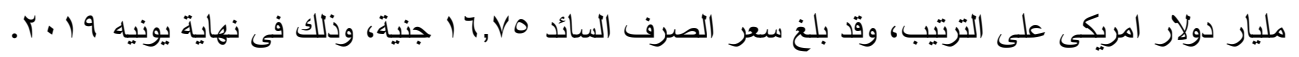




\section{r/}

يمكن صياغة المتغيرات الرئيسية للدراسة (المستقلة والتابعة) كما يوضحها الجدول التالى: جدول رقم: (r/ץ): متغيرات الدراسة وطريقة قياسها

\begin{tabular}{|c|c|c|}
\hline طريقة القياس & المؤشر & r \\
\hline \multicolumn{3}{|c|}{ أولاً: المتغيرات المستقلة } \\
\hline 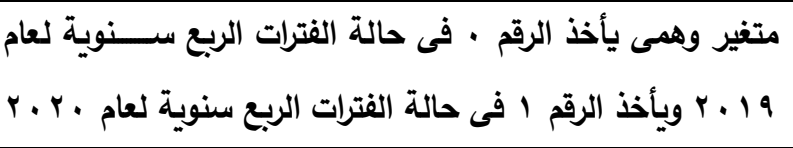 & جائحة كورونا & 1 \\
\hline \multicolumn{3}{|c|}{ ثانياً: المتغيرات التابعة } \\
\hline \multicolumn{3}{|c|}{ • • مؤشرات الربحية Profitability } \\
\hline صافى الربح قبل الضرائب/ متوسط إجمالى الأصول & ROA معدل العائد على الأصول & 1 \\
\hline صافى الربح قبل الضرائب/ متوسط إجمالى حقوق الملكية & معدل العائد على حقوق الملكية ROE & r \\
\hline صافى الربح بعد الضرائب/ متوسط الأسهم العادية & ربحية السهم EPS & $r$ \\
\hline صافى الدخل من العائد */ متوسط إجمالى الأصول المدرة للدخل & هامش صافى العائد من الفوائد NIM & $\varepsilon$ \\
\hline \multicolumn{3}{|c|}{ • مؤشرات السيولة Liquidity } \\
\hline الأصول السائلة */ إجمالى الأصول & $\begin{array}{l}\text { نسبة الأصول السائلة إلى إجمالى الأصول } \\
\text { Liquid Assets to Total Assets }\end{array}$ & 1 \\
\hline صافى القروض/ إجمالى الودائع والقروض قصيرة الأجل & $\begin{array}{l}\text { نسبة القروض إلى الودائع (LtD) نسئ } \\
\text { Net loans to deposit }\end{array}$ & $r$ \\
\hline إجمالى الودائع/ إجمالى الأصول & $\begin{array}{l}\text { نسبة الودائع إلى الأصول (DtA) ن } \\
\text { Total Deposits to Total Assets }\end{array}$ & $r$ \\
\hline \multicolumn{3}{|c|}{ • مؤشرات جودة الائتمان Credit (Assets) Quality } \\
\hline مخصص خسائر القروض/ إجمالى القروض & LLP نسبة مخصص خسائر القروض LLP & 1 \\
\hline إجمالى القروض المتعثرة (غير العاملة)/ إجمالى القروض & NPL نسبة القروض المتعثرة & r \\
\hline مخصص خسائر القروض/ إجمالى القروض المتعثرة & نمبة تغطية القروض المتعثرة Coverage & $r$ \\
\hline صافى القروض/ إجمالى الأصول & 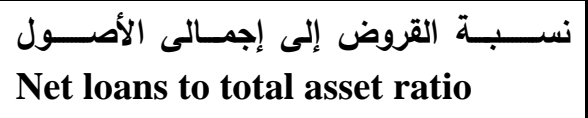 & $\varepsilon$ \\
\hline \multicolumn{3}{|c|}{ • مؤشرات المخاطر المالية Financial Risk } \\
\hline إجمالى حقوق الملكية/ صافى القروض & 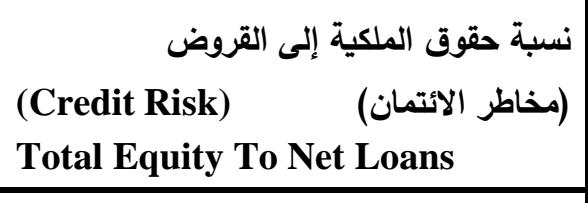 & 1 \\
\hline (قروض البنك - ودائع العملاء)/ إجمالى الأصول & $\begin{array}{l}\text { الفجوة التمويلية (لقياس مخاطر السيولة) } \\
\text { Financing Gap (FGAP) } \\
\end{array}$ & r \\
\hline إجمالى الاستثمارات/ إجمالى الأصول & St مخاطر الاستثمارات Securities Risk & $r$ \\
\hline الأصول المرجحة بالمخاطر / إجمالى الأصول & $\begin{array}{l}\text { مخاطر الأصول المصرفية } \\
\text { Risk of Bank Assets }\end{array}$ & $\varepsilon$ \\
\hline
\end{tabular}




\begin{tabular}{|c|c|c|}
\hline \multicolumn{3}{|c|}{ • مؤشرات الملاءة المالية (المصرفية) Solvency } \\
\hline 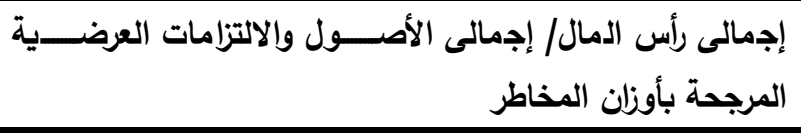 & معيار كفاية رأس المال (CAR) & 1 \\
\hline والأس التمال الأســاســـى (الثـــريحة الأولىى)/ إجمالى الأصـــول & $\begin{array}{c}\text { نســــــة الثـــريحـة الأولى من رأس المـال } \\
\text { (Tier1) }\end{array}$ & r \\
\hline الثيزانية الثريحة الأولى من رأس المال/ إجمالى التعرضـات داخل وخارج & Leverage Ratio & $r$ \\
\hline \multicolumn{3}{|c|}{ • مقاييس الأداء المعتمدة على السوق Market-based measures of performance } \\
\hline القيمة السوقيه لحقوق الملكية/ القيمة الدفترية لحقوق الملكية & \begin{tabular}{|r|} 
نسبة القيمة السوقية إلى القيمة الدفترية \\
The price-to-book ratio (MVBV)
\end{tabular} & 1 \\
\hline ســر السـهم فى نهاية الفترة المالية (سـعر الاغلاق) / ربحية & $\begin{array}{c}\text { نسبة سعر السهر إلى ربحية السهر } \\
\text { Price - Earnings Ratio (P/E) }\end{array}$ & $r$ \\
\hline \multicolumn{3}{|c|}{ ثالثاً: المتغيرات الضابطة } \\
\hline اللوغاريتم الطبيعى لإجمالى الأصول فى نهاية الفترة المالية & حجم البنك Bank Size & 1 \\
\hline 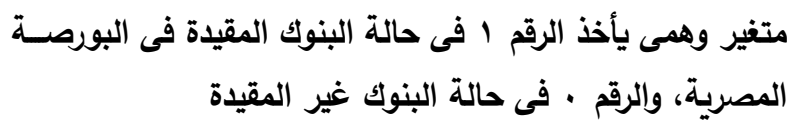 & Stock Market التداول فى البورصة & r \\
\hline
\end{tabular}

المصدر: إعداد الباحثون اعتماداً على الدراسات السابقة ذات الصلة

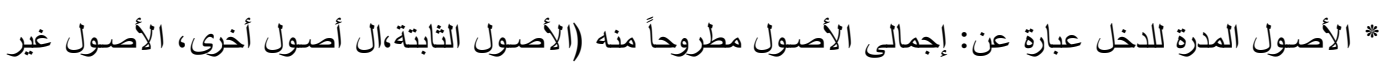
الملموسة، والأصول الضريبية المؤجلة). * الأصول السائلة تتمثل فى: نقدية وأرصدة لدى البنك المركزى، أرصدة لاى البنوك الأخرى، وأذون الخزانة.

$$
\text { ب/ / إع الفروض البحثية }
$$

الفرض الأول: "لا توجد فروق ذات دلالة إحصــائية لمؤشـرات الســلامة المالية للبنوك العاملة فى كي

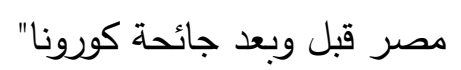

الفرض الثانى: "لا توجد علاقة ذات دلالة إحصـائية بين جائحة كورونا ومؤشـرات السـلامة المالية للبنوك العاملة فى مصر" الفرض الثالث: "لا توجد فروق ذات دلالة إحصــــائية بين البنوك المقيدة والبنوك غير المقيدة فى البورصة المصرية، تتعلق بمؤشرات السلامة المالية أثناء جائحة كورونا".

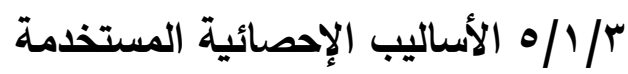

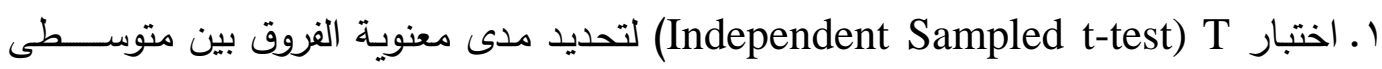

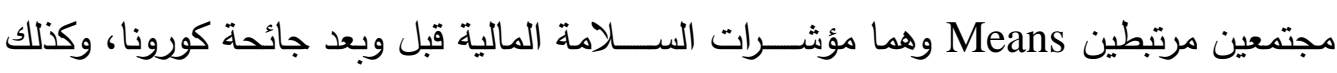
الفروق بين البنوك المقيدة والغير مقيدة فى البورصة المصرية.

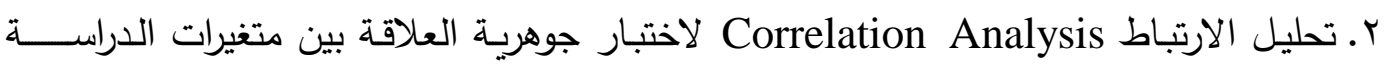

$$
\text { باستخدام معامل الارتباط (بيرسون). }
$$




\section{r/r اختبر الفروض الإحصائية واستخلاص النتائج}

يتناول هذا الجزء مناقثـــة نتائج التحليل الإحصــائى بما فى ذلك الخصائل الخصـائص الإحصــائية

الوصفية لمتغيرات البحث، ثم اختبار وتحليل فروض البحث وذلك على النحو التالى:

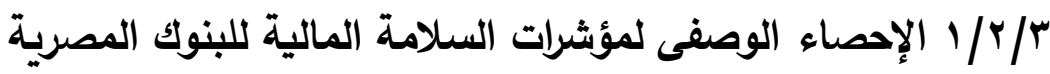

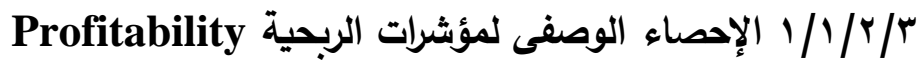

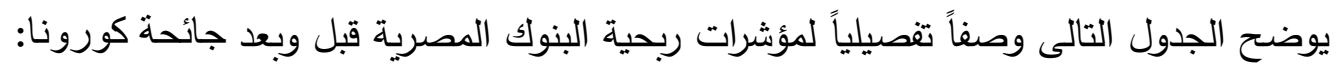

جدول رقم (؛/ آ): وصف إحصائى لمؤشرات الربحية

\begin{tabular}{|c|c|c|c|c|c|c|c|c|}
\hline \multicolumn{2}{|c|}{ NIM } & \multicolumn{2}{|c|}{ EPS } & \multicolumn{2}{|c|}{ ROE } & \multicolumn{2}{|c|}{ ROA } & \multirow[b]{2}{*}{ البيان } \\
\hline الجائحة & قائبل & الجائحة & قائبل & الجائحة & قائحة & الجائحة & قائحة & \\
\hline 11 & 11 & 11 & 11 & 11 & 11 & 11 & 11 & العينة (عدد البنوك) \\
\hline $0 \leqslant$ & $0 \leqslant$ & 01 & 01 & $0 \leqslant$ & $0 \leqslant$ & $0 \varepsilon$ & $0 \leqslant$ & عدد المشاهدات \\
\hline $1,1 \mu v$ & $1,1 \cdot 1$ & $r, 19 V$ & $r, q \leq r$ & $v, 19 v$ & $q, Y \vee$. & $\cdot, v \cdot r$ & $\cdot, \wedge \cdot \varepsilon$ & الوسط \\
\hline 1,100 & $1,1 \leq$ & $\cdot, 97$. & $1, \leqslant 7$. & $v, \cdot \wedge$. & $৭, \wedge \ldots$ & $\cdot, v \ldots$ & $\cdot, \vee \vee Y O$ & الوسيط \\
\hline$\cdot, Y \vee T$ & 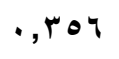 & $\varepsilon, 1 Y q$ & $7,1 Y \wedge$ & $r, O r V$ & L & מדו, י & $\cdot, \mu \Delta \wedge$ & الانحراف المعيارى \\
\hline ס ז, • & • , r & $\cdot, .9-$ & $\cdot, 17$ & .91 & $r, r$. & $\cdot, 1 \leqslant$ & $\cdot, r \leqslant$ & الحد الأدنى \\
\hline 1,79 & 1,7 & 19,rr & $r q, q \leq$ & $|v, \varepsilon|$ & $M r, \wedge r$ & $1, \leqslant \wedge$ & 1,70 & الحد الأقصى \\
\hline
\end{tabular}

المصدر: اعداد الباحثون اعتماداً على نتائج التحليل الإحصائى

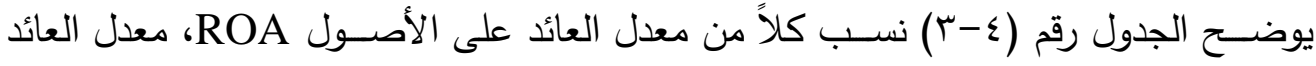

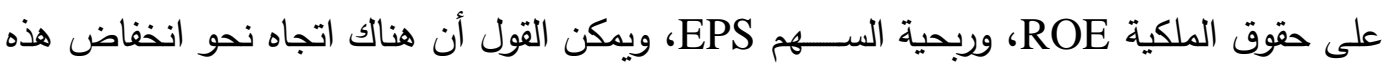

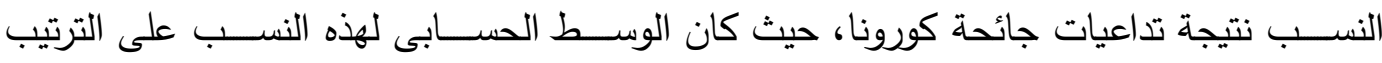

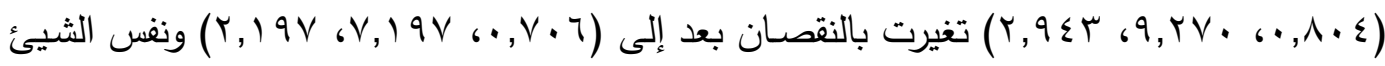

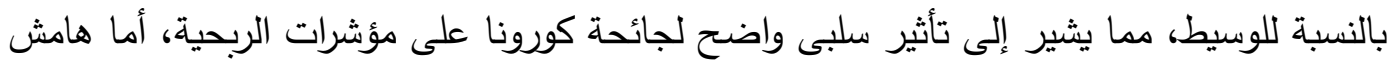

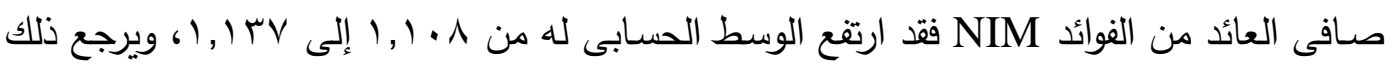
بصفة أساسية لانخفاض تكلفة الودائع نتيجة التأثر بتداعيات الجائحة.

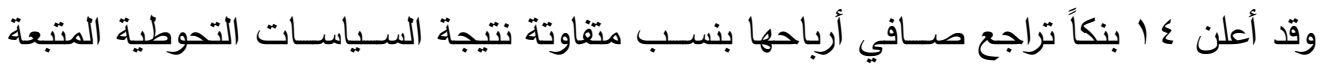

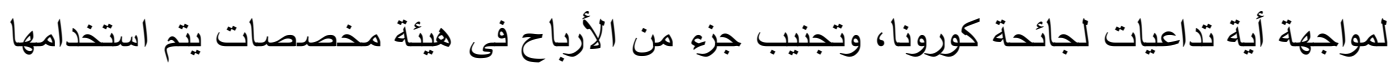

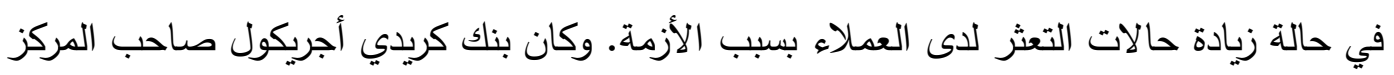

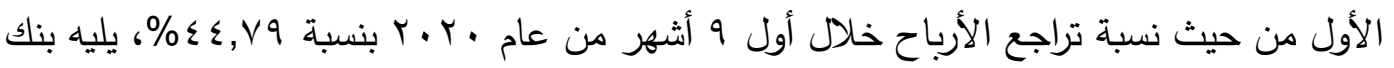

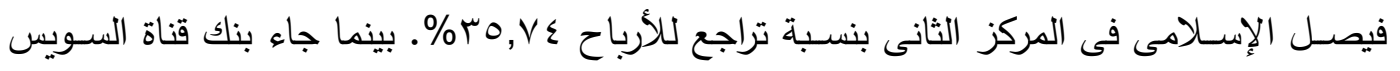

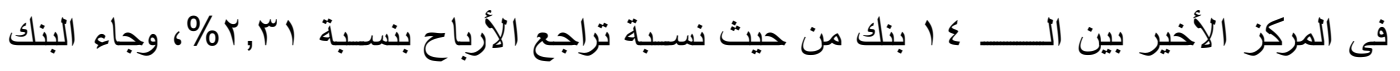

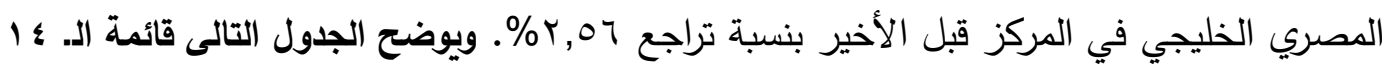

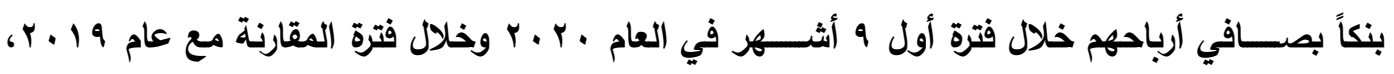
ونسب التراجع في صافي الأرباح بحسب قوائمها المالية: 


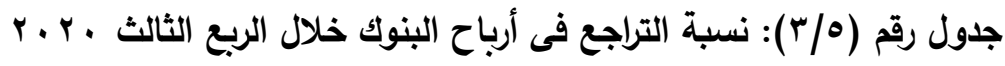

(الأرقام بالجنيه (المصرى)

\begin{tabular}{|c|c|c|c|c|}
\hline الربع الثالث 9 ب r r & 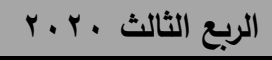 & نسبة التراجع & اسم البنك & الترتيب \\
\hline $1, \wedge q \vee, q r \vee, \ldots$ & $1,, r 1, r \wedge \varepsilon, \ldots$ & $\% \leq \varepsilon, \vee q$ & كريدى أجريكول & 1 \\
\hline$r, . \diamond q, r \vee 1, \ldots$ & $1, r r r, r \otimes r, \ldots$ & $\%$ \% , V $\leq$ & فيصل الإسلامى المصرى & r \\
\hline $1, \neg q \tau, r \mu r, \ldots$ & $1,99 \vee, \varepsilon \wedge \wedge, \ldots$ & $\% r \varepsilon, 1 r$ & الكويت الوطنى & $r$ \\
\hline $1, r q 1, v i r, \ldots$ & $q \leq 0, r \leq \wedge, \cdots$ & $\% r \cdot, \Delta \wedge$ & الإمارات دبى الوطنى & $\varepsilon$ \\
\hline$r, \varepsilon \leq r, q, \varepsilon, \cdots$ & $r, \cdot 10,0 r 0, \ldots$ & $\% \backslash \vee, \varepsilon \wedge$ & الأسكندرية & $\bullet$ \\
\hline$v \varepsilon \neg, \varepsilon 01, r v V$ & $q r,, 09 \cdot, v r r$ & $\% \backslash \bullet, 0 r$ & بلوم مصر & 7 \\
\hline$\Lambda, 0 \leqslant 1, \mid r r, \ldots$ & $v, r q \Delta, \Delta q v, \ldots$ & $\% \mid r, \varepsilon 1$ & التجارى الدولى & v \\
\hline$r, \wedge \vee q, r r \vee, \ldots$ & $r, \diamond r r, q \diamond q, \ldots$ & $\% \backslash r, r \wedge$ & 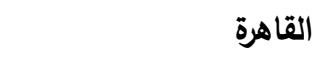 & $\Lambda$ \\
\hline $7, Y \cdot 0,91 \wedge, \leq 97$ & $0, O \vee r, Y r \leq, q \vee q$ & $\% 1 \cdot, Y_{1}$ & قطر الأهلى الوطنى & 9 \\
\hline$\wedge \vee 1, \vee \wedge r, \ldots$ & $\wedge 10,99, \ldots$ & $\% 7, \varepsilon$. & أبو ظبى الإسـلامى & 1. \\
\hline $1,0 r \cdot, 0 r r, r \cdot \varepsilon$ & $1, \varepsilon r \varepsilon, \wedge \bullet \diamond, V \otimes V$ & $\% ч, r q$ & التعمير والإسكان & 11 \\
\hline$r \wedge r, q \backslash \wedge, \varepsilon r r$ & $r q q, \cdot q r, r r q$ & $\% 0, r r$ & أبو ظبى التجارى & Ir \\
\hline$\leqslant \vee \wedge, \leqslant \varepsilon \cdot, \leq \leqslant \wedge$ & $\varepsilon \neg 7,1 \vee 0, \ldots \varepsilon$ & $\% r, 07$ & المصرى الخليجى & Ir \\
\hline$r q \leq, 1, \ldots$ & $\mu \diamond \diamond, q \wedge \wedge, \cdots$ & $\% r, r_{l}$ & قناة السويس & $1 \leq$ \\
\hline
\end{tabular}

المصدر: اعداد الباحثون إعتماداً على التقارير السنوية للبنوك

ويرجع الباحثون تراجع الربحية تأثراً بالأزمة الراهنة نتيجة قرار البنك المركزي بخفض البه الفائدة

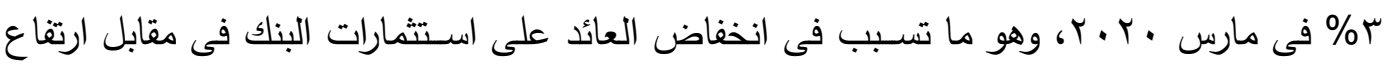
تكلفة العائد على المدخرات، كما كان لقرار إلغاء العمولات على التحويلات، وماكينات الصــــراف الآلى، والبطاقات الائتمانية حتى نهاية العام، تأثير واضتح على ربحية البنوك.

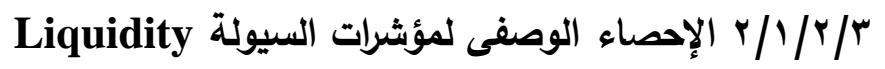

يوضح الجدول التالى وصفاً تفصيلياً لمؤشرات السيولة للبنوك المصرية قبل وبعد جائحة كورونا:

جدول رقم (؟/ץ): وصف إحصائى لمؤشرات السيولة

\begin{tabular}{|c|c|c|c|c|c|c|}
\hline \multicolumn{2}{|c|}{$\overline{\text { DTA }}$} & \multicolumn{2}{|c|}{ LTD } & \multicolumn{2}{|c|}{$\mathrm{LIQ}$} & \multirow{2}{*}{ البيان } \\
\hline بعد الجائحة & قبل الجائحة & بعد الجائحة & قبل الجائحة & بعد الجائحة & قبل الجائحة & \\
\hline 11 & 11 & 11 & 11 & 11 & 11 & العينة (عدد البنوت) \\
\hline 0 & $0\}$ & 0 & $0 \leq$ & $0 \leq$ & $0 \leqslant$ & عدد المشاهدات \\
\hline$\wedge 1, \wedge \vee 0$ & $\Lambda r, V \cdot r$ & $\varepsilon q, 1$ Y० & $\varepsilon 0,9 \vee r$ & $r \wedge, q r_{l}$ & rv,rqr & الوسط \\
\hline$\Lambda r, r \leq 0$ & $\Lambda r, q \vee$. & $\varepsilon 9,7 \ldots$ & $\varepsilon 7,1 \vee$. & $r \cdot, r \wedge$. & $r q, r .0$ & الوسبط \\
\hline$\varepsilon, 9 \cdot 1$ & $0,1 \wedge \wedge$ & $17, \wedge \vee \wedge$ & سr., & $\mid r, q r \wedge$ & I Y, TrV & الانحراف المعيارى \\
\hline צヘ, & $V \cdot, r q$ & $1 \cdot, \cdot 1$ & $11,0 \mathrm{~V}$ & $\Lambda, r v$ & $|r| r$, & الحد الأدنى \\
\hline 19,10 & $\wedge q, \wedge r$ & V1,97 & $V I, Y q$ & $01, \wedge r$ & $7, \ldots$ & الدد الأقصى \\
\hline
\end{tabular}

المصدر: اعداد الباحثون اعتماداً على نتائج التحليل الإحصائى 
يتضـح من الجدول رقم (T/T) أن البنوك المصرية دخلت هذه الأزمة فى وضـع جيد نسبياً بعد

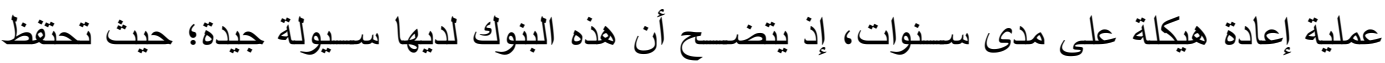

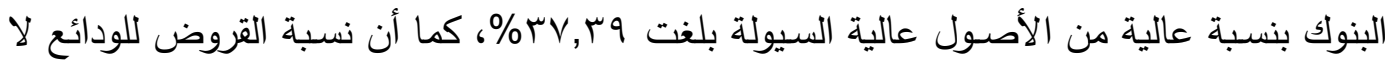

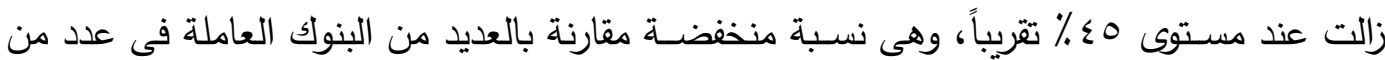

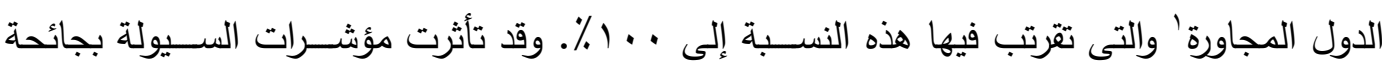

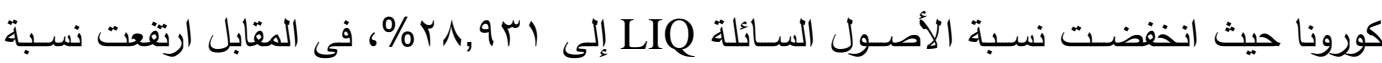

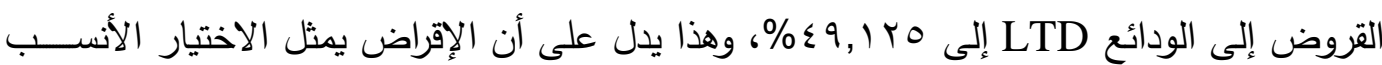
لتوظيف حجم الودائع خلال تداعيات هذه الأزمة.

Credit (Assets) Quality الإحصاء الوصفى لمؤشرات جودة الائتمان / T/T/T يوضح الجدول التالى وصفاً تفيلياً لمؤشرات جودة الائتمان قبل وبعد جائحة كورونا: جدول رقم (r/V): وصف إحصائى لمؤشرات جودة الائتمان

\begin{tabular}{|c|c|c|c|c|c|c|c|c|}
\hline \multicolumn{2}{|c|}{ LtA } & \multicolumn{2}{|c|}{$\mathrm{COV}$} & \multicolumn{2}{|c|}{ NPL } & \multicolumn{2}{|c|}{ LLP } & \multirow[b]{2}{*}{ البيان } \\
\hline بعائحة & قائحة & الجائحة & قبائحة & الجائحة & قبائحة & الجائحة & قائحة & \\
\hline 11 & 11 & 11 & 11 & 11 & 11 & 11 & 11 & العينة (عدد البنوك) \\
\hline $0 \leq$ & $0 \leq$ & $\varepsilon r$ & $\varepsilon \wedge$ & $\varepsilon \wedge$ & $\varepsilon \Lambda$ & 01 & $0 \leqslant$ & عدد المشاهدات \\
\hline$r q, \wedge l$ & $r v, v$. & Ir & 1 ro,. & $\varepsilon, \vee \vee r$ & $0, \vee 7 \wedge$ & $0, q \vee r$ & $7, r \circ 1$ & الوسط \\
\hline$\varepsilon \cdot, \cdot 0$ & $r v, r \leq$ & Ir.,r & $11 \mathrm{~V}$ & $r, q \vee$. & $\varepsilon, \wedge$ & $\leq, 9 \leq$. & $0, \leqslant \wedge 0$ & الوسيط \\
\hline $1 Y, q r$ & $11, v \varepsilon$ & $\varepsilon r, \cdot \varepsilon$ & $07,9 r$ & $Y, 99 \wedge$ & $\varepsilon, 771$ & $r, \cdot v q$ & $r,\{01$ & الانحراف المعيارى \\
\hline$\Lambda, \varepsilon \wedge$ & $q, V r$ & $\Delta r, r \leq$ & $V_{r}, \cdot q$ & $1,0 r$ & $\cdot, \wedge 9$ & $1,9 r$ & 1,9 . & الحد الأدنى \\
\hline $9 \cdot, 9 r$ & $09, .9$ & $r \circ v, 1$ & ו, & IV,r. & $r 1, \varepsilon r$ & $1 \leqslant, V V$ & $1 v, 0$ & الحد الأقصى \\
\hline
\end{tabular}

المصدر: اعداد الباحثون اعتماداً على نتائج التحليل الإحصائى

يوضـح الجدول السـابق التغيرات التى حدثت على مؤشـرات جودة الائتمان والمتمثلة فى نسبة مخصصات خسائر القروض LLP، نسبة القروض المتعثرة NPL، ونسبة تغطية القروض المتعثرة COV

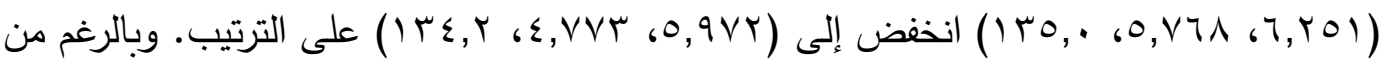
النتيجة السـابقة فقد عززت البنوك العاملة بالقطاع المصـرفى المصـرى مخصـصــاتها خلال الربع

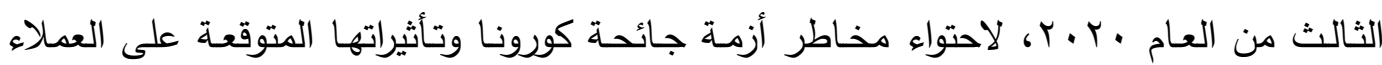

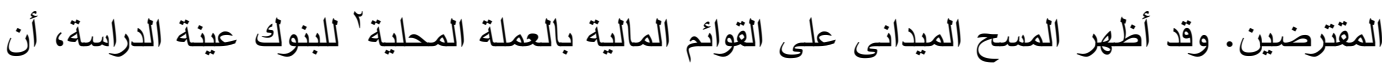
نحو با منها رفعت مخصصات خسائر الائتمان المتوقعة بنسبة تتراوح بين ا (

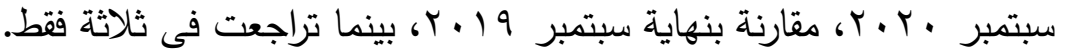

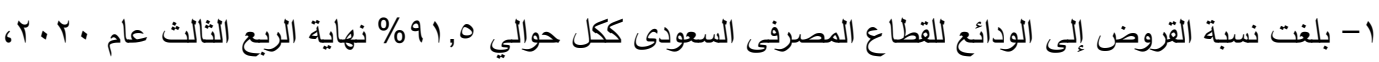

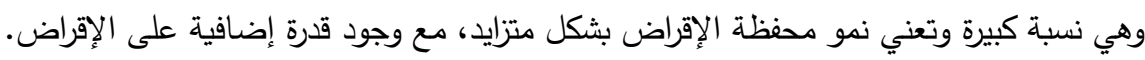
r- التقارير المالية لبنكى الشركة المصرفة العربية الدولية، والعربى الأفريقى الدولى بالدولار الأمريكى. 
ويوضح الجدول التالى تطور مخصصات الخسائر الائتمانية المتوقعة للبنوك عينة الدراسة: جدول رقم (^/^): تطور مخصصات الخسائر الائتمانية المتوقعة

(الأرقام بالجنيه المصرى)

\begin{tabular}{|c|c|c|c|c|}
\hline الربع الثالث 9 ا م r & 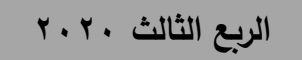 & معدل الزيادة & اسم البنك & الترتيب \\
\hline $1, \cdot \vee r, q \mid r, \Lambda \ldots$ & $1, \leq 97,9 \cdot \varepsilon \cdot, 791$ & $\% r q, o r$ & المصرى الخليجى & 1 \\
\hline$\varepsilon, \leqslant \vee \backslash, \varepsilon \backslash \wedge, \ldots$ & $\neg, 1>q, 7 r q, \ldots$ & $\% r v, \cdot \Lambda$ & القاهرة & r \\
\hline$\leq \vee q, \vee \leq r, \leq \wedge \neg$ & $\neg \bullet \leq, 7 \wedge \neg, \Gamma \leq \varepsilon$ & $\% r q, \leq V$ & الأهلى الكويتى & $r$ \\
\hline$q \leq r, r, r, \ldots$ & $1, r \vee \cdot, \varepsilon \varepsilon \Lambda, \ldots$ & $\% r \varepsilon, \wedge r$ & كريدى أجريكول & $\varepsilon$ \\
\hline$\wedge \bullet r, q 0 \leq, \ldots$ & $1,1 \% \bullet, \wedge \pi 1, \ldots$ & $\% r r,+1$ & الإمارات دبى الوطنى & $\bullet$ \\
\hline $001 \wedge \vee \wedge \cdot \Lambda_{0}$ & $v 1 \cdot r \wedge \leq q 0 \leq$ & $\% r \wedge, \vee r$ & بلوم مصر & 7 \\
\hline $1, \wedge \leqslant v, \varepsilon r v, \ldots$ & $r, r, q, \wedge \neg r, \ldots$ & $\%$ ro, r r & أبو ظبى الإسـلاهى & v \\
\hline$|r, r| \cdot, q \cdot \theta, \ldots$ & $10, r \wedge q, .90, \ldots$ & $\%$ ro, . & التجارى الاولى & $\wedge$ \\
\hline$V, \cdot 1 \leq, V^{\prime},, \varepsilon \leq 1$ & $\wedge, \neg \leq r, \vee q \leq, q \vee q$ & $\% r r, r r$ & قطر الأهلى الوطنى & 9 \\
\hline $1, \wedge \nvdash \varepsilon, \Delta \neg \wedge, \neg r$. & $r, .7 \varepsilon, 9 r 1,007$ & $\%$ Ir, IV & ا التعمير والإسكان & 1. \\
\hline $1, \varepsilon r \wedge, \mid \vee \bullet, \vee \cdot q$ & $1,0 V 1, q q r, r q r$ & $\% q, \nvdash \wedge$ & البركة مصر & 11 \\
\hline$\vee r_{1,1 \wedge}, \ldots$ & $v q,, 7 \leq 1, \ldots$ & $\% \wedge, 1 \Gamma$ & الكويت الوطنى & Ir \\
\hline$r, \wedge \vee \varepsilon, r r ., \ldots$ & $r, \wedge q \leq, r \vee v, \ldots$ & $\% \cdot, V$ & قناة السويس & ir \\
\hline$r, \neg, q, 7 \vee \leq, \ldots$ & $r, r q 0, r \circ q, \ldots$ & $(\% \backslash 1,9 \mu)$ & | الأسكندرية & $1 \leq$ \\
\hline$q q r, . \leq 1, r p q$ & VYq,q.r,rir & $(\% r \varepsilon, O r)$ & أبو ظبى التجارى & 10 \\
\hline$q r \wedge, q r v, \ldots$ & $\diamond \wedge 1, \varepsilon r q, \ldots$ & $(\% r v, \varepsilon 1)$ & فيصل الإسلامى المصرى & 17 \\
\hline
\end{tabular}

المصدر: اعداد الباحثون إعتماداً على التقارير السنوية للبنوك

وكما يتضـح من الجدول السـابق، فقد رفع البنك التجارى الدولى مخصـصـات خسـائر الائتمان

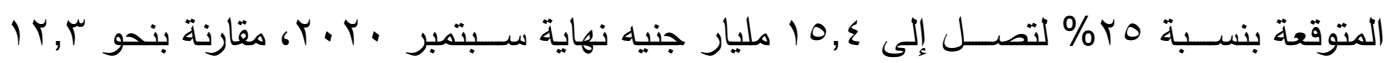

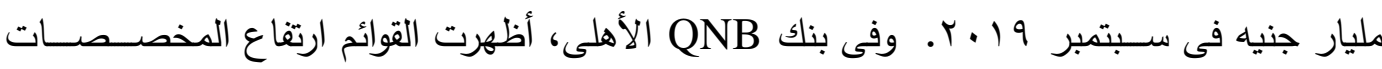

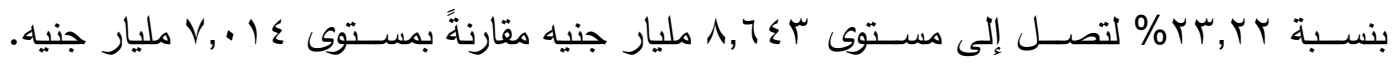

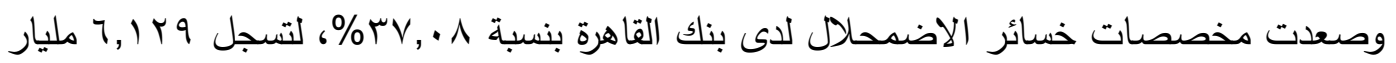

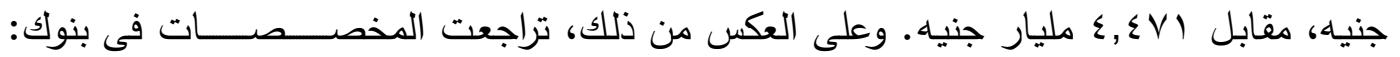

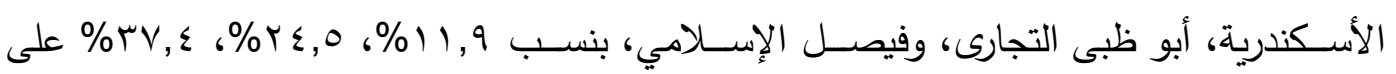

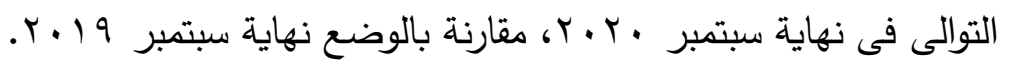

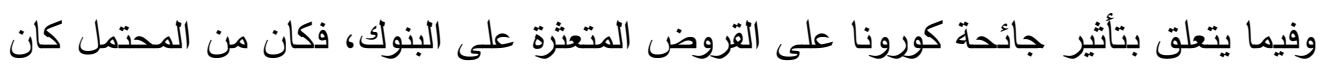

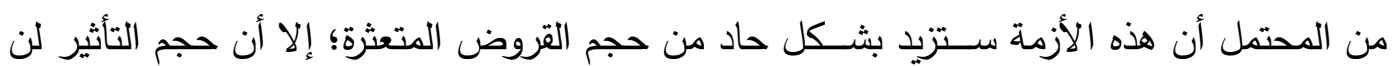

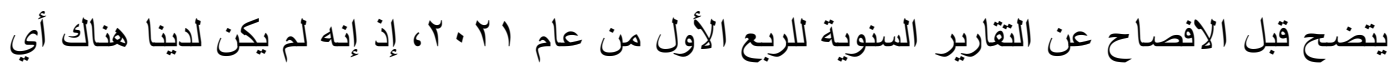

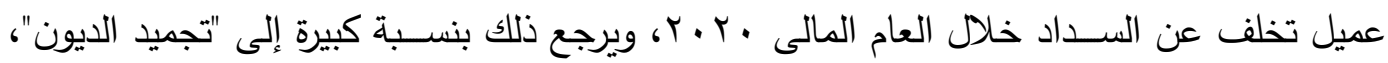
نتيجة القرار الذي اتخذه البنك المركزي المصـرى فى مارس • r. . r، بتأجيل سـداد القروض للأفراد والثركات لمدة ستة أشهر • 


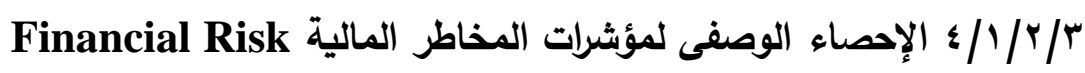

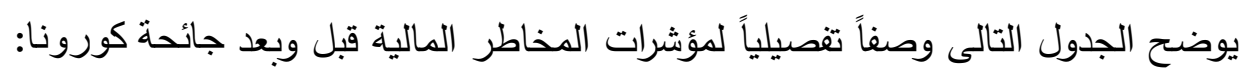

جدول رقم (9/\%): وصف إحصائى لمؤشرات المخاطر المالية

\begin{tabular}{|c|c|c|c|c|c|c|c|c|}
\hline \multicolumn{2}{|c|}{ Assets } & \multicolumn{2}{|c|}{ Securities } & \multicolumn{2}{|c|}{ FGAP } & \multicolumn{2}{|c|}{ Credit } & \multirow[b]{2}{*}{ البيان } \\
\hline الجائحة & قائبل & الجائحة & قائبل & الجائحة & قائحل & الجائحة & قائبل & \\
\hline 11 & 11 & 11 & 11 & 11 & 11 & 11 & 11 & العينة (عدد البنوك) \\
\hline$\varepsilon \varepsilon$ & o. & \& & 0 & 0 & \& & \& & \& & عدد المشاهدات \\
\hline ه & 07,71 & $r V, I V$ & $r 1,11$ & $\leq r, 1-$ & $\leq 0, \cdot-$ & $r, T V$ & $r 9,19$ & الوسط \\
\hline$\Delta \curlyvee, \wedge \vee$ & $0 \leqslant, \leqslant 0$ & $Y Q, Y T$ & 19,9 . & $r q, q-$ & $\{0,0-$ & YY, qT & YI, r & الوسيط \\
\hline$|r, r|$ & $11, \leqslant Y$ & $1 \leqslant, 0 \mathrm{~V}$ & 11,19 & $10, \mu \varepsilon$ & $1 r, \wedge 0$ & $r \wedge, \cdot v$ & $r \leqslant, 00$ & الانحراف المعيارى \\
\hline$m q, r)$ & $r \leqslant, q v$ & $\varepsilon, \Lambda$. & $\varepsilon, \infty$ & $V q, Y-$ & $V \leqslant, r-$ & $11, r r$ & 11,17 & الحد الأدنى \\
\hline$\wedge \vee, \varepsilon Y$ & $\vee q, Y q$ & $70, \cdot 1$ & $\Delta r, q V$ & $r \cdot, r-$ & $r_{1, q-}$ & $1 \leq 4$, & $1 Y \leq, q$ & الحد الأقصى \\
\hline
\end{tabular}

المصدر: اعداد الباحثون اعتماداً على نتائج التحليل الإحصائى

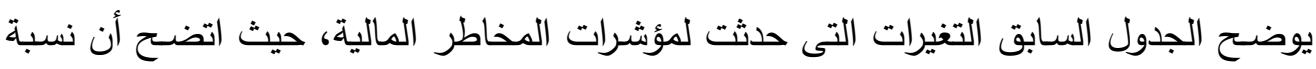

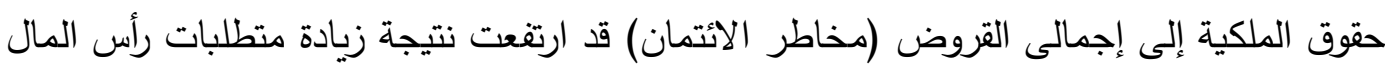

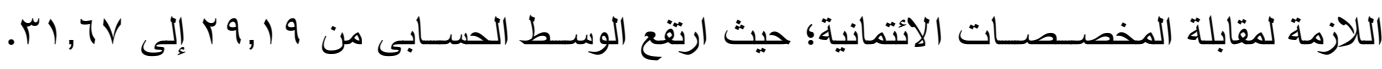

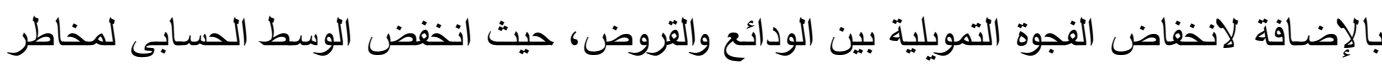

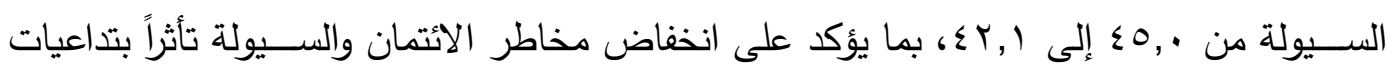

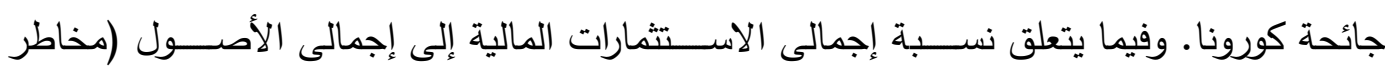

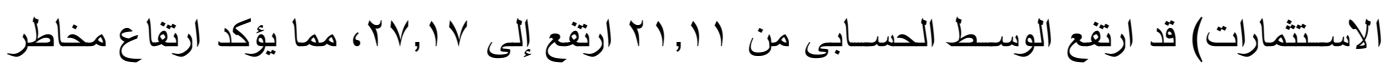

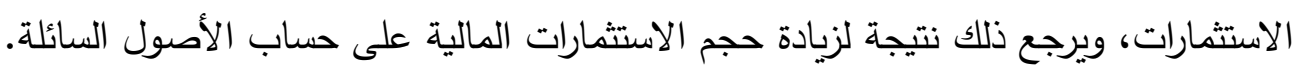

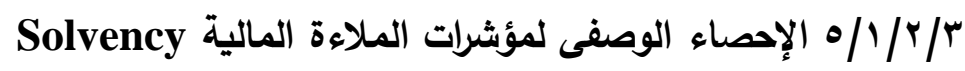

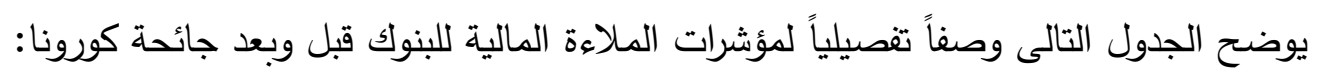

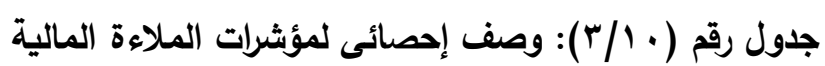

\begin{tabular}{|c|c|c|c|c|c|c|}
\hline \multicolumn{2}{|c|}{ Leverage } & \multicolumn{2}{|c|}{ Tier1 } & \multicolumn{2}{|c|}{ CAR } & \multirow{2}{*}{ البيان } \\
\hline بعد الجائحة & قبل الجائحة & بعد الجائحة & قبل الجائحة & بعد الجائحة & قبل الجائحة & \\
\hline 11 & 11 & 11 & 11 & 11 & 11 & العينة (عدد البنوك) \\
\hline$\leqslant \varepsilon$ & $\leqslant V$ & or & 0. & or & 0. & عدد المشاهدات \\
\hline$\wedge, \wedge \bullet$ & $\vee, \wedge 0$ & $r \varepsilon, 1 r$ & $10, \varepsilon$. & $Y \square, \vee \backslash$ & $I V, V V$ & الوسط \\
\hline $9,0$. & $\Lambda, \cdot r$ & $r q, r^{\prime}$ & $10, r$. & rq,or & $1 V, 07$ & الوسبط \\
\hline 1,817 & $r, Y \wedge \varepsilon$ & $\bullet, \vee \wedge$. & $\varepsilon, r \cdot q$ & $0, \vee \vee 0$ & $r, 0 \leq$. & الانحراف المعيارى \\
\hline$\varepsilon, \wedge 0$ & $\leq, \leq 9$ & $9, \leqslant \wedge$ & $\wedge,+1$ & $I r, \wedge V$ & Ir,or & الدـ الأدنى \\
\hline $11,9 \leq$ & $I r, Y V$ & $r \wedge, q r$ & $r q, Y r$ & $r_{1, .1}$ & $r \cdot, 00$ & الحد الأقصى \\
\hline
\end{tabular}

المصدر: اعداد الباحثون اعتماداً على نتائج التحليل الإحصائى 
يوضـــح الجدول الســـابق رقم ( • ب/ التغيرات التى حدثت على مؤشـــرات الملاءة المالية والمتمثلة فى نسـبة كفاية رأس المال CAR، نسـبة الثـريحة الأولى Tier1، ونسـبة الرافعة المالية Leverage كانت عليه فترة ما قبل الجائحة، حيث كان الوسـط الحسـابى لهذه النسـب على الترتيب ( ) V,VV) • ـ المصرية التحوط من المخاطر المحتملة لخسائر الأيتمان، ما دفعها خلال العام الماضى إلى تعزيز المخصـصـات بثـكل ملحوظ. هذا ويوضـح مؤشـر كفاية رأس المال مدى امتلاك البنك لرأس مال كاف للتحوط ضد المخاطر .

ويرى الباحثون أنه بالرغم من الأثر السـلبى لزيادة المخصـصــات على الأرباح، إلا أنها تعد

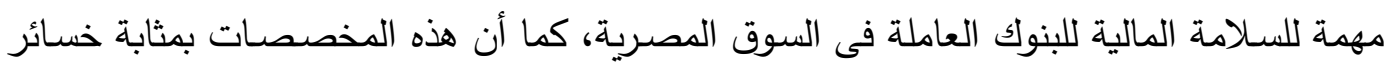
مؤقتة سـُُرَّل فيما بعد إلى أرباح أو لتدعيم المركز المالى للبنك نفسـه. وفى الوقت الراهن ليس من

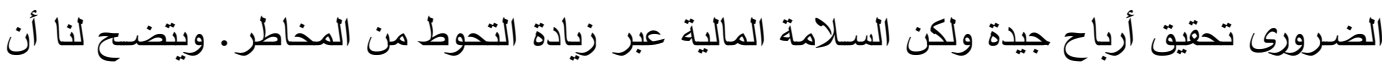

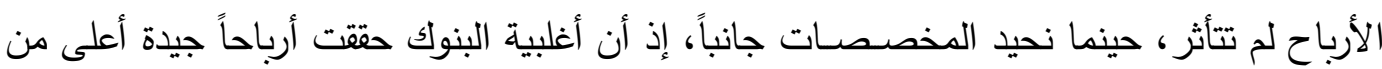
معدلات العام الماضى، لكن نتيجة الاحتياطيات والمخصصات انخفضت الأرباح.  يوضح الجدول التالى وصفاً تفصيلياً لمقاييس الأداء المعتمدة على السوق قبل وبعد جائحة كورونا:

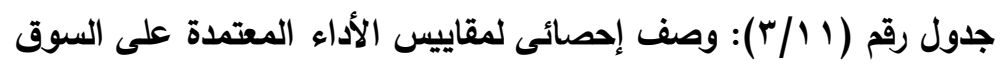

\begin{tabular}{|c|c|c|c|c|}
\hline \multicolumn{2}{|c|}{ PtE } & \multicolumn{2}{|c|}{ MVBV } & \multirow{2}{*}{ البيان } \\
\hline بعد الجائحة & قبل الجائحة & بعد الجائحة & قبل الجائحة & \\
\hline 11 & 11 & 11 & 11 & العينة (عدد البنوك) \\
\hline rV & rV & rr & rr & عدد المشاهدات \\
\hline $19, r \vee 4$ & סrr, & •, VTr & $1, .9$. & الوسط \\
\hline $10, r \wedge$. & $19,0 \ldots$ &., 07. & $\cdot, \wedge \ldots$ & الوسيط \\
\hline איד & ס & $\cdot, \leqslant \vee 0$ & $\cdot, v i r$ & الانحراف المعيارى \\
\hline $7, \leqslant 1$ & $7, Y Y$ & $\cdot, r r$ & • & الحد الأدنى \\
\hline$\leq \neg, Y Y$ & $\varepsilon r, q r$ & $1, \wedge 9$ & r,7q & الحد الأقصى \\
\hline
\end{tabular}

المصدر: اعداد الباحثون اعتماداً على نتائج التحليل الإحصائى

يوضـح الجدول السابق التغيرات التى حدثت على مقاييس الأداء المعتمدة على السوق والمتمثلة

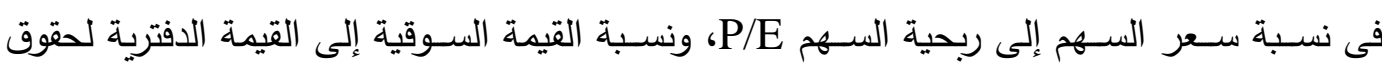
الملكية MVBV، حيث لاحظ الباحث أن هذه النسـب قد انخفضــت بعد جائحة كورونا عما كانت

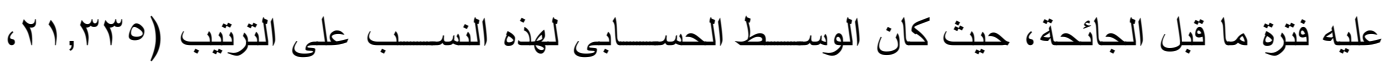

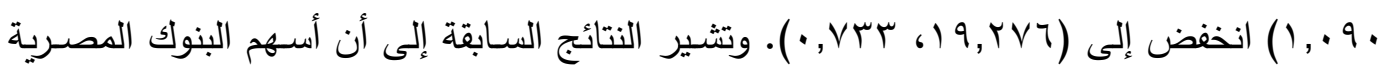

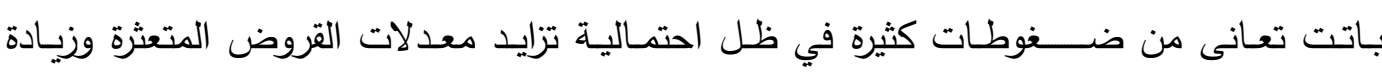
المخصصات لمجابهة تداعيات أزمة كورونا. 


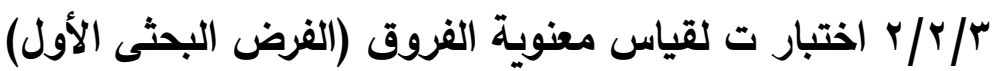

اتضح لنا من نتائج الإحصاء الوصفى، أن هناك بعض التغيرات والفروق فى مؤشرات السلامة

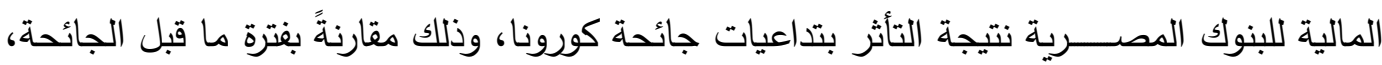
بعض هذه التغيرات كانت موجبة والبعض الأخر كانت تغيرات سـالبة. ولتحديد مدى معنوية الفروق تم الاعتمـاد على اختبار Independent Sampled t-test for Equality of Means) T لتحديد مدى معنويـة الفروق بين متوســــى مجتمعين مرتبطين Means، ثم يتم إجراء اختبار لتحديد مدى تثـتت هذه التغيرات عن وسـطها (Leven's Test for Quality of Vaiances) الحســابى. وفى ضـــوء هذه الاختبارات يقبل الباحث الفرض الخاص بوجود فروق جوهرية بين كلا الفترتين إذا ما كانت قيمة P.Value أقل من القيمة الحرجة ه ه., •. وقد تم إجراء هذه الاختبارات للحكم على صـلاحية الفرض الأول: "لا توجد فروق جوهرية ذات دلالة إحصائية لمؤشرات السـلامة المالية للبنوك المصرية قبل وبعد جائحة كورونا". Profitability معنوية الفروق فى مؤشرات الربحية ويعرض الجدول التالى نتائج اختبارى T T لقياس معنوية الفروق فى مؤشرات الربحية وتجانسها:

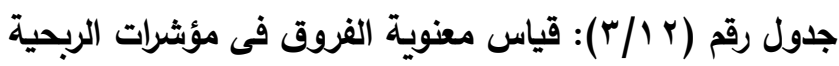

\begin{tabular}{|c|c|c|}
\hline $\begin{array}{c}\text { Leven's Test for Quality } \\
\text { of Vaiances }\end{array}$ & $\begin{array}{l}\text { Paired Sampled t-test for } \\
\text { Equality of Means }\end{array}$ & النسب المالية \\
\hline $\begin{array}{l}\text { F Statistic 8.698 } \\
\text { P- Value } 0.004\end{array}$ & $\begin{array}{l}\text { T Statistic 1.631 } \\
\text { P- Value 0.106 }\end{array}$ & معدل العائد على الأصول ROA \\
\hline $\begin{array}{c}\text { F Statistic } 4.429 \\
\text { P- Value } 0.038\end{array}$ & $\begin{array}{l}\text { T Statistic 3.012 } \\
\text { P-Value } 0.003\end{array}$ & $\begin{array}{l}\text { معدل العائد على حقوق الملكية } \\
\text { ROE }\end{array}$ \\
\hline $\begin{array}{c}\text { F Statistic } 0.859 \\
\text { P- Value } 0.356 \\
\end{array}$ & $\begin{array}{l}\text { T Statistic } 0.716 \\
\text { P-Value } 0.476 \\
\end{array}$ & ربحية السهر \\
\hline $\begin{array}{c}\text { F Statistic 3.508 } \\
\text { P- Value 0.064 } \\
\end{array}$ & $\begin{array}{c}\text { T Statistic }-0.486 \\
\text { P- Value } 0.641\end{array}$ & $\begin{array}{l}\text { هامش صـــــى العائد من الفوائد } \\
\text { NIM }\end{array}$ \\
\hline
\end{tabular}

المصدر: اعداد الباحثون اعتماداً على نتائج التحليل الإحصائى

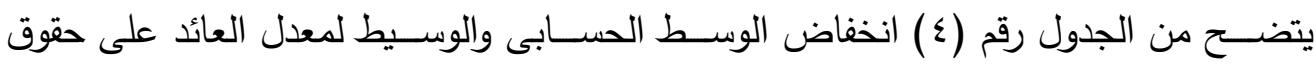

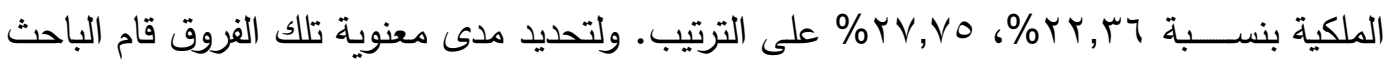

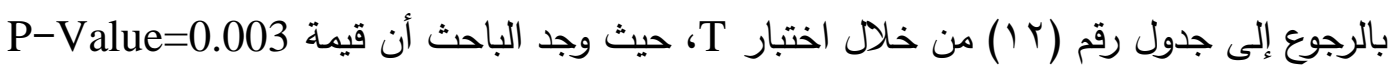
وهى أقل من 0\%، وبالرجوع إلى نتائج اختبار F لقياس مدى تجانس التغيرات، والذى أظهر أن

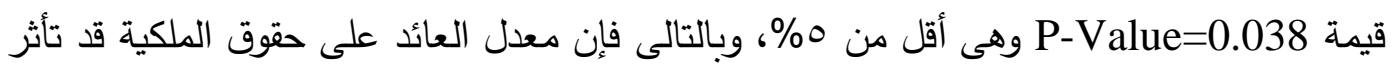

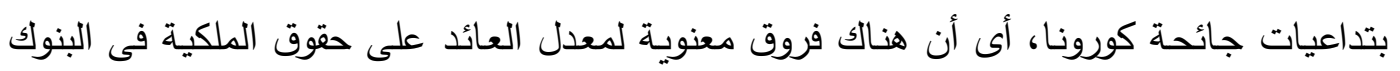
المصــرية قبل وبعد جائحة كورونا. كما اتضــــح من نتائج الجدول رقم (Y I ( عدم معنوية الفروق

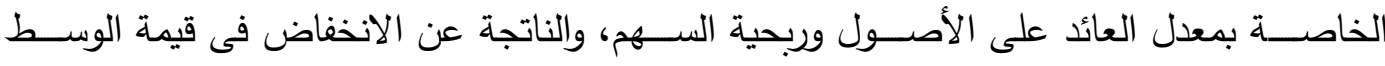

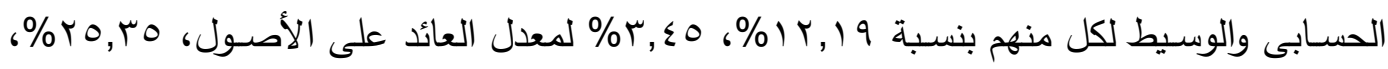

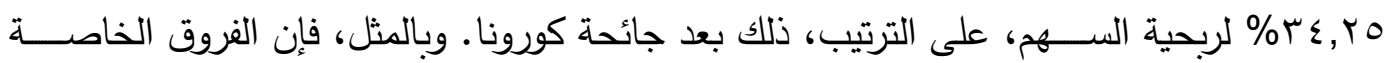
بهامش صافى العائد من الفوائد لم تثبت معنويتها. 
Liquidity r/r/r/T/ معنوية الفروق فى مؤشرات السيولة ويعرض الجدول التالى نتائج اختبارى T T لقياس معنوية القروق فى مؤشرات السيولة وتجانسها:

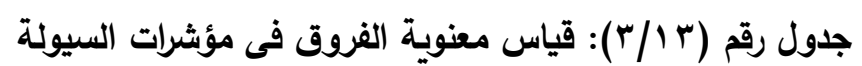

\begin{tabular}{|c|c|c|}
\hline $\begin{array}{c}\text { Leven's Test for Quality } \\
\text { of Vaiances }\end{array}$ & $\begin{array}{c}\text { Paired Sampled t-test for } \\
\text { Equality of Means }\end{array}$ & النسب المالية \\
\hline $\begin{array}{l}\text { F Statistic } 0.255 \\
\text { P- Value } 0.615\end{array}$ & $\begin{array}{l}\text { T Statistic } 3.441 \\
\text { P- Value } 0.001\end{array}$ & $\begin{array}{l}\text { الأصبول الأصول السائلة إلى إجمالى } \\
\text { L.Assets }\end{array}$ \\
\hline $\begin{array}{l}\text { F Statistic } 1.723 \\
\text { P- Value } 0.192\end{array}$ & $\begin{array}{c}\text { T Statistic }-\mathbf{1 . 0 2 5} \\
\text { P- Value } 0.308\end{array}$ & نسبة القروض إلى الودائع \\
\hline $\begin{array}{c}\text { F Statistic } 0.019 \\
\text { P- Value } 0.892\end{array}$ & $\begin{array}{l}\text { T Statistic } 0.850 \\
\text { P- Value } 0.397\end{array}$ & دائع إلى الأصول (DtA) \\
\hline
\end{tabular}

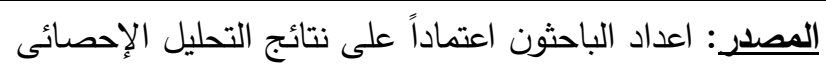

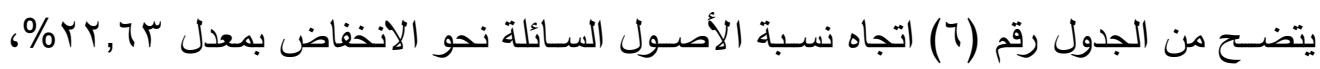
דr, 17\% لكل من الوسط الحسابى والوسيط على الترتيب، وبالنظر إلى قيمة P-Value لاختبار

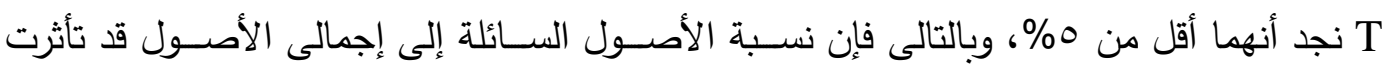

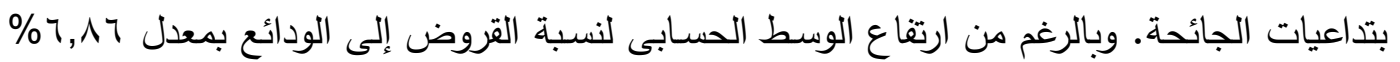
إلا أن هذه الفروق غير معنوية.

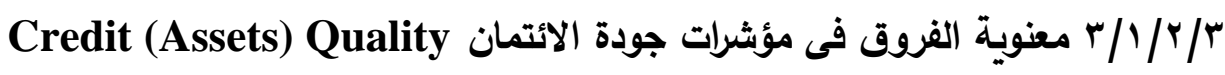

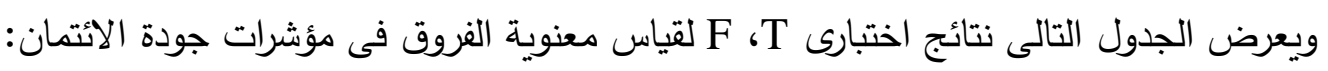
جدول رقم (ع //T): قياس معنوية الفروق فى مؤشرات جودة الائمان

\begin{tabular}{|c|c|c|}
\hline $\begin{array}{l}\text { Leven's Test for Quality } \\
\text { of Vaiances }\end{array}$ & $\begin{array}{l}\text { Paired Sampled t-test for } \\
\text { Equality of Means }\end{array}$ & النسب المالية \\
\hline $\begin{array}{c}\text { F Statistic } 0.591 \\
\text { P- Value } 0.444\end{array}$ & $\begin{array}{c}\text { T Statistic } 0.436 \\
\text { P- Value } 0.664\end{array}$ & $\begin{array}{l}\text { نسبة مخصس خسـائر القروض } \\
\text { LLP }\end{array}$ \\
\hline $\begin{array}{c}\text { F Statistic } 6.794 \\
\text { P- Value } 0.011\end{array}$ & $\begin{array}{l}\text { T Statistic } 1.244 \\
\text { P- Value } 0.217\end{array}$ & NPL المبة القروض المتشرة \\
\hline $\begin{array}{l}\text { F Statistic } 2.735 \\
\text { P- Value } 0.102\end{array}$ & $\begin{array}{l}\text { T Statistic } 0.080 \\
\text { P- Value } 0.936\end{array}$ & $\begin{array}{l}\text { نســـبة تغطية القروض المتعثرة } \\
\text { Coverage }\end{array}$ \\
\hline $\begin{array}{c}\text { F Statistic 1.694 } \\
\text { P- Value } 0.196\end{array}$ & $\begin{array}{c}\text { T Statistic } \mathbf{- 0 . 8 8 9} \\
\text { P- Value } 0.376\end{array}$ & الأصول \\
\hline
\end{tabular}

المصدر: اعداد الباحثون اعتماداً على نتائج التحليل الإحصائى

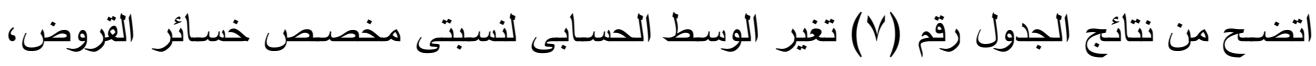

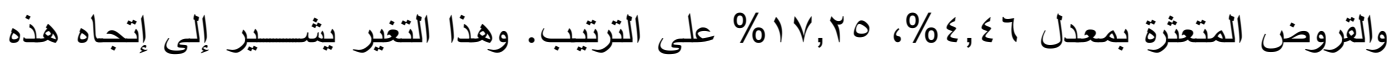

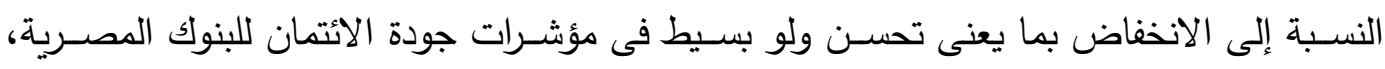

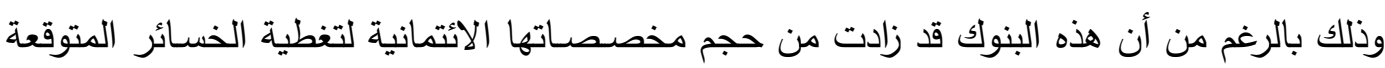

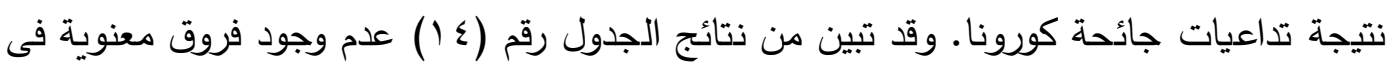
مؤشرات جودة الائتمان للبنوك المصرية قبل وبعد جائحة كورونا. 
ويمكن تفسير انخفاض نسبة مخصص خسائر القروض بالرغم من زيادة حجم المخصص إلى

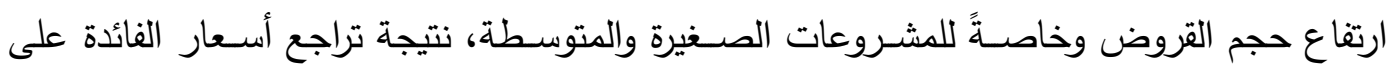

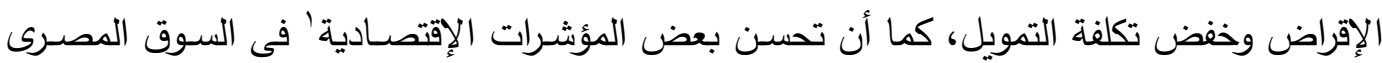
خلال عام ·. . . . قد منح انتعاشة قوية لقطاع الائتمان.

ويرجع التحسن الفورى فى مؤشرات جودة الائتمان بعد جائحة كورونا للأسباب التالية:

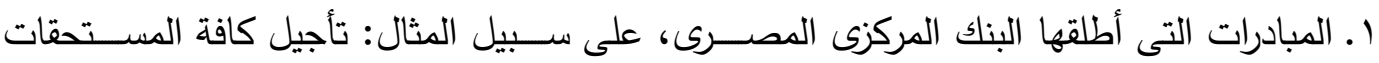

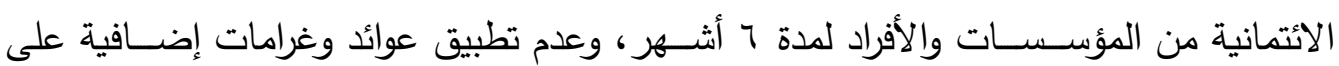

$$
\text { التأخر فى السداد. }
$$

r. انخفاض تكلفة الاقراض نتيجة تخفيض البنك المركزى المصـرى لأسـعار الفائدة على الإقراض

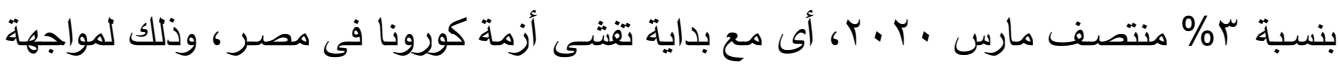

$$
\begin{aligned}
& \text { عمليات التعثر التى قد تطرأ نتيجة تداعيات كورونا. } \\
& \text { r. تحوط البنوك والثركات فى دراسة الائتمان. }
\end{aligned}
$$

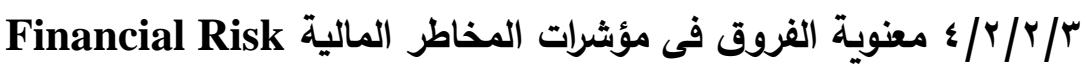

\begin{tabular}{|c|c|c|}
\hline $\begin{array}{c}\text { Leven's Test for Quality } \\
\text { of Vaiances }\end{array}$ & $\begin{array}{c}\text { Paired Sampled t-test for } \\
\text { Equality of Means }\end{array}$ & النسب المالية \\
\hline $\begin{array}{l}\text { F Statistic } 0.213 \\
\text { P- Value } 0.645\end{array}$ & $\begin{array}{c}\text { T Statistic }-0.488 \\
\text { P- Value } 0.626\end{array}$ & $\begin{array}{l}\text { نسبة حقوق الملكية إلى القروض } \\
\text { (Credit Risk) }\end{array}$ \\
\hline $\begin{array}{l}\text { F Statistic } 1.327 \\
\text { P- Value } 0.252\end{array}$ & $\begin{array}{l}\text { T Statistic } \mathbf{- 1 . 0 4 5} \\
\text { P- Value } 0.298\end{array}$ & $\begin{array}{l}\text { الفجوة التمويلية (مخاطر السيولة) } \\
\text { (FGAP) }\end{array}$ \\
\hline $\begin{array}{c}\text { F Statistic } 2.290 \\
\text { P- Value } 0.133 \\
\end{array}$ & $\begin{array}{c}\text { T Statistic }-2.423 \\
\text { P- Value } 0.017 \\
\end{array}$ & $\begin{array}{l}\text { مخاطر الاستثمارات } \\
\text { Securities Risk } \\
\end{array}$ \\
\hline $\begin{array}{l}\text { F Statistic } 0.001 \\
\text { P- Value } 0.972\end{array}$ & $\begin{array}{l}\text { T Statistic } 0.224 \\
\text { P- Value } 0.823\end{array}$ & $\begin{array}{l}\text { مخاطر الأصول المصرفية } \\
\text { Risk of Bank Assets }\end{array}$ \\
\hline
\end{tabular}
ويعرض الجدول التالى نتائج اختبارى F T لقياس معنوية الفروق فى مؤشرات المخاطر المالية:

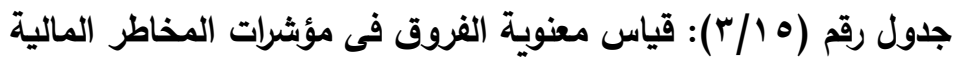

المصدر: اعداد الباحثون اعتماداً على نتائج التحليل الإحصائى

يتضــح من الجدول رقم (9) ارتفاع الوسـط الحســـى والوسـيط لمخاطر الاسـتشمارات بمعدل

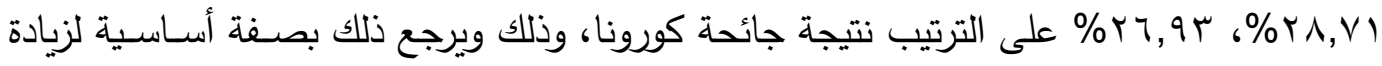
حجم الاستثمارات المالية على حساب الأصول السائلة والقروض، ولتحديد مدى معنوية تلك الفروق

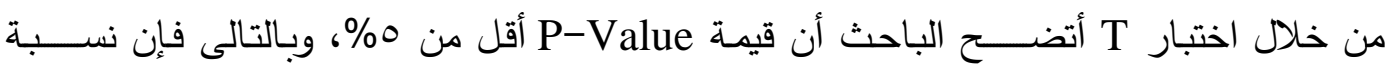

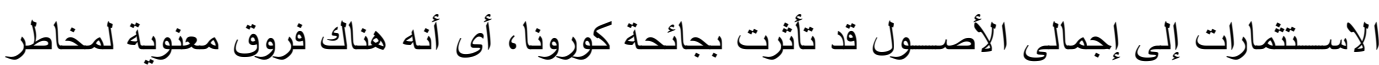

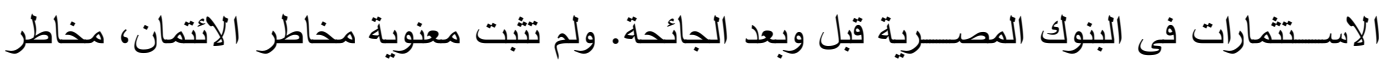

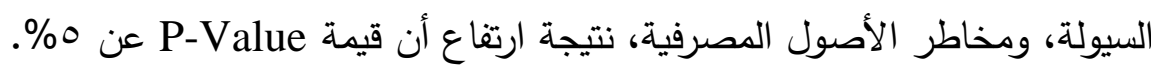

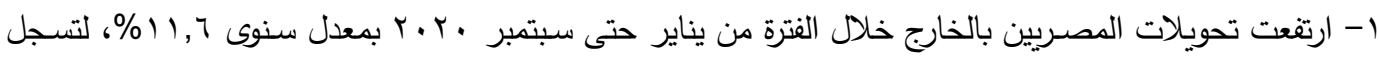
نحو 1,Y, مليار دولار مقابل 19,1 مليار دولار خلال الفترة المماثلة من العام السابق. 


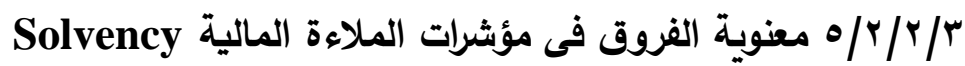

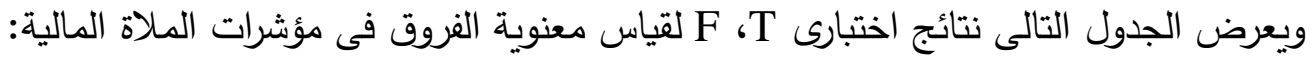

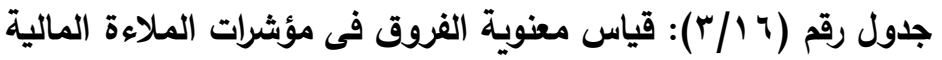

\begin{tabular}{|c|c|c|}
\hline $\begin{array}{c}\text { Leven's Test for Quality } \\
\text { of Vaiances }\end{array}$ & $\begin{array}{c}\text { Paired Sampled t-test for } \\
\text { Equality of Means }\end{array}$ & النسب المالية \\
\hline $\begin{array}{c}\text { F Statistic } 20.746 \\
\text { P- Value } 0.000\end{array}$ & $\begin{array}{c}\text { T Statistic }-9.378 \\
\text { P- Value } 0.000\end{array}$ & معيار كفاية رأس المال (CAR) \\
\hline $\begin{array}{c}\text { F Statistic } 7.378 \\
\text { P- Value } 0.008\end{array}$ & $\begin{array}{c}\text { T Statistic } \mathbf{- 8 . 6 8 7} \\
\text { P- Value } \mathbf{0 . 0 0 0}\end{array}$ & $\begin{array}{l}\text { المال } \\
\text { نسـبة الثــريحة الأولى من رأس } \\
\text { (Tier1) }\end{array}$ \\
\hline $\begin{array}{l}\text { F Statistic 5.005 } \\
\text { P- Value 0.028 }\end{array}$ & $\begin{array}{c}\text { T Statistic }-\mathbf{2 . 3 5 1} \\
\text { P- Value } 0.021\end{array}$ & $\begin{array}{l}\text { نسبة الرافعة المالية } \\
\text { Leverage Ratio }\end{array}$ \\
\hline
\end{tabular}

المصدر: اعداد الباحثون اعتماداً على نتائج التحليل الإحصائى

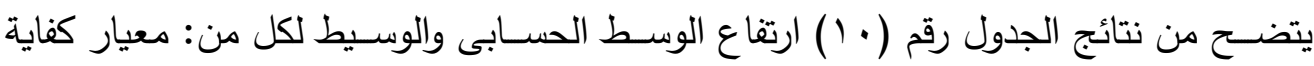

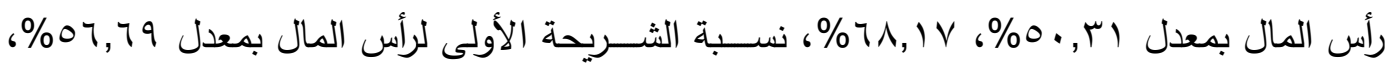

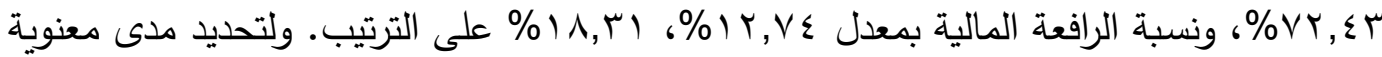

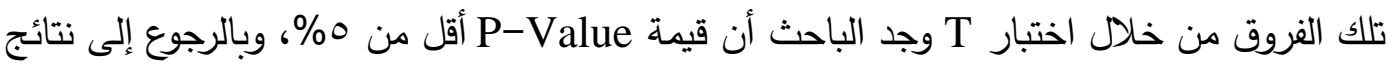

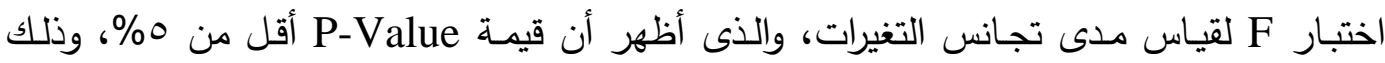

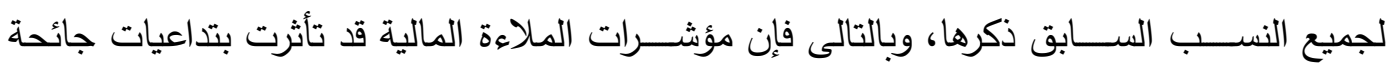
كورونا، أى أنه هناك فروق معنوية لمؤشـرات الملاءة المالية فى البنوك المصـرية قبل وبعد جائحة كورونا، كما أن هذه الفروق متجانسة.

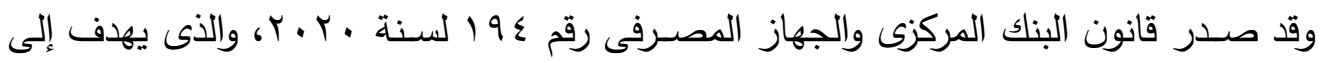

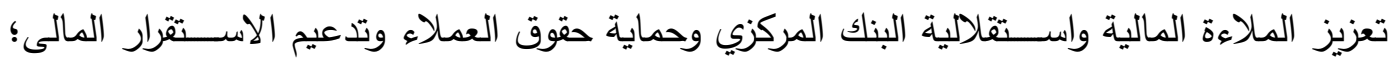

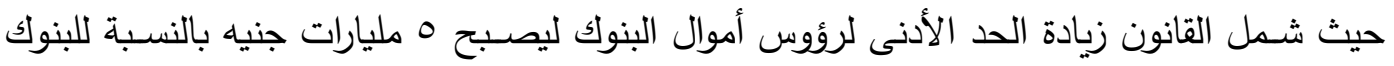

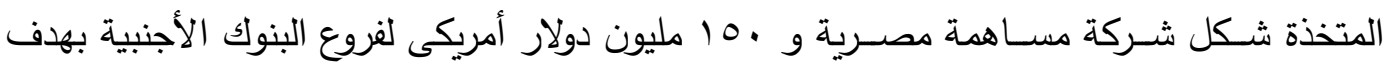

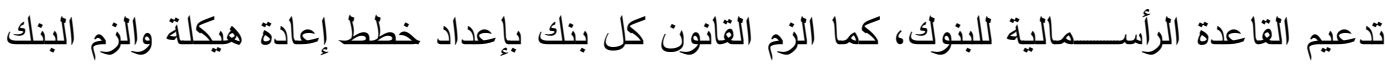
المركزي بإعداد خطة تسوية لكل بنك.

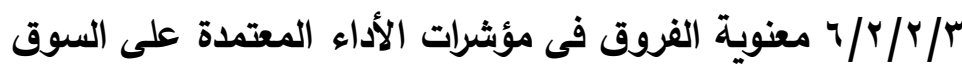

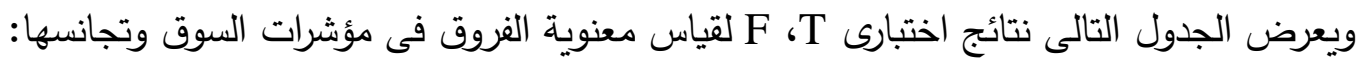

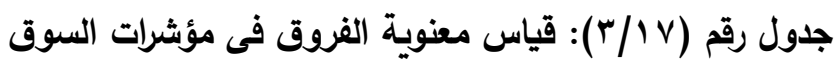

\begin{tabular}{|c|c|c|}
\hline $\begin{array}{c}\text { Leven's Test for Quality } \\
\text { of Vaiances }\end{array}$ & $\begin{array}{c}\text { Paired Sampled t-test for } \\
\text { Equality of Means } \\
\end{array}$ & النسب المالية \\
\hline $\begin{array}{l}\text { F Statistic } 4.761 \\
\text { P- Value } 0.033\end{array}$ & $\begin{array}{l}\text { T Statistic } 2.396 \\
\text { P- Value } 0.019\end{array}$ & $\begin{array}{l}\text { الدفترية القيمة الســوقية إلى القيمة } \\
\text { (MVBV) }\end{array}$ \\
\hline $\begin{array}{l}\text { F Statistic } 0.003 \\
\text { P- Value } 0.959\end{array}$ & $\begin{array}{l}\text { T Statistic } 0.720 \\
\text { P- Value } 0.474\end{array}$ & 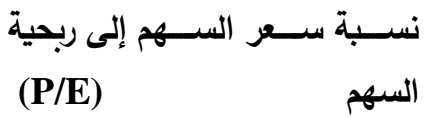 \\
\hline
\end{tabular}

المصدر: اعداد الباحثون اعتماداً على نتائج التحليل الإحصائى (العهى 


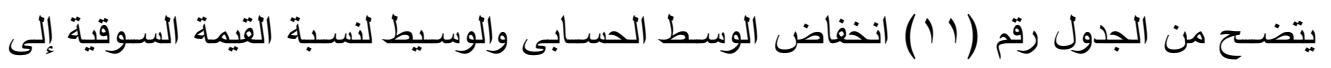

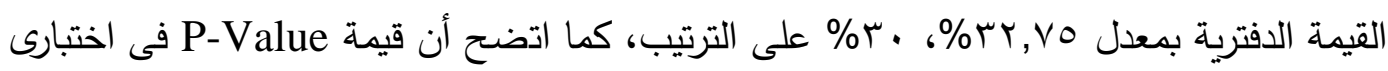
F أقل من 0\% T

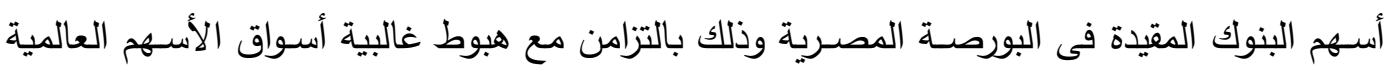
تأثراً بجائحة كورونا، فضلاً عن هبوط أسعار النفط.

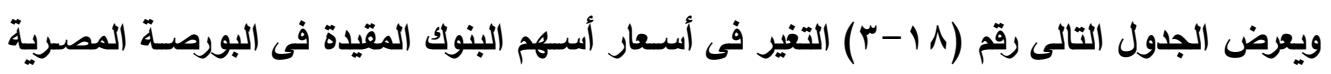

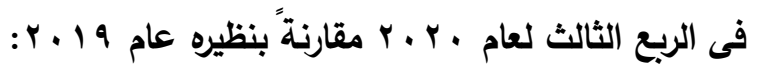

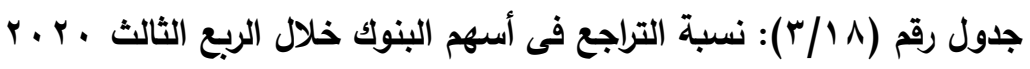

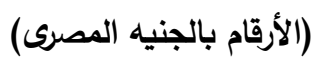

\begin{tabular}{|c|c|c|c|c|}
\hline الربع الثالث 9 r r r & الربع الثالث · r. r r & نسبة التراجع & 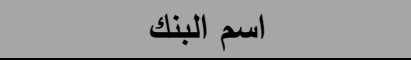 & الترتيب \\
\hline$\varepsilon r, \ldots$ & $1 \leqslant, \wedge \vee$ & $\% ч \varepsilon, 7$. & قطر الأهلى الوطنى & 1 \\
\hline$\leqslant 1,0$ & $r q, 01$ & $\% r q, 1 r$ & كريدى أجريكول & r \\
\hline$\varepsilon \cdot, r Y$ & $r v, 0$. & 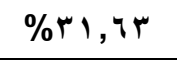 & الكويت الوطنى & $r$ \\
\hline$V\urcorner, \cdot \varepsilon$ & $111,1 \varepsilon$ & $\%$ \%, $0 \wedge$ & الشركة المصرفية العربية الدولية & $\varepsilon$ \\
\hline $1 \leqslant, .9$ & 11,11 & $\%$ Y 1,10 & فيصل الإسلاهى المصرى & 0 \\
\hline ᄉ, 70 & $V, r V$ & $\% 10,90$ & المصرى الخليجى & 9 \\
\hline$V V, 04$ & 79,09 & $\% 1 \leq, 1 \wedge$ & التجارى الدولى & 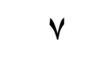 \\
\hline $11, \wedge \mathrm{V}$ & $1 \cdot, r v$ & $\% \backslash Y, \uparrow \leqslant$ & البركة مصر & $\wedge$ \\
\hline Ir,VY & $11,1 \leq$ & $\% \backslash r, \&$ r & أبو ظبى الإسلامى & 9 \\
\hline$\varepsilon \varepsilon, Y \varepsilon$ & $r q, v i$ & $\% 1 \cdot, r \leq$ & التعمير والإسكان & 1. \\
\hline
\end{tabular}

المصدر: اعداد الباحثون إعتماداً على التقارير السنوية للبنوك الإن

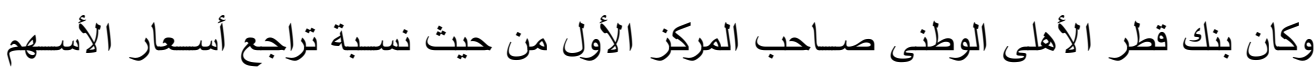

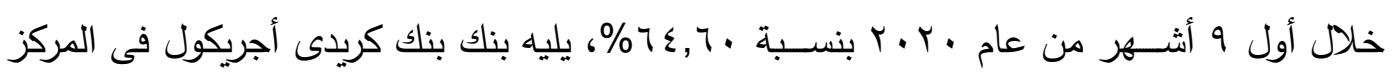

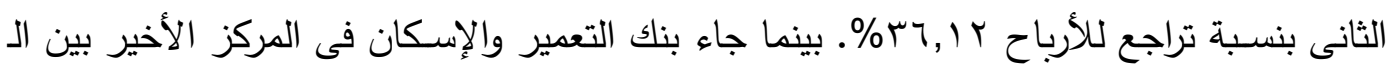

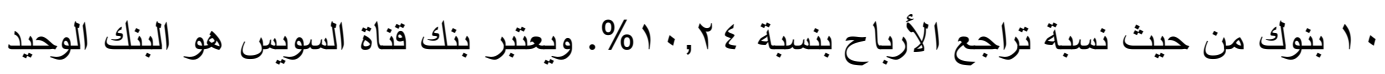

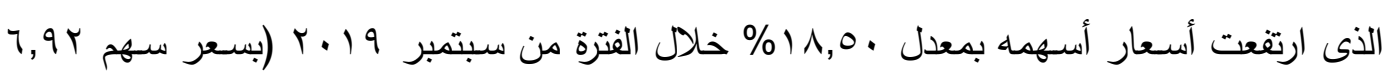

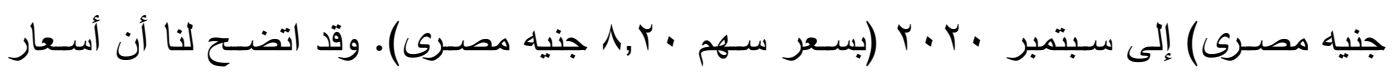

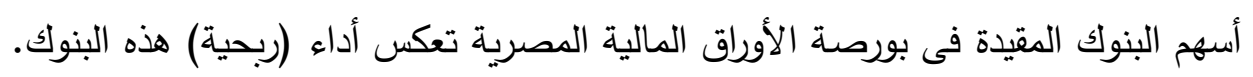

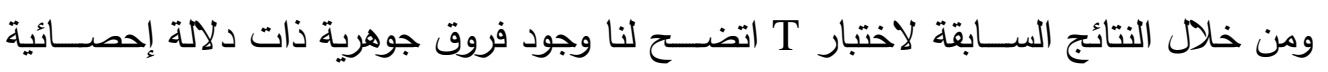

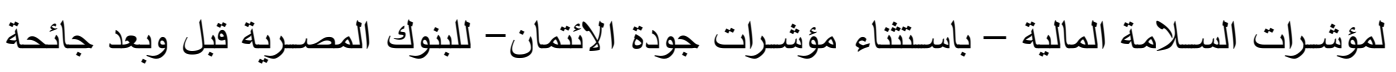

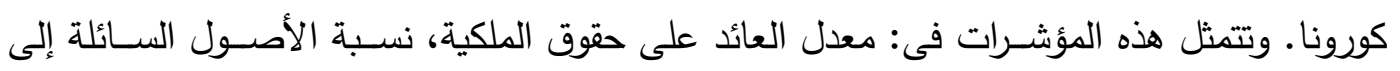

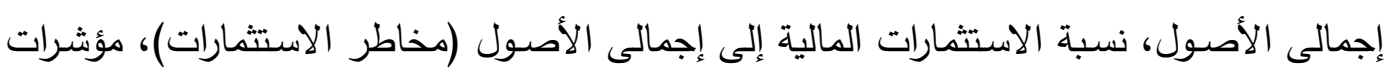

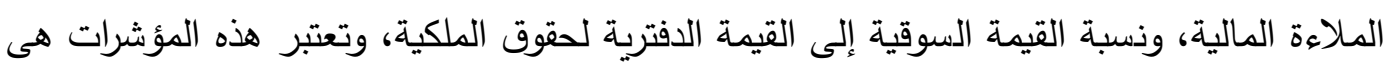
الأكثر تأثراً بتداعيات جائحة كورونا. 


\section{r/r/r/T اختبار تحليل الارتباط بيرسون (الفرض البحثى الثانى)}

من الأسـاليب الإحصـائية التى تستخدم لقياس علاقة الارتباط بين المتغيرات المستقلة المعبرة عنها جائحة كورونا، والمتغيرات التابعة المتمثلة فى مؤشرات السلامة المالية، أسلوب تحليل الارتباط بيرسـون Pearson Correlation لقياس قوة واتجاه العلاقة بين المتغيرات، وذلك للحكم على مدى

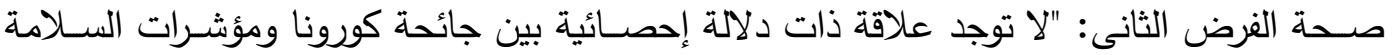

$$
\text { المالية للبنوك العاملة فى مصر ". }
$$

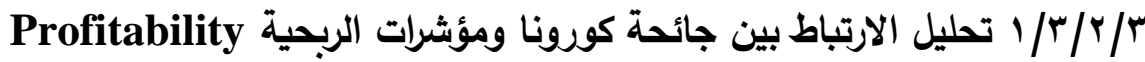
يعرض الجدول التالى نتائج تحليل ارتباط بيرسون بين جائحة كورونا ومؤشرات الربحية: الرئية

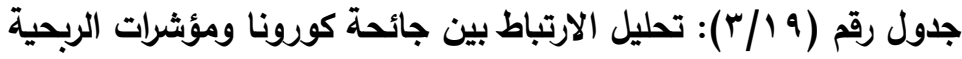

\begin{tabular}{|c|c|c|c|c|c|}
\hline NIM & EPS & ROE & ROA & Corona & \\
\hline $\begin{array}{l}\cdot, \cdot 0 \leqslant 0 \\
(\cdot, 1 \leqslant 1)\end{array}$ & $\begin{array}{l}\cdot, \cdot \vee \vee 1- \\
(\cdot,, \leqslant \vee \uparrow)\end{array}$ & $\begin{array}{c}* *, \cdot, \wedge \Lambda 1- \\
(\cdot,, r r)\end{array}$ & $\begin{array}{l}\cdot, 104- \\
(\cdot, 1,4)\end{array}$ & 1 & Corona \\
\hline $\begin{array}{l}* *,, v \circ r \\
(\cdot, \ldots)\end{array}$ & $\begin{array}{l}*, \text { r.Yq } \\
(\cdot, \text {, r. })\end{array}$ & $\begin{array}{l}* * \cdot, v \cdot q \\
(\cdot, \cdots)\end{array}$ & 1 & $\begin{array}{l}., 107- \\
(\cdot, 1,4)\end{array}$ & ROA \\
\hline $\begin{array}{l}* *, \cdot, \leqslant 44 \\
(\cdot, \ldots)\end{array}$ & $\begin{array}{l}\cdot, 104 \\
(\cdot, 1 \times 4)\end{array}$ & 1 & $\begin{array}{l}* *, \cdot, \cdot q \\
(\cdot, \cdots)\end{array}$ & $\begin{array}{c}* * *, r \wedge 1- \\
(\cdot, \ldots r)\end{array}$ & ROE \\
\hline $\begin{array}{l}\cdot, 1 \text { TY } \\
(\cdot, \mid, Y)\end{array}$ & 1 & $\begin{array}{l}., 104 \\
(\cdot, 1 \times 4)\end{array}$ & $\begin{array}{l}*, r Y q q \\
(\cdot, \cdot r \cdot r)\end{array}$ & $\begin{array}{l}\cdot, \cdot \vee V 1- \\
\left(\cdot, \leqslant \vee V^{\prime}\right)\end{array}$ & EPS \\
\hline 1 & $\begin{array}{l}\cdot, \mid, Y 4 \\
(\cdot, \mid, Y)\end{array}$ & $\begin{array}{l}* * *, \leqslant 44 \\
(\cdot, \ldots)\end{array}$ & $\begin{array}{l}* *, v, v \circ r \\
(\cdot, \ldots)\end{array}$ & $\begin{array}{l}\cdot, \cdot, \leqslant 0 \\
(\cdot, 7 \leqslant 1)\end{array}$ & NIM \\
\hline
\end{tabular}

\%॰ الارتباط معنوى عند مستوى دلالة * *

\% ا الارتباط معنوى عند مستوى دلالة * * المصدر: اعداد الباحثون اعتماداً على نتائج التحليل الإحصائى دلى الإئه يتضـــح من نتائج الجدول رقم (9 (1) وجود علاقة ارتباط عكســى بين جائحة كورونا ومعدل العائد على حقوق الملكية، عند مستوى معنوية ل \% ؛ وفى المقابل فإن العلاقة العكسية بين جائحة

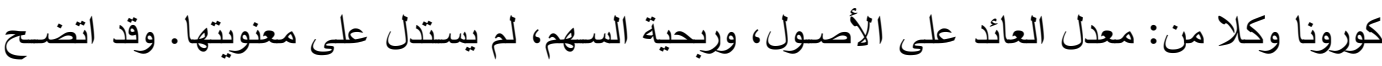
عدم وجود علاقة ارتباطية بين جائحة كورونا وهامش صافى العائد من الفوائد.

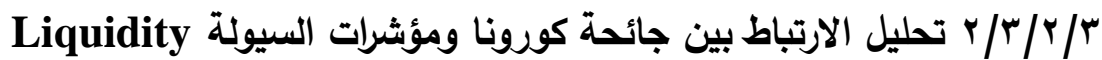
يعرض الجدول التالى نتائج تحليل ارتباط بيرسون بين جائحة كورونا ومؤشرات الربحية:

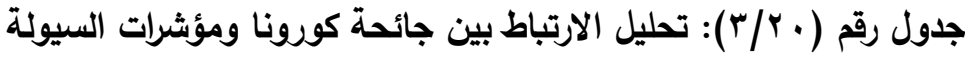

\begin{tabular}{|c|c|c|c|c|}
\hline DTA & LTD & LIQ & Corona & \\
\hline $\begin{array}{l}\cdot, \cdot \wedge r- \\
(\cdot, r q \vee)\end{array}$ & $\begin{array}{c}\cdot, .99 \\
(\cdot, r \cdot \Lambda)\end{array}$ & $\begin{array}{c}* *, r \mid V- \\
(\cdot, \ldots l)\end{array}$ & 1 & Corona \\
\hline $\begin{array}{c}\cdot, \wedge \\
(\cdot, \leqslant 11)\end{array}$ & $\begin{array}{c}* *,, \leqslant Y \diamond- \\
(\cdot, \cdots)\end{array}$ & 1 & $\begin{array}{c}* *, r \mid V- \\
(\cdot, \cdots 1)\end{array}$ & LIQ \\
\hline
\end{tabular}




\begin{tabular}{|c|c|c|c|c|}
\hline $\begin{array}{c}* *, \leq 41- \\
(\cdot, \cdots)\end{array}$ & 1 & $\begin{array}{c}* *,, \leqslant \text { r }- \\
(\cdot, \cdots)\end{array}$ & $\begin{array}{c}., .99 \\
(\cdot, 4.1)\end{array}$ & LTD \\
\hline 1 & $\begin{array}{c}* *, \leq \ 1- \\
(\cdot, \cdots)\end{array}$ & $\begin{array}{c}\cdot, \wedge . \\
(\cdot, \varepsilon \mid 1)\end{array}$ & $\begin{array}{l}\cdot, \wedge r- \\
(\cdot, r q \vee)\end{array}$ & DTA \\
\hline
\end{tabular}

\% ا * الارتباط معنوى عند مستوى دلالة *

المصدر: اعداد الباحثون اعتماداً على نتائج التحليل الإحصائى دلائي

يتضـــح من نتائج الجدول رقم (·r) وجود علاقة ارتباط عكســية معنوية بين جائحة كورونا ونسبة الأصول السائلة إلى إجمالى الأصول، عند مستوى معنوية ا \%؛ بما يعنى أن جائحة كورونا

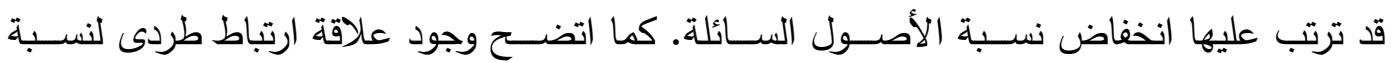
القروض إلى الودائع وجائحة كورونا، ولكنها غير معنوية.

Credit Quality r/r/r/r/r تحليل الارتباط بين جائحة كورونا ومؤشرات جودة الائتمان يعرض الجدول التالى نتائج تحليل ارتباط بيرسون بين جائحة كورونا ومؤشرات جودة الائتمان: جدول رقم (Y/YlY): تحليل الارتباط بين جائحة كورونا ومؤشرات جودة الائتمان

\begin{tabular}{|c|c|c|c|c|c|}
\hline LtA & $\mathrm{COV}$ & NPL & $\mathbf{L L P}$ & Corona & \\
\hline $\begin{array}{l}\cdot, \wedge \wedge \\
(\cdot, \mu \vee q)\end{array}$ & $\begin{array}{l}\cdot, \cdot \wedge- \\
(\cdot, 9+7)\end{array}$ & $\begin{array}{l}\cdot, I Y V- \\
(\cdot, Y \mid V)\end{array}$ & $\begin{array}{l}\cdot, \cdot \leq \varepsilon- \\
(\cdot, 7 \div \varepsilon)\end{array}$ & 1 & Corona \\
\hline $\begin{array}{c}* *, \leq \vee\urcorner- \\
(\cdot, \cdots)\end{array}$ & $\begin{array}{l}., 19 V- \\
(., .71)\end{array}$ & $\begin{array}{l}* *, \wedge, 0 \\
(\cdot, \cdots)\end{array}$ & 1 & $\begin{array}{l}\cdot, \cdot \leq r- \\
(\cdot, 77 \varepsilon)\end{array}$ & LLP \\
\hline $\begin{array}{c}* *, \leqslant Y q- \\
(\cdot, \cdot \cdot)\end{array}$ & $\begin{array}{c}* *, 0, \cdot- \\
(\cdot, \cdots,)\end{array}$ & 1 & $\begin{array}{l}* *, \wedge \cdot 0 \\
(\cdot, \cdots)\end{array}$ & $\begin{array}{l}\cdot, I V- \\
(\cdot, r \mid V)\end{array}$ & NPL \\
\hline $\begin{array}{l}* *, Y \wedge \neg \\
(\bullet, \cdot, 7)\end{array}$ & 1 & $\begin{array}{c}* *, 0, \ldots- \\
(\cdot, \ldots)\end{array}$ & $\begin{array}{l}., 19 V- \\
(\cdot, 91)\end{array}$ & $\begin{array}{l}\cdot, \cdot \wedge- \\
(\cdot, 9+4)\end{array}$ & $\mathrm{COV}$ \\
\hline 1 & $\begin{array}{l}* *, r \wedge \neg \\
(\cdot, \cdot \neg)\end{array}$ & $\begin{array}{c}* *,, \varepsilon r q- \\
(\cdot, \cdots)\end{array}$ & $\begin{array}{c}* *, \varepsilon \vee \neg- \\
(\cdot, \cdots \cdot)\end{array}$ & $\begin{array}{c}\cdot, \wedge \neg \\
(\cdot,+\vee \checkmark)\end{array}$ & $\mathbf{L t A}$ \\
\hline
\end{tabular}

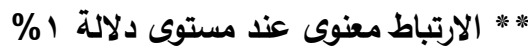
المصدر: اعداد الباحثون اعتماداً على نتائج التحليل الإحصائى دلائى يتضـح من نتائج الجدول رقم (Y) وجود علاقة ارتباط عكسى بين جائحة كورونا ومؤشـرات جودة الأتتمان (نسبة مخصدات خسائر القروض، نسبة القروض المتعثرة، ونسبة تغطية القروض المتعثرة)، إلا أن هذه العلاقة غير معنوية.

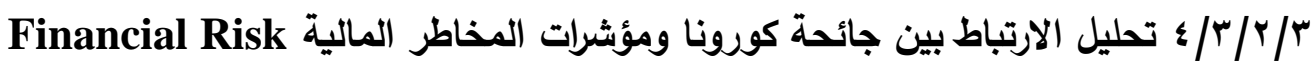
يعرض الجدول التالى نتائج تحليل ارتباط بيرسون بين جائحة كورونا ومؤشرات المخاطر المالية:

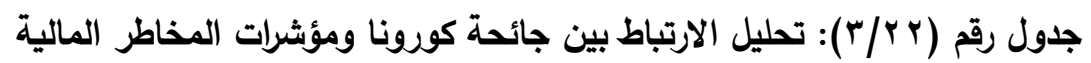

\begin{tabular}{|c|c|c|c|c|c|}
\hline Assets & Securities & FGAP & Credit & Corona & \\
\hline$\cdot, \cdot r r-$ & $*,, r r q$ & $\cdot, 1 \cdot 1$ & $\cdot, \cdot \leq \vee$ & 1 & Corona \\
$(\cdot, \wedge r r)$ & $(\cdot, \cdot, \vee)$ & $(\cdot, r q \wedge)$ & $(\cdot, r r q)$ & & \\
\hline
\end{tabular}




\begin{tabular}{|c|c|c|c|c|c|}
\hline $\begin{array}{c}* *, Y \vee Y- \\
(\cdot, \cdot \wedge)\end{array}$ & $\begin{array}{l}* *,, \leq 7 \leq \\
(\cdot, \cdots)\end{array}$ & $\begin{array}{c}* *, 071- \\
(\cdot, \ldots)\end{array}$ & 1 & $\begin{array}{c}\cdot, \cdot \leq V \\
(\cdot, 7 r y)\end{array}$ & Credit \\
\hline $\begin{array}{c}\cdot, \vee \vee q r \\
(\cdot, \cdots)\end{array}$ & $\begin{array}{c}* *,, \leqslant \mid \vee- \\
(\cdot, \cdots)\end{array}$ & 1 & $\begin{array}{c}* *, 071- \\
(\cdot, \cdots)\end{array}$ & $\begin{array}{c}\cdot, 1 \cdot 1 \\
(\cdot, r q \wedge)\end{array}$ & FGAP \\
\hline $\begin{array}{c}* *, r, q- \\
(\cdot, \cdot, r)\end{array}$ & 1 & $\begin{array}{c}* *,, \varepsilon \mid V- \\
(\cdot, \cdots)\end{array}$ & $\begin{array}{l}* *,, \leq 7 \leq \\
(\cdot, \ldots)\end{array}$ & $\begin{array}{l}*, r p q \\
(\cdot, \cdot \cap \vee)\end{array}$ & Securities \\
\hline 1 & $\begin{array}{c}* *, r, q- \\
(\cdot,, r)\end{array}$ & $\begin{array}{l}* *, \vee \vee q r \\
(\cdot, \ldots)\end{array}$ & $\begin{array}{l}\cdot, r \vee r- \\
(\cdot, \cdot \wedge)\end{array}$ & $\begin{array}{l}\cdot, \cdot r r- \\
(\cdot, \wedge r r)\end{array}$ & Assets \\
\hline
\end{tabular}

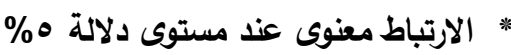

\%

المصدر: اعداد الباحثون اعتماداً على نتائج التحليل الإحصائى التى

يتضح من نتائج الجدول رقم (Yr) وجود علاقة ارتباط طردى معنوى بين جائحة كورونا ونسبة

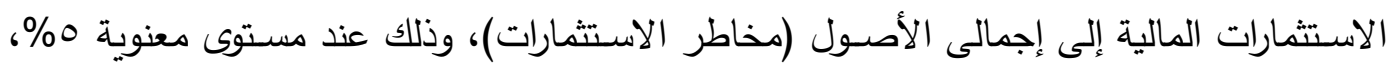

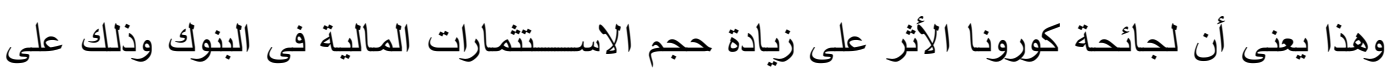
حساب الأصسول السـائلة. كما اتضـح وجود علاقة ارتباط طردى بين جائحة كورونا وكلاً من: نسبة التها حقوق الملكية إلى إجمالى القروض (مخاطر الائتمان)، والفجوة التمويلية (مخاطر السـيوله)، ولكن هذه العلاقة غير معنوية.

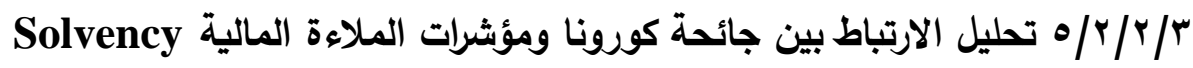
يعرض الجدول التالى نتائج تحليل ارتباط بيرسون بين جائحة كورونا ومؤشرات الملاءة المالية: جدول رقم (r/Yr): تحليل الارتباط بين جائحة كورونا ومؤشرات الملاءة المالية

\begin{tabular}{|c|c|c|c|c|}
\hline Leverage & Tier1 & CAR & Corona & \\
\hline $\begin{array}{l}*, r \leq r \\
(\cdot, \cdot r l)\end{array}$ & $\begin{array}{l}* *, 707 \\
(\cdot, \ldots)\end{array}$ & $\begin{array}{l}* *, 7 \wedge \varepsilon \\
(\cdot, \ldots)\end{array}$ & 1 & Corona \\
\hline $\begin{array}{c}* *,, \leqslant \diamond q \\
(\cdot, \ldots)\end{array}$ & $\begin{array}{l}* *, q \wedge r \\
(\cdot, \cdots)\end{array}$ & 1 & $\begin{array}{c}* *, \text {, ๆ } \\
(\cdot, \cdots)\end{array}$ & CAR \\
\hline $\begin{array}{l}* *, o r v \\
(\cdot, \ldots)\end{array}$ & 1 & $\begin{array}{l}* *, q \wedge r \\
(\cdot, \ldots)\end{array}$ & $\begin{array}{l}* *,, 707 \\
(\cdot, \ldots)\end{array}$ & Tier1 \\
\hline 1 & $\begin{array}{l}* *,, \circ H V \\
(\cdot, \ldots)\end{array}$ & $\begin{array}{c}* *,, \leq \diamond q \\
(\cdot, \ldots)\end{array}$ & $\begin{array}{l}*, r \leq r \\
(\cdot, \cdot r l)\end{array}$ & Leverage \\
\hline
\end{tabular}

الارتباط معنوى عند مستوى دلالة •\%

*\% الارتباط مغنوى عند مستوى دلالة 1\% المصدر: اعداد الباحثون اعتماداً على نتائج التحليل الإحصائى دلأه يتضــــح من نتائج الجدول رقم (r/Y) وجود علاقة ارتباط طردى معنوى بين جائحة كورونـا

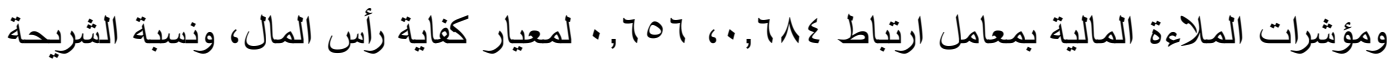

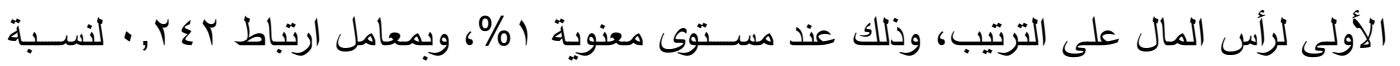

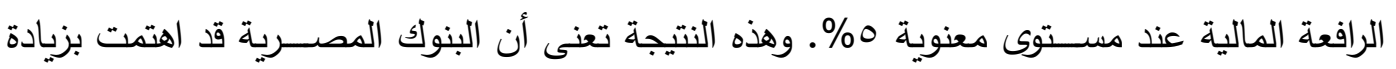
رؤوس أموالها تحسباً لأية تأثيرات سلبية لجائة كورونا. 


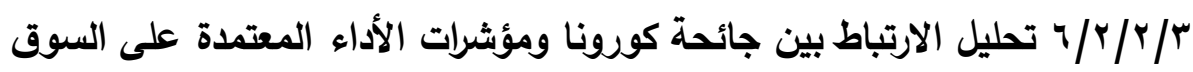

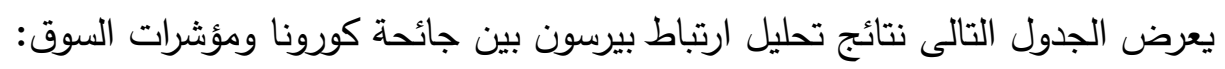

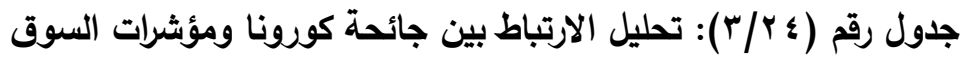

\begin{tabular}{|c|c|c|c|}
\hline PtE & MVBV & Corona & \\
\hline $\begin{array}{l}\cdot, \cdot, 99- \\
(\cdot,, \leqslant \vee \leqslant)\end{array}$ & $\begin{array}{l}*, \text { Y } \wedge \vee- \\
(\cdot,, 19)\end{array}$ & 1 & Corona \\
\hline $\begin{array}{l}* *, \cdot, r) \\
(\cdot, \ldots)\end{array}$ & 1 & $\begin{array}{l}*, \cdot, Y \wedge \vee- \\
(\cdot, .19)\end{array}$ & MVBV \\
\hline 1 & $\begin{array}{l}* * *_{\cdot}^{*},{ }^{\prime} \\
(\cdot, \ldots, \ldots)\end{array}$ & $\begin{array}{l}\cdot, \cdot 99- \\
(\cdot, \leqslant \vee \leqslant)\end{array}$ & PtE \\
\hline
\end{tabular}

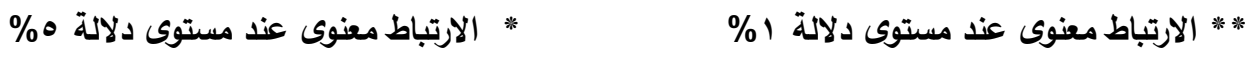

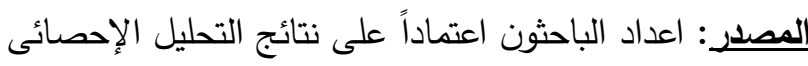

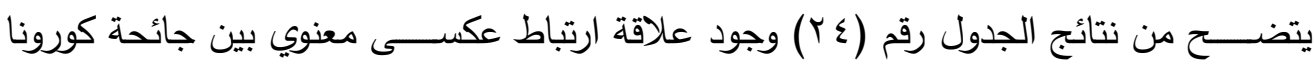

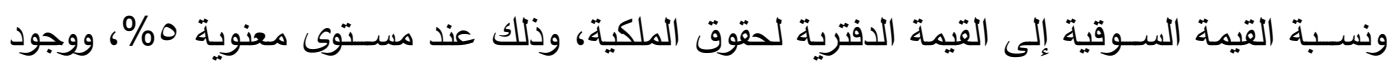

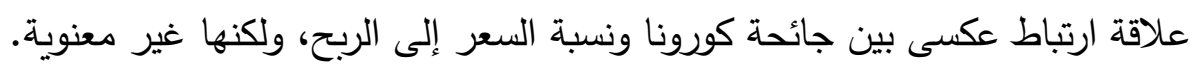

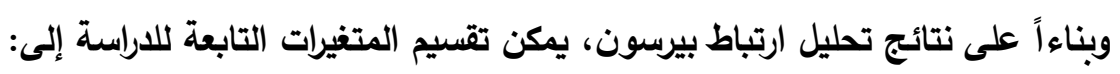

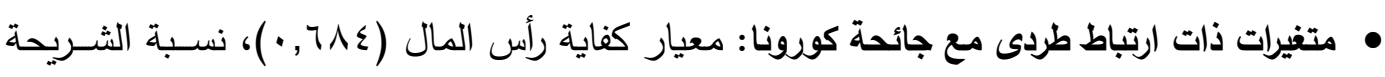

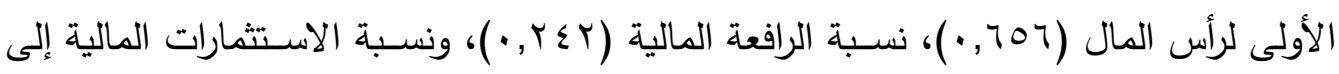

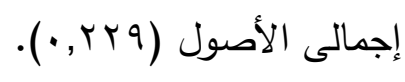

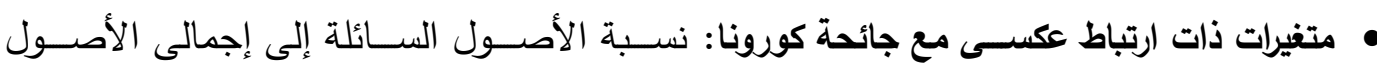

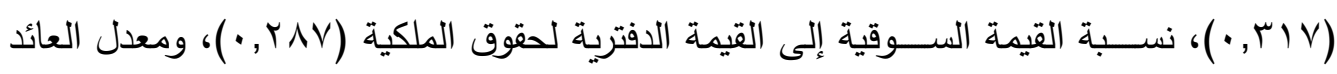

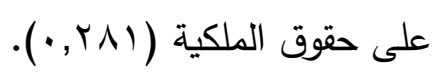

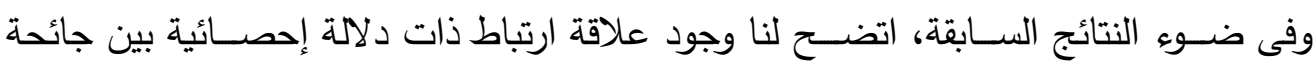

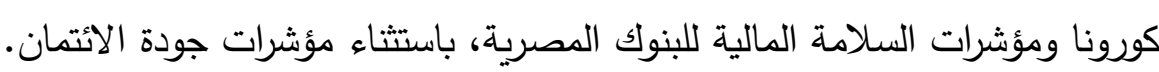

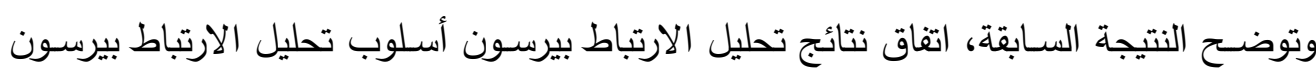
Pearson Correlation الأكثر تأثراً بتداعيات جامعة كورونا.

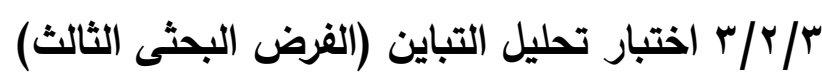

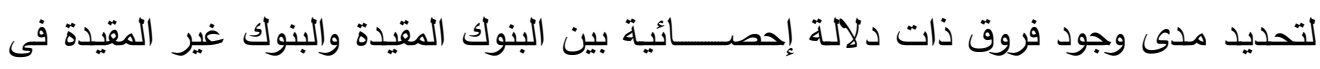

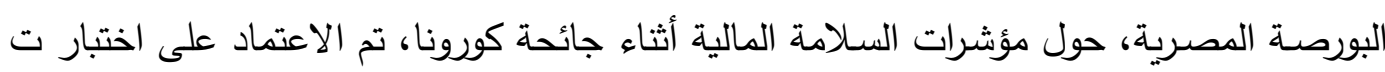
T-Test

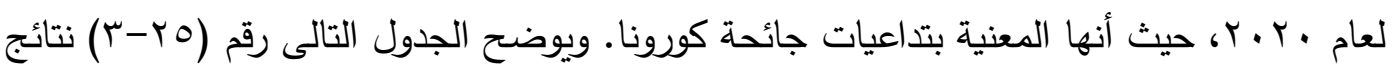

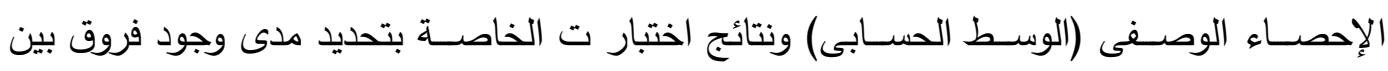
البنوك عينة الدراسة، ومدى جوهرية هذه الفروق: 
جدول رقم: (r/ץ/ץ): معنوية الفروق بين البنوك عينة الدراسة

\begin{tabular}{|c|c|c|c|c|c|c|c|}
\hline \multicolumn{2}{|c|}{ T- Test اختبار } & \multicolumn{2}{|c|}{ البنوك غير المقيدة } & \multicolumn{2}{|c|}{ البنوك المقيدة } & \multirow[b]{2}{*}{ المؤشر } & \multirow[b]{2}{*}{ ? } \\
\hline 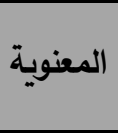 & قيمة T T & الوسطابى & ن & الوسطابى & $\dot{ن}$ & & \\
\hline \multicolumn{8}{|c|}{ Profitability مؤشرات الربحية P } \\
\hline$\cdot, r \wedge \bullet$ & $\cdot, \wedge \vee \vee$ & •, & 11 & $\cdot, \vee \curlyvee \wedge$ & rq & معدل العائد على الأصول (\%) & 1 \\
\hline$\cdot, 1 v$ & $1, r q r$ & T,orr & 11 & $V, O H \leq$ & rq & معدل العائد على حقوق الملكية (\%) & r \\
\hline$\cdot, \cdot r q$ & Y,Y०Y- & $r, q \mu$, & 11 & $1, Y \circ 1$ & rr & ربحية السهم (جنيه مصرى) & $r$ \\
\hline$\cdot, \wedge r q$ & $\cdot, r i v-$ & $1,1 \leqslant 1$ & 11 & $1,1 \mathrm{r}$ & rq & هامش صافى العائد من الفوائد (\%) & $\varepsilon$ \\
\hline \multicolumn{8}{|c|}{ • مأشرات السيولة Liquidity مؤل } \\
\hline., .94 & $1, \times 1 \cdot-$ & $r r, 1 . q$ & 11 & $r \curlyvee, \wedge \leq r$ & r & نسبة الأصول السائلة إلى إجمالى الأصول & 1 \\
\hline$\cdot, 1 \leqslant r$ & $1,\{9 r-$ & or,q1؛ & 11 & $\leq \longleftarrow, \vee r$. & r & نسبة القروض إلى الودائع (\%) & r \\
\hline$\cdot,+10$ & $r, 01$. & $\vee 9,710$ & 11 & $\wedge r, \ldots$ & rq & نسبة الودائع إلى الأصول (\%) & $r$ \\
\hline \multicolumn{8}{|c|}{ • مؤشرات جودة الائتمان Credit (Assets) Quality } \\
\hline$\cdot, .9$ & $r, \leqslant r q$ & $\leq, \leq r \leq$ & 10 & $7,71 \vee$ & tra & نسبة مخصص خسائر القروض (\%) & 1 \\
\hline$\cdot, 10 \mathrm{r}$ & $1,\{01$ & $r, \Lambda \cdot 1$ & $1 \varepsilon$ & $0,1 \vee \mu$ & $r \leq$ & نسبة القروض المتعثرة (\%) & r \\
\hline$\cdot, 000$ & $\cdot, 097-$ & $\mid \leq \cdot, \wedge \wedge 1$ & 11 & $|r|, \wedge \circ r$ & rr & نسبة تغطية القروض المتعثرة (\%) & $r$ \\
\hline$\cdot, r v i$ & $1,11 r-$ & $\varepsilon Y, \diamond \vee \leqslant$ & 11 & 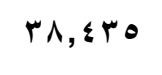 & m & نسبة القروض إلى إجمالى الأصول (\%) & $\varepsilon$ \\
\hline \multicolumn{8}{|c|}{ • مؤشرات المخاطر المالية Financial Risk } \\
\hline$\cdot, r q \mu$ & 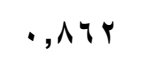 & $r v, \ldots r$ & 11 & $r \varepsilon, \ldots q$ & r & نسبة حقوق الملكية إلى القروض (\%) & 1 \\
\hline$\cdot, \cdot \wedge 9$ & $1, V r r-$ & $r v, \cdot r q-$ & 11 & $\varepsilon \varepsilon, Y V \cdot-$ & rq & الفجوة التمويلية (مخاطر السيولة) (\%) & r \\
\hline$\cdot, .10$ & r,ort & $Y \cdot, \leqslant 1 \wedge$ & 11 & $r \cdot, 0 \leq 1$ & $r$ & مخاطر الاستثمارات (\%) & $r$ \\
\hline$\cdot, \operatorname{vrr}$ & $\cdot$ & $00,1 \leq \leq$ & 14 & $07,0 \leqslant 1$ & r & مخاطر الأصول المصرفية (\%) & $\varepsilon$ \\
\hline \multicolumn{8}{|c|}{ • مؤشرات الملاءة المالية (المصرفية) Solvency } \\
\hline$\cdot, 9 \vee 9$ & $\cdot, \cdot, 4$ & Y, $7 \vee V$ & iv & rq,VYr & ro & معيار كفاية رأس المال (\%) & 1 \\
\hline$\cdot, \wedge \wedge \vee$ & $\cdot, 1 \leq r-$ & $r \leqslant, r q r$ & iv & $r \leqslant, \cdot \varepsilon \wedge$ & ro & الثريحة الأولى من رأس المال (\%) & $r$ \\
\hline$\cdot, q \leq r$ & $\cdot, \cdot v r-$ & $\wedge, \wedge \wedge 1$ & ir & $\wedge, \wedge \leq$. & m & نسبة الرافعة المالية (\%) & $r$ \\
\hline
\end{tabular}

المصدر: اعداد الباحثون اعتماداً على نتائج التحليل الإحصائى 


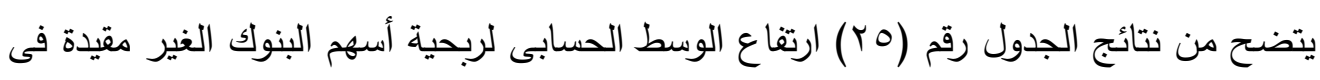

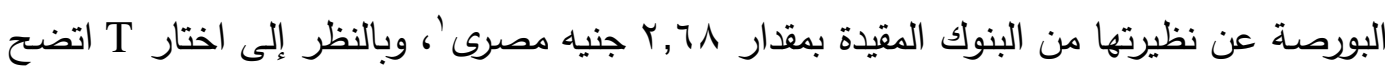

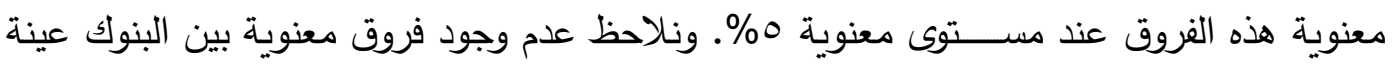
الدراسة وذلك لبقية مؤشرات الربحية.

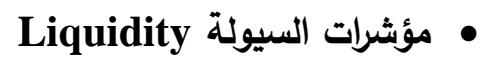

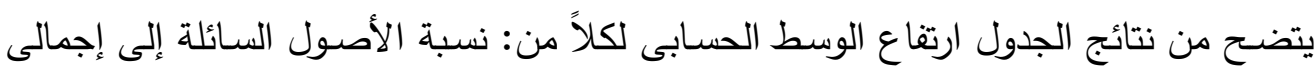

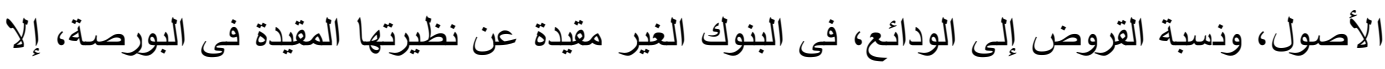

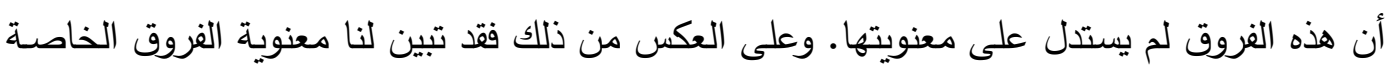

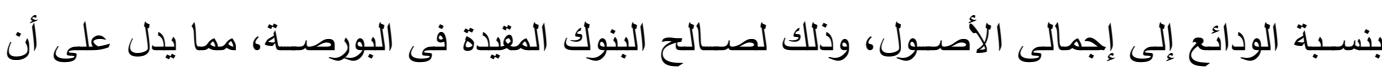

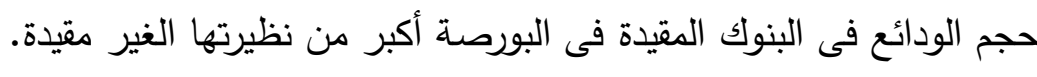

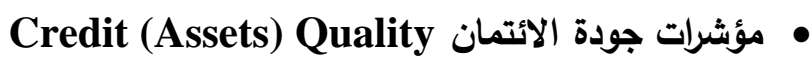

نلاحظ ارتفاع مؤشرات جودة الائمان فى البنوك الغير مقيدة عن نظيرتها المقيدة فى البورصة،

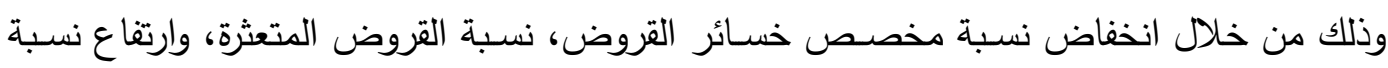

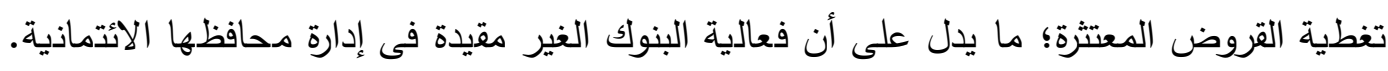
وقد اتضح عدم معنوية الفروق الخاصة بجميع مؤشرات جودة الأتمان.

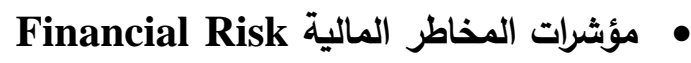

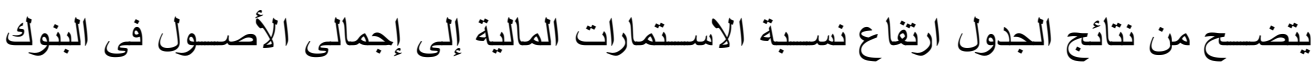

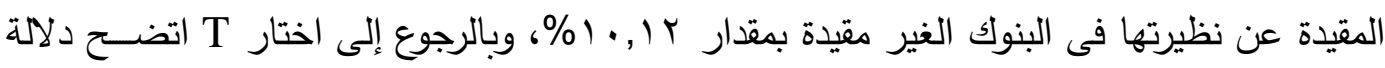

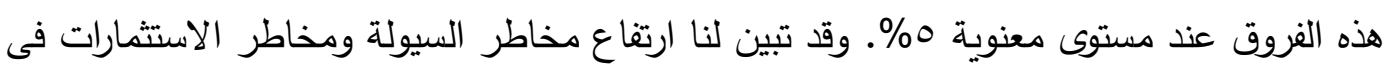

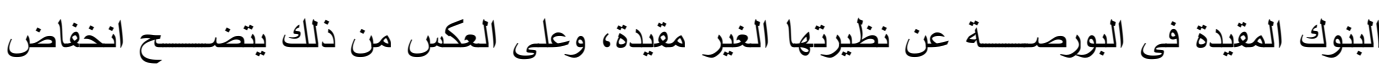

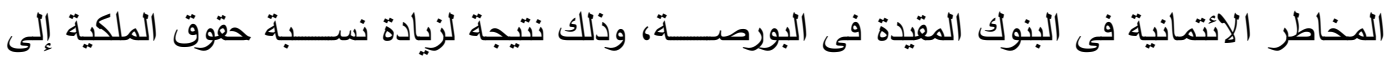

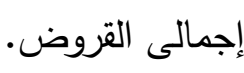

\section{Solvency مؤشرات الملاءة المالية (المصرفية)}

تبين لما من نتائج الجدول رقم (Y0) عدم وجود فروق معنوية بين البنوك المقيدة والبنوك الغير مقيدة فى البورصة؛ حيث نلاحظ التقارب الثديد فى متوسطات مؤشرات الملاءة المالية بين البنوك

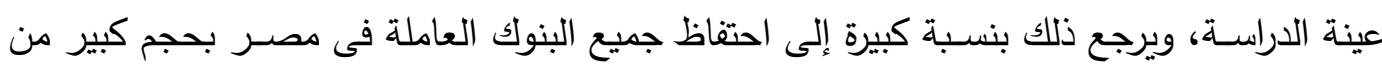
رأس المال تحسباً لأية تأثيرات سلبية لجائحة كورونا.

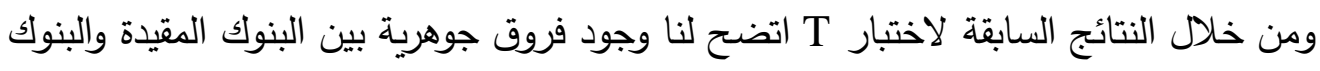

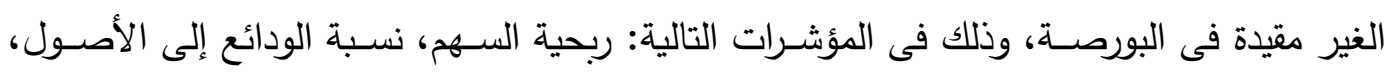

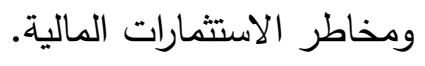

1- اتضح لنا أن مصدر هذه الفروق يتمثل فى ارتفاع ربحية السهم لبنك الإمارات دبى الوطنى E-NBD. 


\section{القسم الرابع: النتائج والتوصيات والدراسات المستقبلية}

يتتاول هذا الجزء أهم النتائج التى توصـلت إليها الدراسـة، والتوصـيات، والدراسـات المستقبلية، ويمكن تتاول ذلك على النحو التالى:

ع/ أنتائج الدراسة

فى ضـــوء مشـكلة البحث وأهدافه والإطار النظرى، يمكن تتاول أهم الدلالات المســمدة من الإطار النظرى ونتائج الدراسة التطبيقية على النحو التالى:

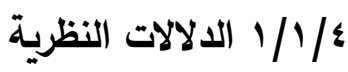

فى ضوء الإطار النظرى لهذا البحث، يستنتج الباحث الدلالات التالية:

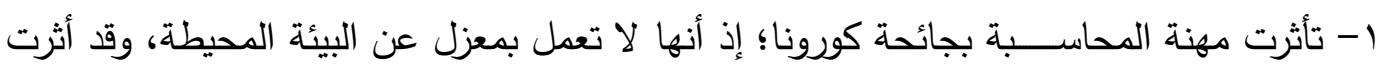
الجائحة بشكل كبير على الفروض المحاسبية، وبصفة خاصة فرضية الإستمرار، والثبات.

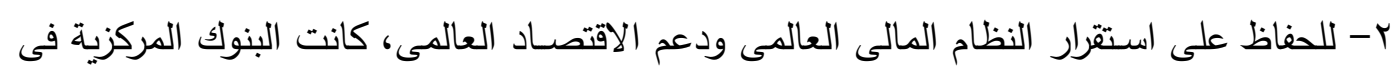
مختلف بلدان العالم هى أول خط للدفاع فى مواجهة جائحة كورونا.

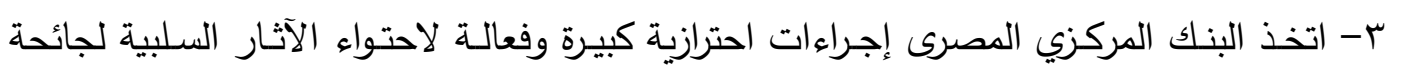
كورونـا على الاقتصاد الوطنى. ع- تشكل جائحة كورونا تحدياً جديداً للاستقرار المالى؛ إذ أن الاستقرار المالى يتحقق عندما يتمكن

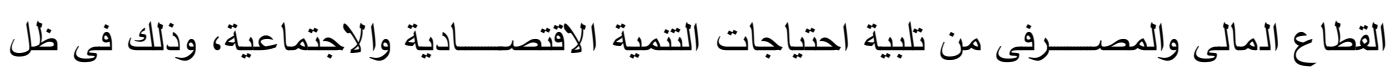
القوانين التى تحكم العمل المصرفى. ه- توصلت الدراسـة التحليلية إلى تحسن مؤشرات السـلامة المالية للقطاع المصرفى المصرى بعد تداعيات جائحة كورونا، وتمثل هذا التحسن فى :

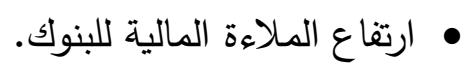
• تحسن نسبة القروض غير المنتظمة (جودة الأصول). • • • • • • عستوى السيولة المرتفع سواء بالعملة المحلية أو الأجنبية.

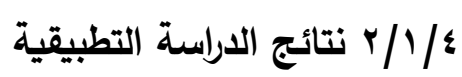

توصلت الدراسة التطبيقية إلى مجموعة النتائج التالية:

1-تراجع صافي ربحية البنوك المصرية بنسب متفاوتة نتيجة السياسات التحوطية المتبعة لمواجهة أية تداعيات لجائحة كورونا، وتجنيب جزء من الأرباح فى هيئة مخصصات يتم استخدامها في حالة زيادة حالات التعثر لاى العملاء بسبب الأزمة.

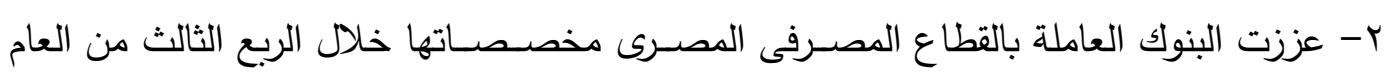
• . . . . . لاحتواء مخاطر أزمة جائحة كورونا وتأثيراتها المتوقعة على العملاء المقترضين. ب- تراجعت أسـعار أسـهم البنوك المقيدة فى البورصــة المصـرية وذلك بالتزامن مع هبوط غالبية أسواق الأسهم العالمية تأثراً بجائحة كورونا، فضلاً عن هبوط أسعار النفط.

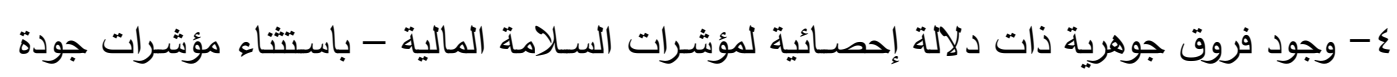

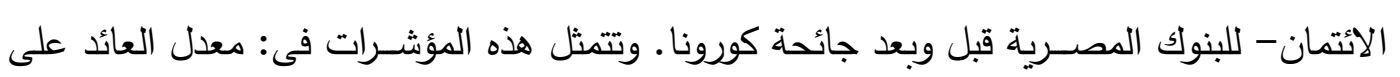


حقوق الملكية، نسبة الأصسول السـائلة إلى إجمالى الأصسول، نسبة الاستثمارات المالية إلى إجمالى

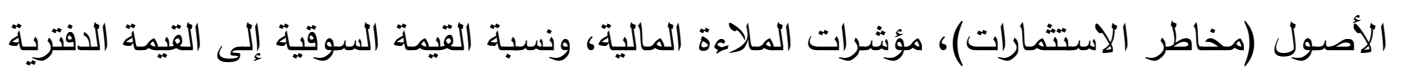
لحقوق الملكية، وتعتبر هذه المؤشرات هى الأكثر تأثراً بتداعيات جائحة كورونا.

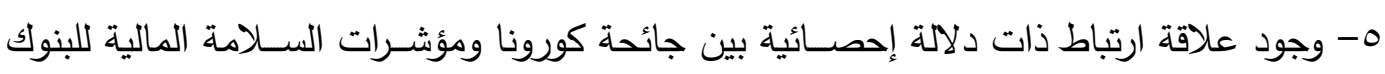
المصرية، باستثناء مؤشرات جودة الائتمان. צ- وجود فروق جوهرية بين البنوك المقيدة والبنوك الغير مقيدة فى البورصــة، وذلك فى المؤشـرات التالية: ربحية السهم، نسبة الودائع إلى الأصول، ومخاطر الاستثمارات المالية. ع/ التوصيات

من خلال ما تم عرضه فى فصول البحث، والنتائج التى تحققت، فيما يلى عدد من التوصيات:

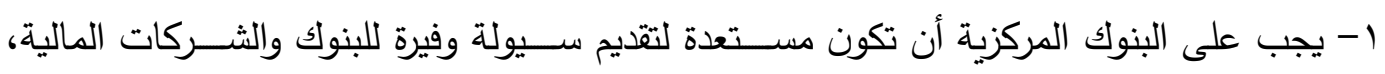
وخاصـة للتي تقرض المؤسسـات الصـيرة والمتوسطة، لإنها من المتوقع أن تكون هذه المؤسسـات اقل قدرة لمواجهة هذه الأزمة.

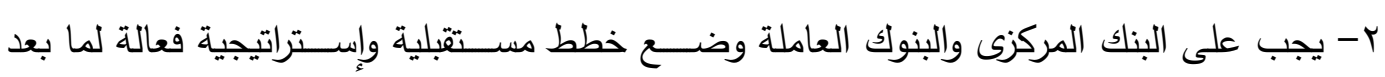
جائحة كورونا.

ب- يجب على البنوك الأخذ بعين الاعتبار مقترحات لجنة بازل فى ما يخص تجاوز الآثار السـلبية

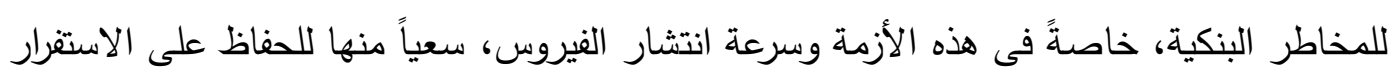
المالى. ع- السـعي لصـياغة نموذج خاص بالتتبؤ بالأزمات المالية والاقتصـادية ويكون موضـوع التطبيق لضمان الاستقرار المالى والمصرفى. وفى النهاية يرى الباحثون أنه كلما طال أمد الجائحة، كلما كانت النتائج السلبية أشد، والعكس

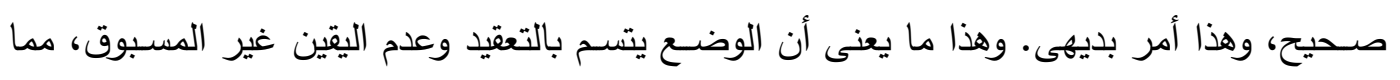

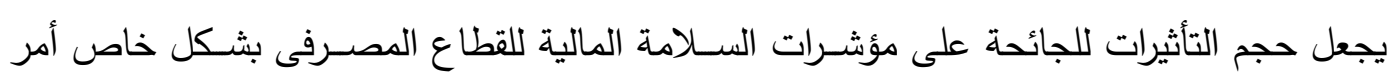

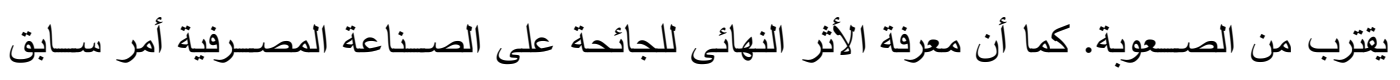
لأوانه؛ إذ أن تحديد ذلك ســـيكون مرتبطاً بعدة عوامل أهمها: القطاع التى توجه لـه تمويلات

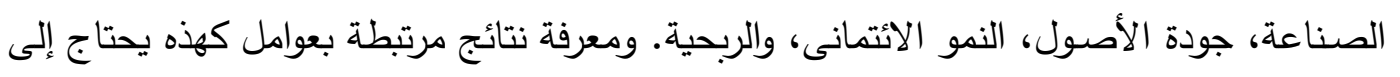
أقل أطول مما غطته الدراسة الحالية. ع/T الاراسات المستقبلية المقترحة يمكن أن تثكل الدراسة أساساً لعديد من الدراسات المستقبلية، من أهمها: ا- أثر تطبيق معيار IFRS9 على مؤشرات السلامة المالية فى ضوء جائحة كورونا. r- دراسة تحليلية لمدى تأثير معايير بازل للرقابة المصرفية بجائحة كورونا. ب- أثر جائحة كورونا على المؤسسات الصغيرة والمتوسطة. ع - مدى تأثر سوق الأوراق المالية فى البورصة المصرية بجائحة كورونا. 


\section{مراجع الدراسة

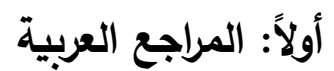

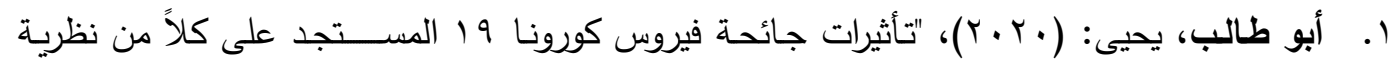

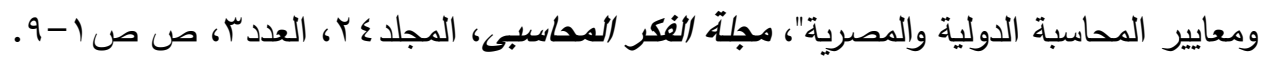

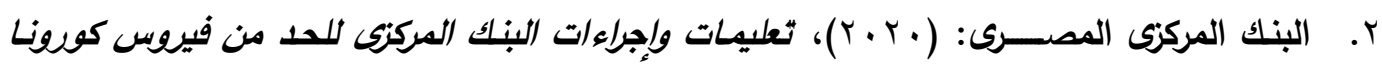

المستجب" ، أوراق عمل، ديسمبر · المبات

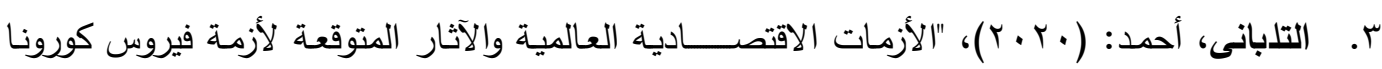

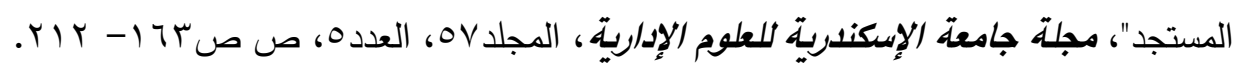

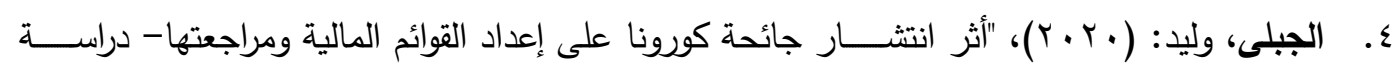

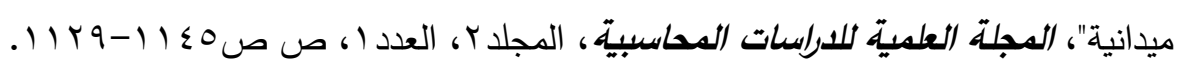

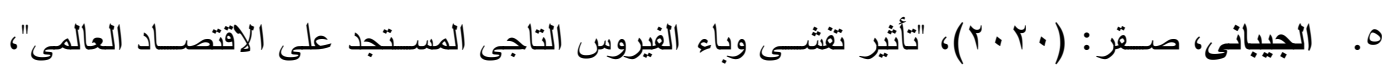

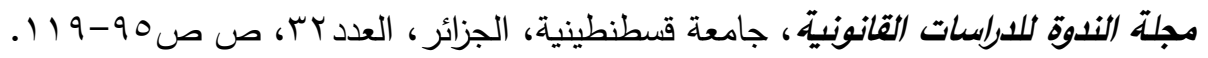

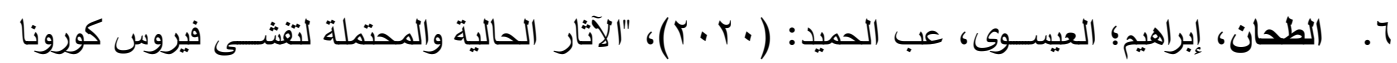

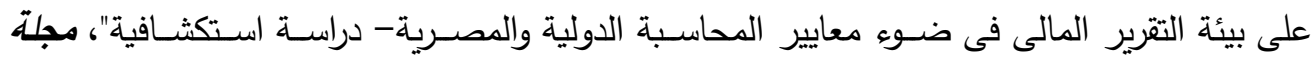

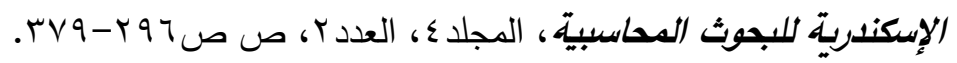

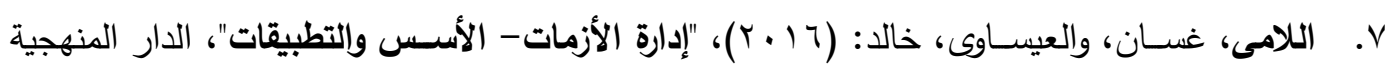

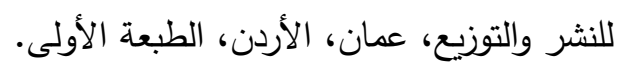

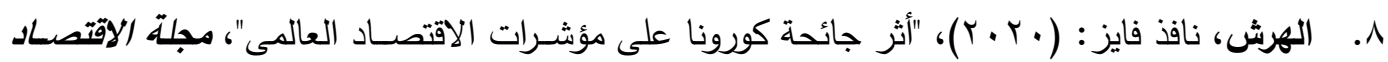

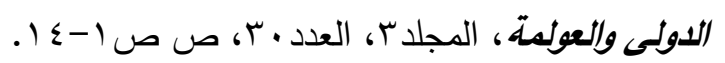

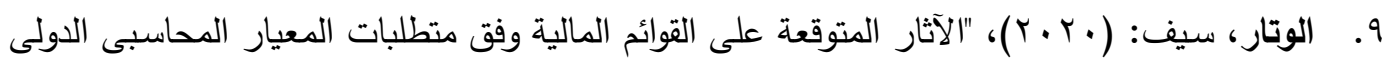

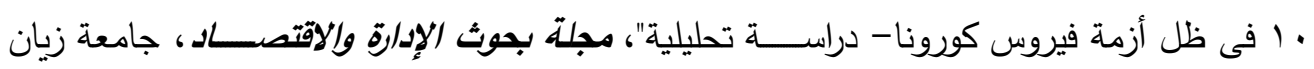

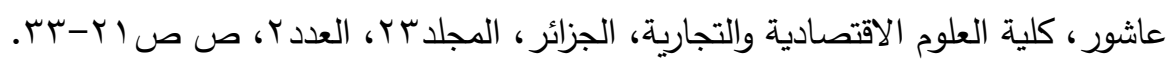

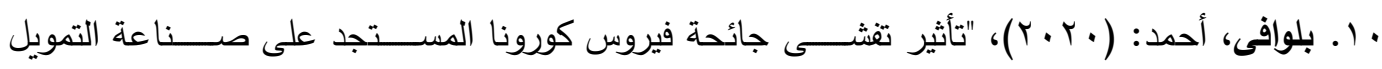

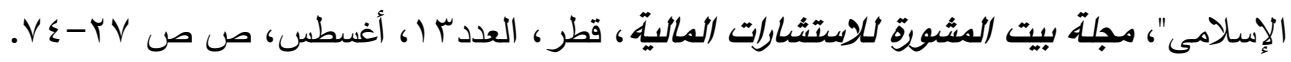

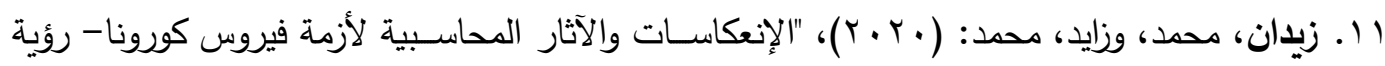

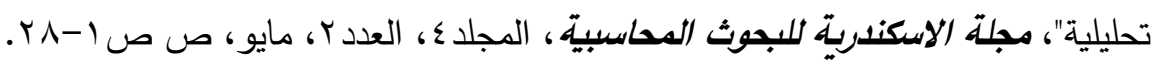

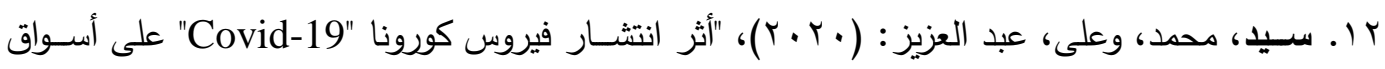

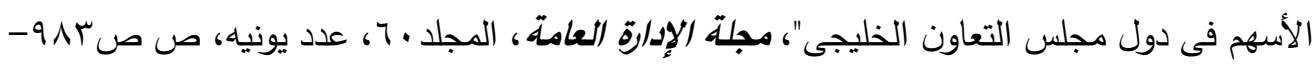

.1. ro

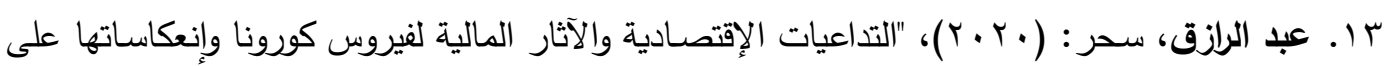

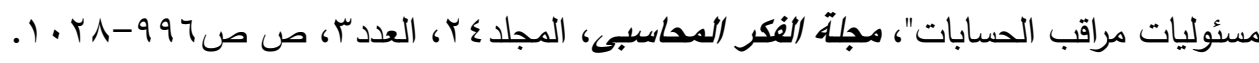

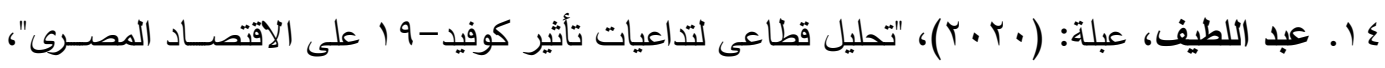

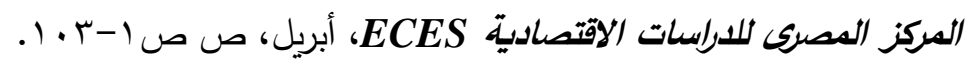

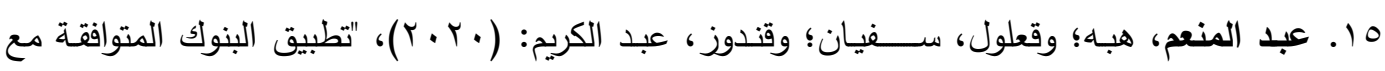

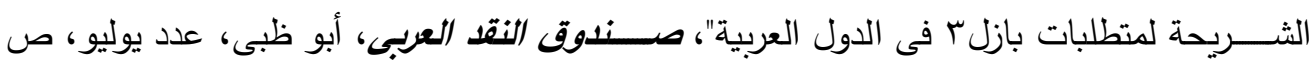




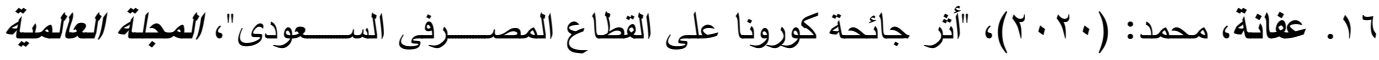

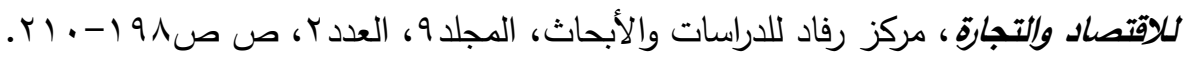

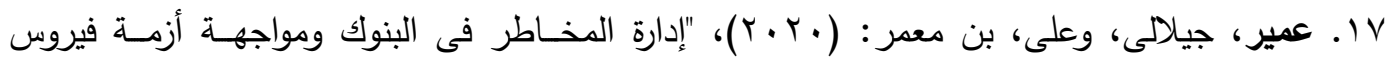

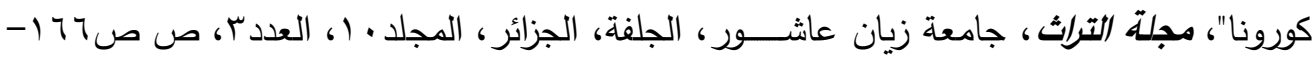

$$
\begin{aligned}
& .1 \wedge \mathrm{V}
\end{aligned}
$$

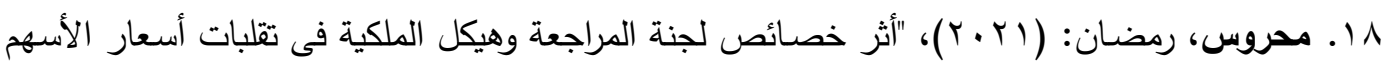

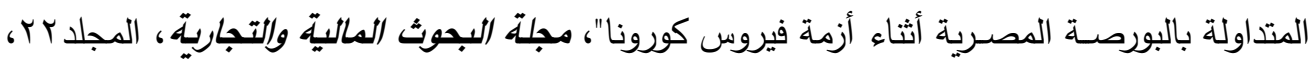

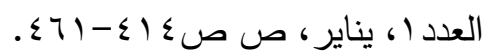

$$
\begin{aligned}
& \text { ثانياً: المراجع الأجنبية }
\end{aligned}
$$

1. Abu-Bakr, Ahmed: (2020), "Corona Virus (COVID-19): Effect and Survival Strategy for Businesses", Journal of Economics and Business, Vol.3, No.2, P.P:661-671.

2. Adrian, Tobias and Natalucci, Fabio: (2020), "covid 19 crisis poses threat to financial stability", International Monetary Fund (IMF), 14.April.

3. Al-Ubadi, Sabeha and Abed, Rajaa: (2020), "The impact of the COVID-19 andemic on the financial stability of Khaleej Commercial Bank under International Accounting Standard 34 Interim Financial Reporting", International Journal of Trade and Global Markets, Vol.10, Issue. 4, P.P:1-22.

4. Deloitte, (2020a), "Financial Reporting Considerations for Virus Impacts", The Wall Street Journal- Risk \& Compliance Journal, 10 March.

5. Ehrentraud, J.\& Zamil, R: (2020), "Prudential response to debt under Covid-19: the supervisory challenges", the Financial Stability Institute (FSI) of the Bank for International Settlements (BIS), Retrieved at 8:30 PM, 19/01/2021 from www.bis.org.

6. ESMA: (2020), "Accounting implications of the COVID-19 outbreak on the calculation of expected credit losses in accordance with IFRS 9", www.esma.europa.eu.

7. Fernandes, N: (2020), "Economic effects of coronavirus outbreak (covid-19) on the world economy", IESE Business school, Spin, No at Date: 22, March.

8. Liu, H., Manzoor, A., Wang, C., Zhang, L., and Manzoor, Z: (2020), "The COVID19 Outbreak and Affected Countries Stock Markets Response", International Journal of Environmental Research and Public Health, Vol.17, P.P:1-19.

9. Noonan, Laura \& Morris, Stephen \& Arnold, Martin: (2020), "New accounting rules pose threat to banks amid corona virus crisis". https://www.ft.com.

10. Rajrs, Abin: (2020), "Impact of Corana Virus on Indian Economy", Solutions to Tackle Manuscript in Preparation.

11. World Economic Forum (WEF): (2020), "Impact of COVID-19 on the Global Financial System", Platform for Shaping the Future of Financial and Monetary Systems. WEF, Switzerland, May 8th.

12. Yeltulme, Mwinlaaru, Peter., Kwesi, Ofori, Isaac., Agyeman Adiyiah, Kwadwo., and Adu-Asare, Idun, Anthony: (2017), "NonPerforming Loans and Universal Bank's Profitability", Munich Personal RePEc Archive (MPRA), Paper No. 82902, Retrieved from https://mpra.ub.uni-muenchen.de/82902. 


\section{فرقات الدراسة \\ أولاً: نتائج اختبار ت لقياس معنوبة الفروق \\ Profitability - معنوية الفروق فى مؤشرات الربحية البية ل}

\begin{tabular}{|l|l|c|c|c|c|c|c|c|}
\hline \multicolumn{2}{|c|}{} & \multicolumn{2}{|c|}{$\begin{array}{l}\text { Levene's Test for } \\
\text { Equality of Variances }\end{array}$} & \multicolumn{5}{c|}{ t-test for Equality of Means } \\
\cline { 3 - 9 } & F & Sig. & $\mathbf{t}$ & Df & $\begin{array}{l}\text { Sig. (2- } \\
\text { tailed) }\end{array}$ & $\begin{array}{c}\text { Mean } \\
\text { Difference }\end{array}$ & $\begin{array}{l}\text { Std. Error } \\
\text { Difference }\end{array}$ \\
\hline $\begin{array}{l}\text { Return on } \\
\text { Assets }\end{array}$ & $\begin{array}{l}\text { Equal variances } \\
\text { assumed }\end{array}$ & 8.698 & .004 & 1.631 & 106 & .106 & .09852 & .06042 \\
\hline $\begin{array}{l}\text { Return on } \\
\text { Equity }\end{array}$ & $\begin{array}{l}\text { Equal variances } \\
\text { assumed }\end{array}$ & 4.429 & .038 & 3.012 & 106 & .003 & 2.07315 & .68840 \\
\hline $\begin{array}{l}\text { Earnings } \\
\text { Per Share }\end{array}$ & $\begin{array}{l}\text { Equal variances } \\
\text { assumed }\end{array}$ & .859 & .356 & .716 & 100 & .476 & .74588 & 1.04160 \\
\hline $\begin{array}{l}\text { Net Interest } \\
\text { Margin }\end{array}$ & $\begin{array}{l}\text { Equal variances } \\
\text { assumed }\end{array}$ & 3.508 & .064 & -.468 & 106 & .641 & -.02870 & .06139 \\
\hline
\end{tabular}

riquidity معنوية الفروق فى مؤشرات السيولية

\begin{tabular}{|c|c|c|c|c|c|c|c|c|}
\hline & \multicolumn{2}{|c|}{$\begin{array}{c}\text { Levene's Test for } \\
\text { Equality of Variances }\end{array}$} & \multicolumn{5}{|c|}{ t-test for Equality of Means } \\
\hline & & $\mathbf{F}$ & Sig. & $\mathbf{T}$ & df & $\begin{array}{l}\text { Sig. (2- } \\
\text { tailed) }\end{array}$ & $\begin{array}{c}\text { Mean } \\
\text { Difference }\end{array}$ & $\begin{array}{l}\text { Std. Error } \\
\text { Difference }\end{array}$ \\
\hline $\begin{array}{l}\text { Liquid Assets } \\
\text { to Total Assets }\end{array}$ & $\begin{array}{l}\text { Equal variances } \\
\text { assumed }\end{array}$ & .255 & .615 & 3.441 & 106 & .001 & 8.46185 & 2.45913 \\
\hline $\begin{array}{ll}\text { Loans } & \text { to } \\
\text { Deposit } & \end{array}$ & $\begin{array}{l}\text { Equal variances } \\
\text { assumed }\end{array}$ & 1.723 & .192 & -1.025 & 106 & .308 & -3.15259 & 3.07578 \\
\hline $\begin{array}{l}\text { Deposits to } \\
\text { Total Assets }\end{array}$ & $\begin{array}{l}\text { Equal variances } \\
\text { assumed }\end{array}$ & .019 & .892 & .850 & 106 & .397 & .82648 & .97186 \\
\hline
\end{tabular}

r redit Quality معنوية الفروق فى مؤشرات جودة الائتمان

\begin{tabular}{|l|l|c|c|c|c|c|c|c|}
\hline \multicolumn{2}{|l|}{} & \multicolumn{2}{|c|}{$\begin{array}{c}\text { Levene's Test for } \\
\text { Equality of Variances }\end{array}$} & \multicolumn{2}{c|}{ t-test for Equality of Means } \\
\cline { 3 - 9 } & & F & Sig. & t & df & $\begin{array}{c}\text { Sig. (2- } \\
\text { tailed) }\end{array}$ & $\begin{array}{c}\text { Mean } \\
\text { Difference }\end{array}$ & $\begin{array}{l}\text { Std. Error } \\
\text { Difference }\end{array}$ \\
\hline $\begin{array}{l}\text { Loans Loss } \\
\text { Provision }\end{array}$ & $\begin{array}{l}\text { Equal variances } \\
\text { assumed }\end{array}$ & .591 & .444 & .436 & 103 & .664 & .27857 & .63959 \\
\hline $\begin{array}{l}\text { Non Performing } \\
\text { Loans }\end{array}$ & $\begin{array}{l}\text { Equal variances } \\
\text { assumed }\end{array}$ & 6.794 & .011 & 1.244 & 94 & .217 & .99500 & .79993 \\
\hline Coverage Ratio & $\begin{array}{l}\text { Equal variances } \\
\text { assumed }\end{array}$ & 2.735 & .102 & .080 & 89 & .936 & .85348 & 10.67583 \\
\hline Loans to Asset & $\begin{array}{l}\text { Equal variances } \\
\text { assumed }\end{array}$ & 1.694 & .196 & -.889 & 106 & .376 & -2.11185 & 2.37584 \\
\hline
\end{tabular}


Financial Risk ـ معنوية الفروق فى مؤشرات المخاطر المالية

\begin{tabular}{|l|l|c|c|c|c|c|c|c|}
\hline \multicolumn{2}{|l}{} & \multicolumn{2}{|c|}{$\begin{array}{c}\text { Levene's Test for } \\
\text { Equality of Variances }\end{array}$} & \multicolumn{5}{c|}{ t-test for Equality of Means } \\
\cline { 3 - 10 } & F & Sig. & T & df & $\begin{array}{c}\text { Sig. (2- } \\
\text { tailed) }\end{array}$ & $\begin{array}{c}\text { Mean } \\
\text { Difference }\end{array}$ & $\begin{array}{l}\text { Std. Error } \\
\text { Difference }\end{array}$ \\
\hline $\begin{array}{l}\text { Total Equity To } \\
\text { Net Loans }\end{array}$ & $\begin{array}{l}\text { Equal variances } \\
\text { assumed }\end{array}$ & .213 & .645 & -.488 & 106 & .626 & -2.47685 & 5.07445 \\
\hline Financing Gap & $\begin{array}{l}\text { Equal variances } \\
\text { assumed }\end{array}$ & 1.327 & .252 & -1.045 & 106 & .298 & -2.93889 & 2.81273 \\
\hline $\begin{array}{l}\text { Total Securities } \\
\text { to Total Assets }\end{array}$ & $\begin{array}{l}\text { Equal variances } \\
\text { assumed }\end{array}$ & 2.290 & .133 & -2.423 & 106 & .017 & -6.05204 & 2.49745 \\
\hline Assets Risk & $\begin{array}{l}\text { Equal variances } \\
\text { assumed }\end{array}$ & .001 & .972 & .224 & 92 & .823 & .54662 & 2.43832 \\
\hline
\end{tabular}

Solvency معنوية الفروق فى مؤشرات الملاءة المالية

\begin{tabular}{|l|l|c|c|c|c|c|c|c|}
\hline \multicolumn{2}{|l}{} & \multicolumn{2}{|c|}{$\begin{array}{c}\text { Levene's Test for } \\
\text { Equality of Variances }\end{array}$} & \multicolumn{3}{|c|}{ t-test for Equality of Means } \\
\cline { 3 - 10 } & & F & Sig. & T & df & $\begin{array}{c}\text { Sig. (2- } \\
\text { tailed) }\end{array}$ & $\begin{array}{c}\text { Mean } \\
\text { Difference }\end{array}$ & $\begin{array}{l}\text { Std. Error } \\
\text { Difference }\end{array}$ \\
\hline $\begin{array}{l}\text { Capital } \\
\text { Adequacy Ratio }\end{array}$ & $\begin{array}{l}\text { Equal variances } \\
\text { assumed }\end{array}$ & 20.746 & .000 & -9.378 & 100 & .000 & -8.93772 & .95305 \\
\hline Tier one Capital & $\begin{array}{l}\text { Equal variances } \\
\text { assumed }\end{array}$ & 7.378 & .008 & -8.687 & 100 & .000 & -8.72568 & 1.00441 \\
\hline Leverage Ratio & $\begin{array}{l}\text { Equal variances } \\
\text { assumed }\end{array}$ & 5.005 & .028 & -2.351 & 89 & .021 & -1.00122 & .42582 \\
\hline
\end{tabular}

$$
\text { ף- معنوية الفروق فى مؤشرات الأداء المعتمدة على السوق }
$$

\begin{tabular}{|l|l|c|c|c|c|c|c|c|}
\hline \multicolumn{2}{|l|}{} & \multicolumn{2}{|c|}{$\begin{array}{c}\text { Levene's Test for } \\
\text { Equality of Variances }\end{array}$} & \multicolumn{5}{|c|}{ t-test for Equality of Means } \\
\cline { 2 - 9 } & F & Sig. & T & df & $\begin{array}{l}\text { Sig. (2- } \\
\text { tailed) }\end{array}$ & $\begin{array}{c}\text { Mean } \\
\text { Difference }\end{array}$ & $\begin{array}{l}\text { Std. Error } \\
\text { Difference }\end{array}$ \\
\hline $\begin{array}{l}\text { The Price-to- } \\
\text { Book ratio }\end{array}$ & $\begin{array}{l}\text { Equal variances } \\
\text { assumed }\end{array}$ & 4.761 & .033 & 2.396 & 64 & .019 & .35758 & .14923 \\
\hline $\begin{array}{l}\text { Price Earnings } \\
\text { Ratio }\end{array}$ & $\begin{array}{l}\text { Equal variances } \\
\text { assumed }\end{array}$ & .003 & .959 & .720 & 52 & .474 & 2.05889 & 2.85774 \\
\hline
\end{tabular}


ثانياً: نتائج اختبار تحليل ارتباط بيرسون

Profitability تحليل الارتباط بين جائحة كورونا ومؤشرات الربحية البية

\begin{tabular}{|c|c|c|c|c|c|c|}
\hline & & Coranavirus & $\begin{array}{c}\text { Return on } \\
\text { Assets }\end{array}$ & $\begin{array}{c}\text { Return on } \\
\text { Equity }\end{array}$ & $\begin{array}{l}\text { Earnings } \\
\text { Per Share }\end{array}$ & $\begin{array}{c}\text { Net Interest } \\
\text { Margin }\end{array}$ \\
\hline Coranavirus & $\begin{array}{l}\text { Pearson Correlation } \\
\text { Sig. (2-tailed) }\end{array}$ & 1 & $\begin{array}{l}-.156 \\
.106\end{array}$ & $\begin{array}{l}-.281^{* * *} \\
.003\end{array}$ & $\begin{array}{r}-.071 \\
.476\end{array}$ & $\begin{array}{l}.045 \\
.641\end{array}$ \\
\hline $\begin{array}{ll}\text { Return } & \text { on } \\
\text { Assets } & \end{array}$ & $\begin{array}{l}\text { Pearson Correlation } \\
\text { Sig. (2-tailed) }\end{array}$ & $\begin{array}{l}. .156 \\
.106\end{array}$ & $\overline{1}$ & $\begin{array}{l}.709^{* *} \\
.000\end{array}$ & $\begin{array}{l}.229^{*} \\
.020\end{array}$ & $\begin{array}{l}.753^{* *} \\
.000\end{array}$ \\
\hline $\begin{array}{ll}\text { Return } & \text { on } \\
\text { Equity } & \end{array}$ & $\begin{array}{l}\text { Pearson Correlation } \\
\text { Sig. (2-tailed) }\end{array}$ & $\begin{array}{l}-.281^{* * *} \\
.003\end{array}$ & $\begin{array}{l}.709^{* *} \\
.000\end{array}$ & 1 & $\begin{array}{l}.153 \\
.126\end{array}$ & $\begin{array}{l}.466^{* *} \\
.000\end{array}$ \\
\hline $\begin{array}{ll}\text { Earnings } & \text { Per } \\
\text { Share } & \end{array}$ & $\begin{array}{l}\text { Pearson Correlation } \\
\text { Sig. (2-tailed) }\end{array}$ & $\begin{array}{l}-.071 \\
.476\end{array}$ & $\begin{array}{l}.229^{*} \\
.020\end{array}$ & $\begin{array}{l}.153 \\
.126\end{array}$ & 1 & $\begin{array}{l}.136 \\
.172\end{array}$ \\
\hline $\begin{array}{l}\text { Net Interest } \\
\text { Margin }\end{array}$ & $\begin{array}{l}\text { Pearson Correlation } \\
\text { Sig. (2-tailed) }\end{array}$ & $\begin{array}{l}.045 \\
.641\end{array}$ & $\begin{array}{l}.753^{* *} \\
.000\end{array}$ & $\begin{array}{l}.466^{* *} \\
.000\end{array}$ & $\begin{array}{l}.136 \\
.172\end{array}$ & 1 \\
\hline
\end{tabular}

r Liquidity تحليل الارتباط بين جائحة كورونا ومؤشرات السيولة

\begin{tabular}{|c|c|c|c|c|c|}
\hline & & Coranavirus & $\begin{array}{c}\text { Liquid Assets to } \\
\text { Total Assets }\end{array}$ & $\begin{array}{l}\text { Loans to } \\
\text { Deposit }\end{array}$ & $\begin{array}{c}\text { Deposits to } \\
\text { Total Assets }\end{array}$ \\
\hline Coranavirus & $\begin{array}{l}\text { Pearson Correlation } \\
\text { Sig. (2-tailed) }\end{array}$ & 1 & $\begin{array}{c}-.317^{* *} \\
.001\end{array}$ & $\begin{array}{l}.099 \\
.308\end{array}$ & $\begin{array}{r}-.082 \\
.397\end{array}$ \\
\hline $\begin{array}{l}\text { Liquid Assets to } \\
\text { Total Assets }\end{array}$ & $\begin{array}{l}\text { Pearson Correlation } \\
\text { Sig. (2-tailed) }\end{array}$ & $\begin{array}{c}-.317^{* *} \\
.001\end{array}$ & 1 & $\begin{array}{l}-.425^{* *} \\
.000\end{array}$ & $\begin{array}{l}.080 \\
.411\end{array}$ \\
\hline $\begin{array}{ll}\text { Loans } & \text { to } \\
\text { Deposit } & \end{array}$ & $\begin{array}{l}\text { Pearson Correlation } \\
\text { Sig. (2-tailed) }\end{array}$ & $\begin{array}{l}.099 \\
.308\end{array}$ & $\begin{array}{l}. .425^{* *} \\
.000\end{array}$ & 1 & $\begin{array}{l}-.461^{* *} \\
.000\end{array}$ \\
\hline $\begin{array}{ll}\text { Deposits } & \text { to } \\
\text { Total Assets } & \end{array}$ & $\begin{array}{l}\text { Pearson Correlation } \\
\text { Sig. (2-tailed) }\end{array}$ & $\begin{array}{l}.082 \\
.397\end{array}$ & $\begin{array}{l}.080 \\
.411\end{array}$ & $\begin{array}{l}-.461^{\text {** }} \\
.000\end{array}$ & 1 \\
\hline
\end{tabular}

Credit Quality r- تحليل الارتباط بين جائحة كورونا ومؤشرات جودة الائتمان

\begin{tabular}{|c|c|c|c|c|c|c|}
\hline & & Coranavirus & $\begin{array}{c}\text { Loans Loss } \\
\text { Provision }\end{array}$ & $\begin{array}{c}\text { Non Performing } \\
\text { Loans }\end{array}$ & $\begin{array}{c}\text { Coverage } \\
\text { Ratio }\end{array}$ & $\begin{array}{c}\text { Loans to } \\
\text { Asset }\end{array}$ \\
\hline Coranavirus & $\begin{array}{l}\text { Pearson Correlation } \\
\text { Sig. (2-tailed) }\end{array}$ & 1 & $\begin{array}{r}.043 \\
.664\end{array}$ & $\begin{array}{l}-.127 \\
.217\end{array}$ & $\begin{array}{r}-.008 \\
.936\end{array}$ & $\begin{array}{l}.086 \\
.376\end{array}$ \\
\hline $\begin{array}{ll}\text { Loans } & \text { Loss } \\
\text { Provision } & \end{array}$ & $\begin{array}{l}\text { Pearson Correlation } \\
\text { Sig. (2-tailed) }\end{array}$ & $\begin{array}{l}.043 \\
.664\end{array}$ & 1 & $\begin{array}{l}.805^{* *} \\
.000\end{array}$ & $\begin{array}{l}.197 \\
.061\end{array}$ & $\begin{array}{c}-.476^{* *} \\
.000\end{array}$ \\
\hline $\begin{array}{l}\text { Non Performing } \\
\text { Loans }\end{array}$ & $\begin{array}{l}\text { Pearson Correlation } \\
\text { Sig. (2-tailed) }\end{array}$ & $\begin{array}{l}. .127 \\
.217\end{array}$ & $\begin{array}{l}.805^{* *} \\
.000\end{array}$ & 1 & $\begin{array}{l}-.500^{* * *} \\
.000\end{array}$ & $\begin{array}{c}-.426^{* *} \\
.000\end{array}$ \\
\hline Coverage Ratio & $\begin{array}{l}\text { Pearson Correlation } \\
\text { Sig. (2-tailed) }\end{array}$ & $\begin{array}{l}-.008 \\
.936\end{array}$ & $\begin{array}{l}-.197 \\
.061\end{array}$ & $\begin{array}{c}.500^{* *} \\
.000\end{array}$ & 1 & $\begin{array}{l}.286^{* *} \\
.006\end{array}$ \\
\hline Loans to Asset & $\begin{array}{l}\text { Pearson Correlation } \\
\text { Sig. (2-tailed) }\end{array}$ & $\begin{array}{l}.086 \\
.376\end{array}$ & $\begin{array}{c}-.476^{* *} \\
.000\end{array}$ & $\begin{array}{l}-.426^{* *} \\
.000\end{array}$ & $\begin{array}{l}.286^{* *} \\
.006\end{array}$ & 1 \\
\hline
\end{tabular}


Financial Risk تحليل الارتباط بين جائحة كورونا ومؤشرات المخاطر المالية

\begin{tabular}{|l|l|c|c|c|c|c|}
\hline \multicolumn{2}{|l|}{} & Coranavirus & $\begin{array}{c}\text { Total Equity } \\
\text { To Net Loans }\end{array}$ & $\begin{array}{c}\text { Financing } \\
\text { Gap }\end{array}$ & $\begin{array}{c}\text { Securities to } \\
\text { Total Assets }\end{array}$ & $\begin{array}{c}\text { Assets } \\
\text { Risk }\end{array}$ \\
\hline \multirow{2}{*}{ Coranavirus } & Pearson Correlation & 1 & .047 & .101 & $.229^{*}$ & -.023 \\
& Sig. (2-tailed) & & .626 & .298 & .017 & .823 \\
\hline Total Equity To & Pearson Correlation & .047 & 1 & $-.561^{* *}$ & $.464^{* *}$ & $-.272^{* *}$ \\
Net Loans & Sig. (2-tailed) & .626 & & .000 & .000 & .008 \\
\hline \multirow{2}{*}{ Financing Gap } & Pearson Correlation & .101 & $-.561^{* *}$ & 1 & $-.417^{* *}$ & $.792^{* *}$ \\
& Sig. (2-tailed) & .298 & .000 & & .000 & .000 \\
\hline Total Securities \\
to Total Assets & Pearson Correlation & $.229^{*}$ & $.464^{* *}$ & $-.417^{* *}$ & 1 & $-.316^{* *}$ \\
& Sig. (2-tailed) & .017 & .000 & .000 & & .002 \\
\hline \multirow{2}{*}{ Assets Risk } & Pearson Correlation & -.023 & $-.272^{* *}$ & $.792^{* *}$ & $-.316^{* *}$ & 1 \\
& Sig. (2-tailed) & .823 & .008 & .000 & .002 & \\
\hline *. Correlation is significant at the 0.05 level (2-tailed). \\
**. Correlation is significant at the 0.01 level (2-tailed).
\end{tabular}

Solvency تحليل الارتباط بين جائحة كورونا ومؤشرات الملاءة المالية

\begin{tabular}{|c|c|c|c|c|c|}
\hline & & Coranavirus & $\begin{array}{c}\text { Capital } \\
\text { Adequacy Ratio }\end{array}$ & $\begin{array}{l}\text { Tier one } \\
\text { Capital }\end{array}$ & $\begin{array}{c}\text { Leverage } \\
\text { Ratio }\end{array}$ \\
\hline Coranavirus & $\begin{array}{l}\text { Pearson Correlation } \\
\text { Sig. (2-tailed) }\end{array}$ & 1 & $\begin{array}{l}.684^{* * *} \\
.000\end{array}$ & $\begin{array}{l}.656^{* *} \\
.000\end{array}$ & $\begin{array}{l}.242^{*} \\
.021\end{array}$ \\
\hline $\begin{array}{l}\text { Capital } \\
\text { Adequacy Ratio }\end{array}$ & $\begin{array}{l}\text { Pearson Correlation } \\
\text { Sig. (2-tailed) }\end{array}$ & $\begin{array}{l}.684^{* *} \\
.000\end{array}$ & 1 & $\begin{array}{l}.982^{* *} \\
.000\end{array}$ & $\begin{array}{l}.459^{* * *} \\
.000\end{array}$ \\
\hline Tier one Capital & $\begin{array}{l}\text { Pearson Correlation } \\
\text { Sig. (2-tailed) }\end{array}$ & $\begin{array}{l}.656^{* *} \\
.000\end{array}$ & $\begin{array}{l}.982^{* *} \\
.000\end{array}$ & 1 & $\begin{array}{l}.537^{* *} \\
.000\end{array}$ \\
\hline Leverage Ratio & $\begin{array}{l}\text { Pearson Correlation } \\
\text { Sig. (2-tailed) }\end{array}$ & $\begin{array}{l}.242^{*} \\
.021\end{array}$ & $\begin{array}{l}.459^{* *} \\
.000\end{array}$ & $\begin{array}{l}.537^{\text {** }} \\
.000\end{array}$ & 1 \\
\hline \multicolumn{6}{|c|}{$\begin{array}{l}\text { **. Correlation is significant at the } 0.01 \text { level (2-tailed). } \\
* \text {. Correlation is significant at the } 0.05 \text { level (2-tailed). }\end{array}$} \\
\hline
\end{tabular}

צ- تحليل الارتباط بين جائحة كورونا ومؤشرات الأداء المعتمدة على السوق

\begin{tabular}{|l|l|c|c|c|}
\hline \multicolumn{2}{|l|}{} & Coranavirus & $\begin{array}{c}\text { The Price to } \\
\text { Book ratio }\end{array}$ & $\begin{array}{c}\text { Price } \\
\text { Earnings Ratio }\end{array}$ \\
\hline Coranavirus & Pearson Correlation & 1 & $-.287^{*}$ \\
Sig. (2-tailed) & & .019 & -.099 \\
The Price-to-Book & Pearson Correlation & $-.287^{*}$ & 1 & .474 \\
ratio & Sig. (2-tailed) & .019 & $.661^{* *}$ \\
\hline Price Earnings & Pearson Correlation & -.099 & $.661^{* *}$ & .000 \\
Ratio & Sig. (2-tailed) & .474 & .000 & 1 \\
\hline *. Correlation is significant at the 0.05 level (2-tailed). & & \\
**. Correlation is significant at the 0.01 level (2-tailed). & \\
\hline
\end{tabular}


ثالثاً: نتائج اختبار تحليل التباين

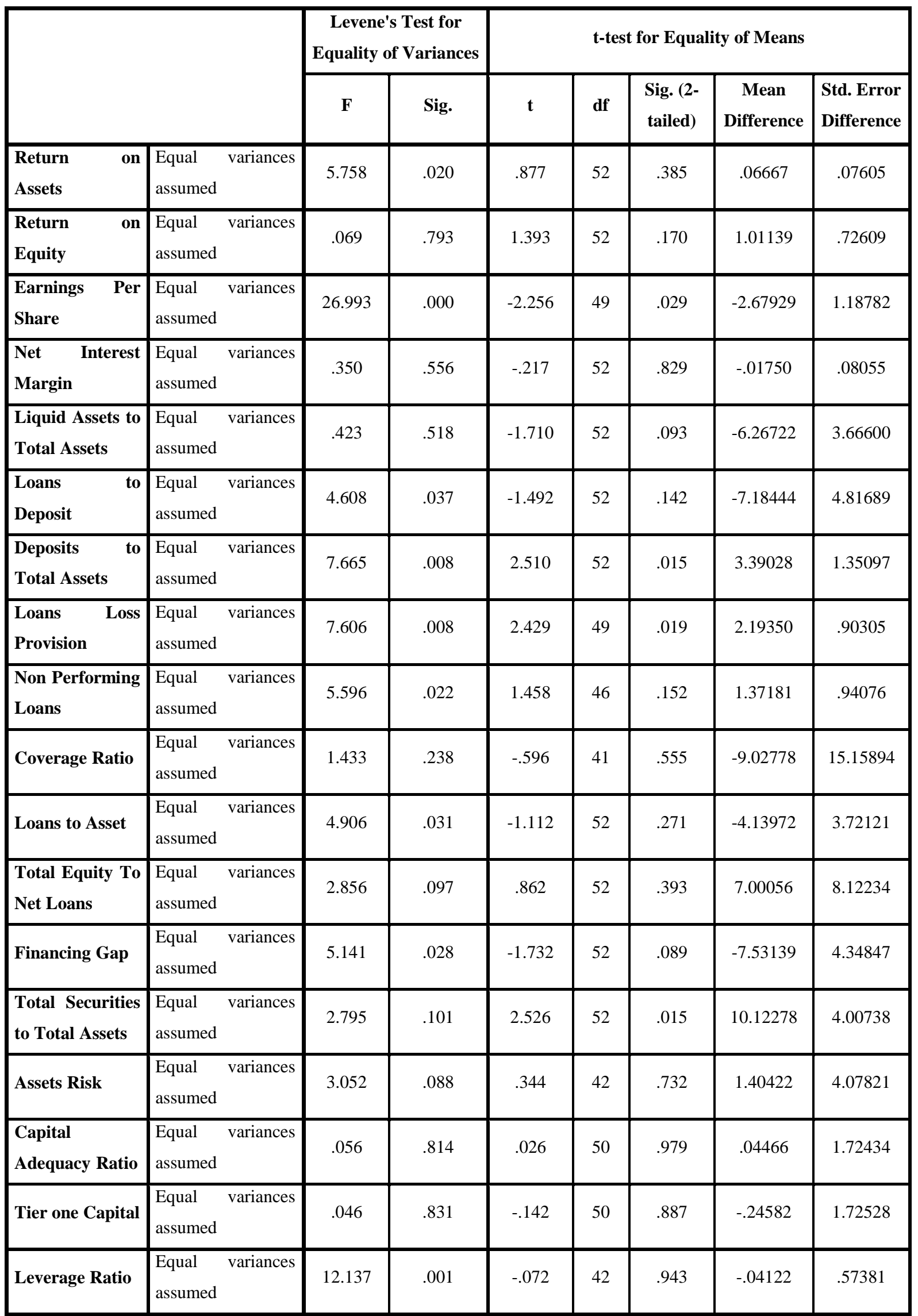

